\title{
UNREVIEWED DISPOSAL QUESTION EVALUATION: WASTE DISPOSAL IN ENGINEERED TRENCH \#3
}

\author{
L. L. Hamm \\ F. G. Smith, III \\ G. P. Flach \\ R. A. Hiergesell \\ B. T. Butcher
}

\section{JULY 2013}

Savannah River National Laboratory Savannah River Nuclear Solutions Savannah River Site Aiken, SC 29808

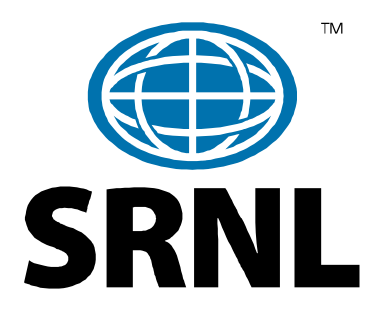




\section{DISCLAIMER}

This work was prepared under an agreement with and funded by the U.S. Government. Neither the U. S. Government or its employees, nor any of its contractors, subcontractors or their employees, makes any express or implied: 1. warranty or assumes any legal liability for the accuracy, completeness, or for the use or results of such use of any information, product, or process disclosed; or 2. representation that such use or results of such use would not infringe privately owned rights; or

3. endorsement or recommendation of any specifically identified commercial product, process, or service.

Any views and opinions of authors expressed in this work do not necessarily state or reflect those of the United States Government, or its contractors, or subcontractors.

Printed in the United States of America

Prepared For U.S. Department of Energy 
Key Words:

Performance Assessment

UDQE

ET\#3

Retention:

Permanent

\title{
UNREVIEWED DISPOSAL QUESTION EVALUATION: WASTE DISPOSAL IN ENGINEERED TRENCH \#3
}

\author{
L. L. Hamm \\ F. G. Smith, III \\ G. P. Flach \\ R. A. Hiergesell \\ B. T. Butcher
}

\section{JULY 2013}

Savannah River National Laboratory

Savannah River Nuclear Solutions

Savannah River Site

Aiken, SC 29808 
SRNL-STI-2013-00393, REV . 0

\section{REVIEWS AND APPROVALS}

$\overline{\text { L.L. Hamm, Author / Reviewer*, Engineering Modeling \& Simulation } \quad \text { Date }}$

F.G. Smith, III, Author / Reviewer*, Engineering Modeling \& Simulation Date

G.P. Flach, Author, Radiological Performance Assessment $\quad$ Date

$\overline{\text { R.A. Hiergesell, Author, Radiological Performance Assessment } \quad \text { Date }}$

B. T. Butcher, Author / Reviewer*, Radiological Performance Assessment $\quad$ Date

$\overline{\text { D.A. Crowley, Manager, Radiological Performance Assessment } \quad \text { Date }}$

$\overline{\text { R.S. Alyward, Manager, Environmental Restoration Technology } \quad \text { Date }}$

\begin{tabular}{ll}
\hline G. K. Humphries, Environmental Compliance & Date
\end{tabular}

$\begin{array}{ll}\text { M.G. Looper, SWM Chief Engineer } & \text { Date }\end{array}$

J.L. Mooneyhan, Solid Waste Facility Manager $\quad$ Date

*Reviews performed by authors were cross-checks of work performed by the other authors 


\section{TABLE OF CONTENTS}

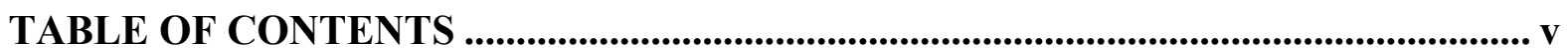

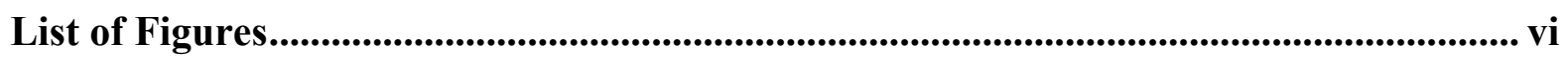

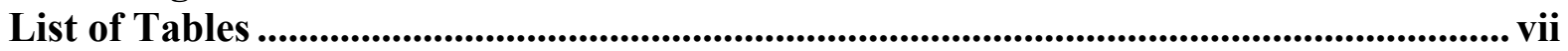

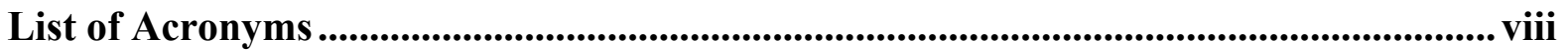

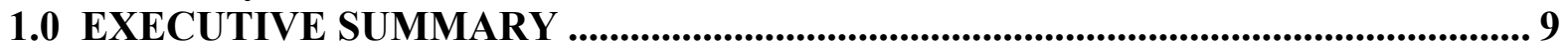

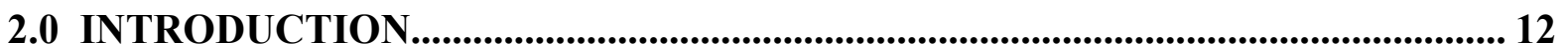

2.1 Background .......................................................................................................... 12

2.2 General Modeling Approach .............................................................................................. 13

3.0 KEY INPUTS AND ASSUMPTIONS................................................................... 18

4.0 VADOSE ZONE ANALYSIS ......................................................................... 19

4.1 Vadose Zone Conceptual Model.............................................................................. 19

4.2 ET\#3 Vadose Zone Flow Model .......................................................................... 21

4.3 ET\#3 Vadose Zone Transport Model ................................................................ 24

4.3.1 Vadose Zone Transport Methodology ................................................................... 24

4.3.2 Vadose Zone Transport Results............................................................................ 25

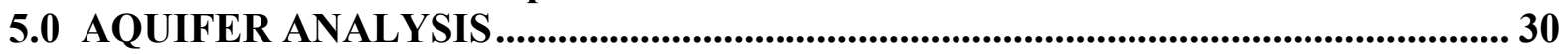

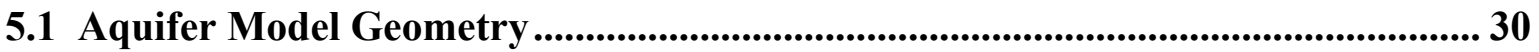

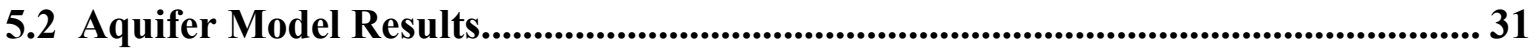

5.2.1 Dispersion Tensor Correction Factors ................................................................ 32

5.2.2 Interim Measures Correction Factors............................................................. 32

5.2.3 Maximum Well Concentration Comparisons...................................................... 34

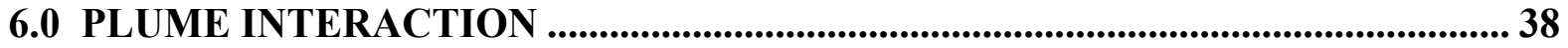

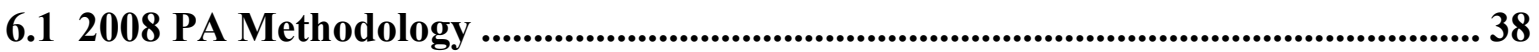

6.2 Plume Interaction Concept .......................................................................... 39

6.3 ET\#3 and ET\#4 Plume Interaction Factors ....................................................... 41

7.0 PERFORMANCE EVALUATION ........................................................................... 44

7.1 Exposure Pathways and Dose Factors ............................................................... 44

7.2 Groundwater Pathway .............................................................................................. 45

7.3 Non-Groundwater Pathways ....................................................................... 46

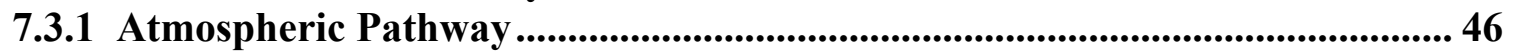

7.3.2 Radon Pathway..................................................................................................... 47

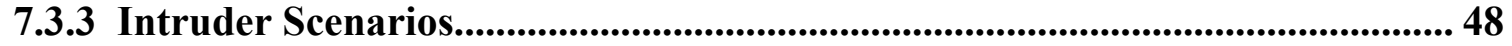

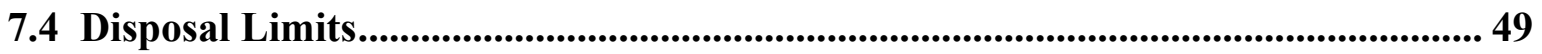

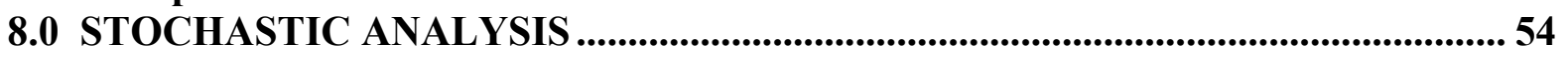

8.1 Stochastic Approach............................................................................................. 54

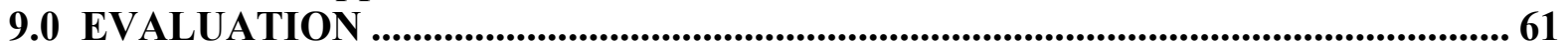

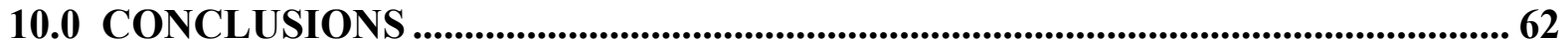

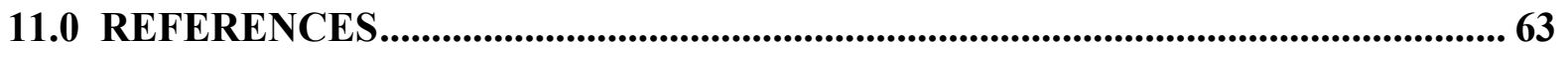

APPENDIX: UDQ SCREENING ................................................................................................. 67 


\section{LIST OF FIGURES}

Figure 1-1 Max SOF histogram plot (no time windowing option) based on a 10,000 trial simulation.

Figure 4-1 Close-up view of proposed ET\#3 footprint showing the vertical cross-section chosen to represent the ET\#3 vadose zone conceptual model.

Figure 4-2 2D vadose zone model of ET\#3 showing material zones and the coverage of both

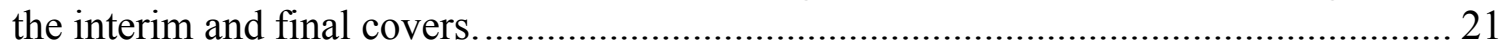

Figure 4-3 Flow results (streamlines) for the ET\#3 model before SIC (i.e., no cover present).

Figure 4-4 Flow results (streamlines) for the ET\#3 model during IC (the application of the interim cover).

Figure 4-5 Flow results (streamlines) for the ET\#3 model after EIC (i.e., 0-5 years after the application of the final cover).

Figure 4-6 Comparison of transport results (flux to water table) for a tracer..................... 26

Figure 4-7 Comparison of transport results (flux to water table) for C-14........................ 26

Figure 4-8 Comparison of transport results (flux to water table) for H-3 . ........................ 27

Figure 4-9 Comparison of transport results (flux to water table) for I-129 ....................... 27

Figure 4-10 Comparison of transport results (flux to water table) for Mo-93 .................... 28

Figure 4-11 Comparison of transport results (flux to water table) for $\mathrm{Np}-237 . \ldots \ldots \ldots \ldots \ldots . . . .28$

Figure 4-12 Comparison of transport results (flux to water table) for Sr-90...................... 29

Figure 4-13 Comparison of transport results (flux to water table) for Tc-99...................... 29

Figure 5-1 New 3D Aquifer flow model used for analyzing ET\#3................................. 31

Figure 5-2 Well concentrations for C-14 in ST\#12 (IM 2012) and ET\#3 (new) aquifer

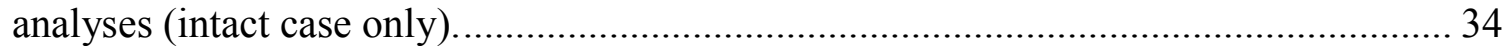

Figure 5-3 Well concentrations for H-3 in ST\#12 (IM 2012) and ET\#3 (new) aquifer

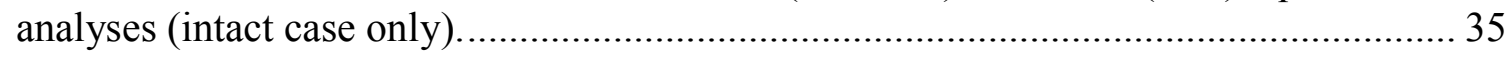

Figure 5-4 Well concentrations for I-129 in ST\#12 (IM 2012) and ET\#3 (new) aquifer

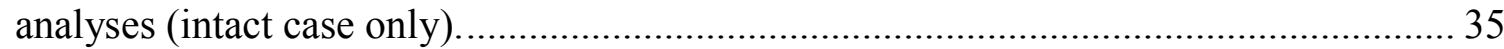

Figure 5-5 Well concentrations for Mo-93 in ST\#12 (IM2012) and ET\#3 (new) aquifer

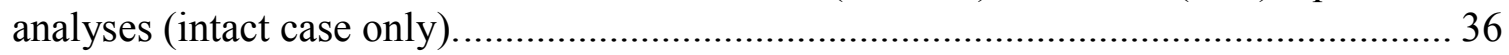

Figure 5-6 Well concentrations for Np-237 in ST\#12 (IM2012) and ET\#3 (new) aquifer

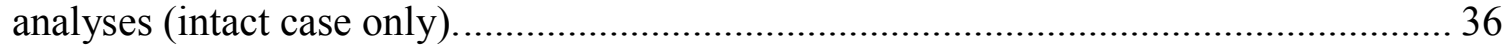

Figure 5-7 Well concentrations for Sr-90 in ST\#12 (IM2012) and ET\#3 (new) aquifer

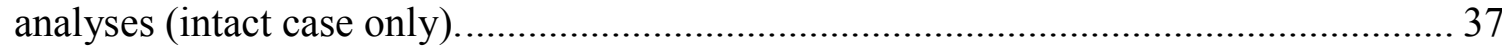

Figure 5-8 Well concentrations for Tc-99 in ST\#12 (IM2012) and ET\#3 (new) aquifer

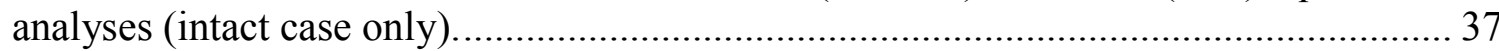

Figure 6-1 Disposal units in E-Area showing basic streamline paths from the centroid of each unit.

Figure 6-2 Maximum tracer concentration profile along 100-m boundary for each unique entity (i.e., group or unit).

Figure 6-3 Maximum tracer concentration profile based on one set of source strengths..... 42

Figure 6-4 Maximum tracer concentration profile along the 100-m boundary for a 50\% ET\#3

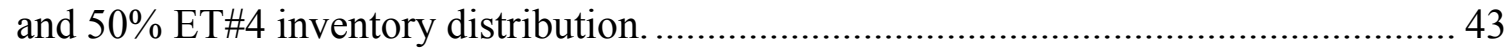

Figure 8-1 Log-normal distribution for $\mathrm{Np}-237$ based on available historical inventory data for ST and ET facilities. 
Figure 8-2 cdf for Np-237 based on available historical inventory data for ST and ET facilities (example calculation shown by arrows).................................................. 58

Figure 8-3 Max SOF histogram plot (no time windowing option) based on two 10,000 trial

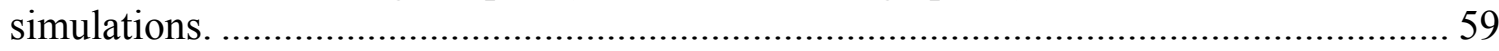

\section{LIST OF TABLES}

Table 2-1 Parent nuclides evaluated in this UDQE. ................................................... 14

Table 4-1 ET\#3 timeline in terms of absolute versus relative timing................................ 22

Table 4-2 $\mathrm{K}_{\mathrm{d}}$ values employed in ET\#3 transport analyses. ......................................... 25

Table 5-1 Tensor factors for the seven special parent nuclides...................................... 32

Table 5-2 IM Inventory Factor for each disposal unit in SLITw...................................... 33

Table 6-1 2008 PA Plume Interaction Factors................................................................. 41

Table 7-1 All E-Area pathways being considered and their current time windows............. 44

Table 7-2 List of GW parent nuclides for ST\#12 highlighting those that require further

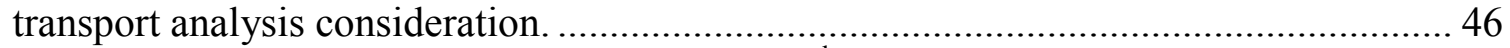

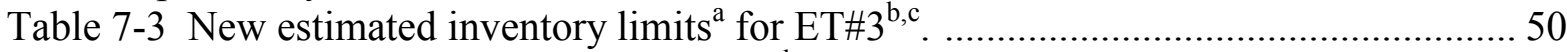

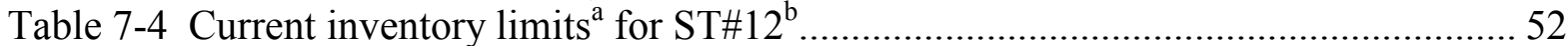

Table 8-1 Historical inventories for the 74 parent nuclides considered for ET\#3............... 55

Table 8-2 Average SOF Contribution for each of the 74 parent nuclides during the 10,000

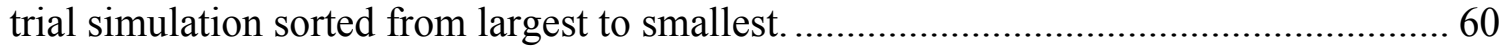




\section{LIST OF ACRONYMS}

$\begin{array}{ll}\text { cdf } & \text { Cumulative Density Function } \\ \text { CDP } & \text { Cellulose Degradation Products } \\ \text { CIG } & \text { Components-In-Grout } \\ \text { DAS } & \text { Disposal Authorization Statement } \\ \text { DCF } & \text { Dose Conversion Factor } \\ \text { DOE } & \text { United States Department of Energy } \\ \text { ELLWF } & \text { E-Area Low Level Waste Facility } \\ \text { EIC } & \text { End of Institutional Control } \\ \text { EPA } & \text { United States Environmental Protection Agency } \\ \text { EPP } & \text { End of Performance Period } \\ \text { ET } & \text { Engineered Trench } \\ \text { GW } & \text { Groundwater } \\ \text { IC } & \text { Institutional Control } \\ \text { ICRP } & \text { International Commission on Radiological Protection } \\ \text { ILV } & \text { Intermediate Level Vault } \\ \text { IM } & \text { Interim Measures } \\ \text { LAWV } & \text { Low Activity Waste Vault } \\ \text { MCL } & \text { Maximum Contaminant Level } \\ \text { NRC } & \text { Nuclear Regulatory Commission } \\ \text { NRCDA } & \text { Naval Reactor Component Disposal Area } \\ \text { PA } & \text { Performance Assessment } \\ \text { PIF } & \text { Plume Interaction Factor } \\ \text { PORFLOW } & \text { Acronym for the multidimensional flow and transport code employed } \\ \text { SA } & \text { Special Analysis } \\ \text { SCDHEC } & \text { South Carolina Department of Health and Environmental Control } \\ \text { SIC } & \text { Start of Institutional Control } \\ \text { SOF } & \text { Sum-of-Fractions } \\ \text { SRNL } & \text { Savannah River National Laboratory } \\ \text { ST } & \text { Slit Trench } \\ \text { SLITc } & \text { Center Set of Slit Trenches (ST\#1-7) } \\ \text { SLITe } & \text { East Set of Slit Trenches (ST\#14-21) } \\ \text { SLITw } & \text { West Set of Slit Trenches (ST\#8-13) } \\ \text { SWM } & \text { Solid Waste Management } \\ \text { UDQ } & \text { Unreviewed Disposal Question } \\ \text { UDQE } & \text { Unreviewed Disposal Question Evaluation } \\ \text { WITS } & \text { Waste Information Tracking System } \\ & \end{array}$




\subsection{EXECUTIVE SUMMARY}

Because Engineered Trench \#3 (ET\#3) will be placed in the location previously designated for Slit Trench \#12 (ST\#12), Solid Waste Management (SWM) requested that the Savannah River National Laboratory (SRNL) determine if the ST\#12 limits could be employed as surrogate disposal limits for ET\#3 operations. SRNL documented in this Unreviewed Disposal Question Evaluation (UDQE) that the use of ST\#12 limits as surrogates for the new ET\#3 disposal unit will provide reasonable assurance that Department of Energy (DOE) 435.1 performance objectives and measures (USDOE, 1999) will be protected. Therefore new ET\#3 inventory limits as determined by a Special Analysis (SA) are not required.

Based on this UDQE, ET\#3 disposal will consist of generic waste and crushable waste containers (i.e., no special waste forms and/or non-crushable waste containers). ET\#3 disposal operations are expected to start around 10/1/2013 but a potential start date as early as $9 / 1 / 2013$ has been requested and is considered acceptable.

Based on the current disposal limit methodology, the ST\#12 disposal limits could be used as "conservative" surrogates for ET\#3 operations provided that each ST\#12 disposal limit be less than or equal to corresponding ET\#3 disposal limits for: (1) every "parent" nuclide ${ }^{1}$ to be disposed of in ET\#3, (2) for every groundwater (GW) and non-GW pathway; and (3) for every time window within each pathway. If indeed every prospective ET\#3 limit were greater than or equal to the corresponding ST\#12 limit, then this methodology would place no constraint on the disposal unit's inventory composition as long as the sum-of-fractions (SOF) did not exceed one. Any one of the possible parent nuclides could make up the entire disposal unit if desired and performance measures would not be exceeded.

Initial evaluations of existing 2008 Performance Assessment (PA) vadose zone results (for existing ET and ST units) indicated that for some time windows within certain GW pathways, ST disposal limits would not be limiting for ET application. In addition, since the 2008 PA, (WSRC, 2008) numerous key input parameters and transport models have been updated (i.e., some from new DOE standards, International Committees, and ongoing SRNL research and development activities). To ascertain the composite impact on all currently operating E-Area Low-Level Waste Facility (ELLWF) disposal units, the majority of this new information was considered in a recent UDQE (Flach, 2013) that employed an approximate perturbation analysis approach (i.e., adjusting existing inventory fractions for key nuclides with factors that approximate the impact of new information). SWM requested SRNL follow this approach to evaluate the use of ST\#12 limits as surrogates for ET\#3. To achieve the goals set out by SWM required that SRNL conduct full vadose zone and aquifer transport analyses utilizing a new ET\#3 model for seven key parent nuclides identified as currently exceeding a sum-of-fractions (SOF) contribution of 1\% in ST\#9 and ET\#2 (Sink, 2013). Selection of this subset of parent nuclides substantially reduced the amount of detailed modeling by focusing only on potentially significant contributors to the future ET\#3

\footnotetext{
${ }^{1}$ Parent nuclides refer to the list of 78 nuclides that passed the initial groundwater screening and/or inadvertent intruder screening in the 2008 PA (WSRC, 2008) and were subsequently analyzed in the detailed modeling for each disposal unit. Subtracted from this list are four parent nuclides that have no inventory in E-Area leaving a total of 74 parents evaluated by this UDQE.
} 
SOF's. As requested by SWM, the new ET\#3 model employed only the new information addressed in the recent UDQE (Flach, 2013) and the specific considerations necessary to account for the differing ET\#3 geometry. The remaining 67 parent nuclides from the 2008 PA were evaluated using the existing 2008 PA analyses and making the necessary "new information" adjustments as described in this report.

These new and updated analyses indicate that both the GW and non-GW pathways ST\#12 disposal limits would not be conservative (i.e., ST values would not be lower than ET values) over every time window or scenario for several key parent nuclides. Therefore, from a "strictly" deterministic approach, the use of ST\#12 disposal limits as surrogates for ET\#3 operations could not be justified without performing the transport analyses for all GW parent nuclides (i.e., not just the seven considered).

Based on observations made while comparing the above vadose zone fluxes and results from the perturbation analyses, it became apparent that many of the non-conservative disposal limits should not dominate the overall maximum SOF. For example, some parent nuclides had non-conservative ST\#12 disposal limits (relative to prospective ET\#3 limits) but from a historical inventory perspective would contribute very little to the max SOF due to their very low expected final inventory. These observations strongly suggested that a more flexible disposal limit strategy should be considered. In this report we referred to this strategy as the "stochastic" approach.

This proposed approach is philosophically different than that used to set prior inventory limits because it does not rigorously ensure performance objectives at the individual parent nuclide level for ET\#3. Instead, it relies on the expectation that the final ET\#3 inventory composition will not be significantly different from historical Slit Trench and Engineered Trench disposal compositions (see Sink, 2012).

The use of the current ST\#12 disposal limits will give rise to some non-zero probability of exceeding a performance measure; however, as the stochastic analysis results in this report show, this probability is extremely small. Therefore, the requirement of "reasonable assurance" in DOE Order 435.1 (USDOE, 1999) is satisfied. The results from the stochastic analysis are shown in Figure 1-1 (see details in Chapter 8 of this report). These results indicate that the likelihood of exceeding a maximum SOF greater than one is less than $\sim 0.05 \%$. The average (expected) value of the maximum SOF is only $\sim 0.27$. These results assume a 50\%:50\% inventory split between ET\#3 and ET\#4. If newer information shows a significant increase in the ET\#3's maximum SOF (e.g., reaching a 5\% probability of exceeding a SOF of one); then, offsetting measures such as reducing the allowable inventory in ET\#4 could be employed to compensate.

The ST\#12 and ST\#13 footprints are at the northwest end of E-Area and they have very little plume overlap with adjacent disposal units due to the general direction of groundwater flow. As can be seen in Chapter 6 (under plume interaction), neither the adjacent west set of ST disposal units (ST\#8-11) nor the Intermediate Level Vault (ILV) contributes significantly to groundwater concentrations in line with these units thereby providing significant margin for higher inventories in both of these units. This kind of margin is not available in the remainder of disposal units in the ELLWF. 
SRNL-STI-2013-00393, REV . 0

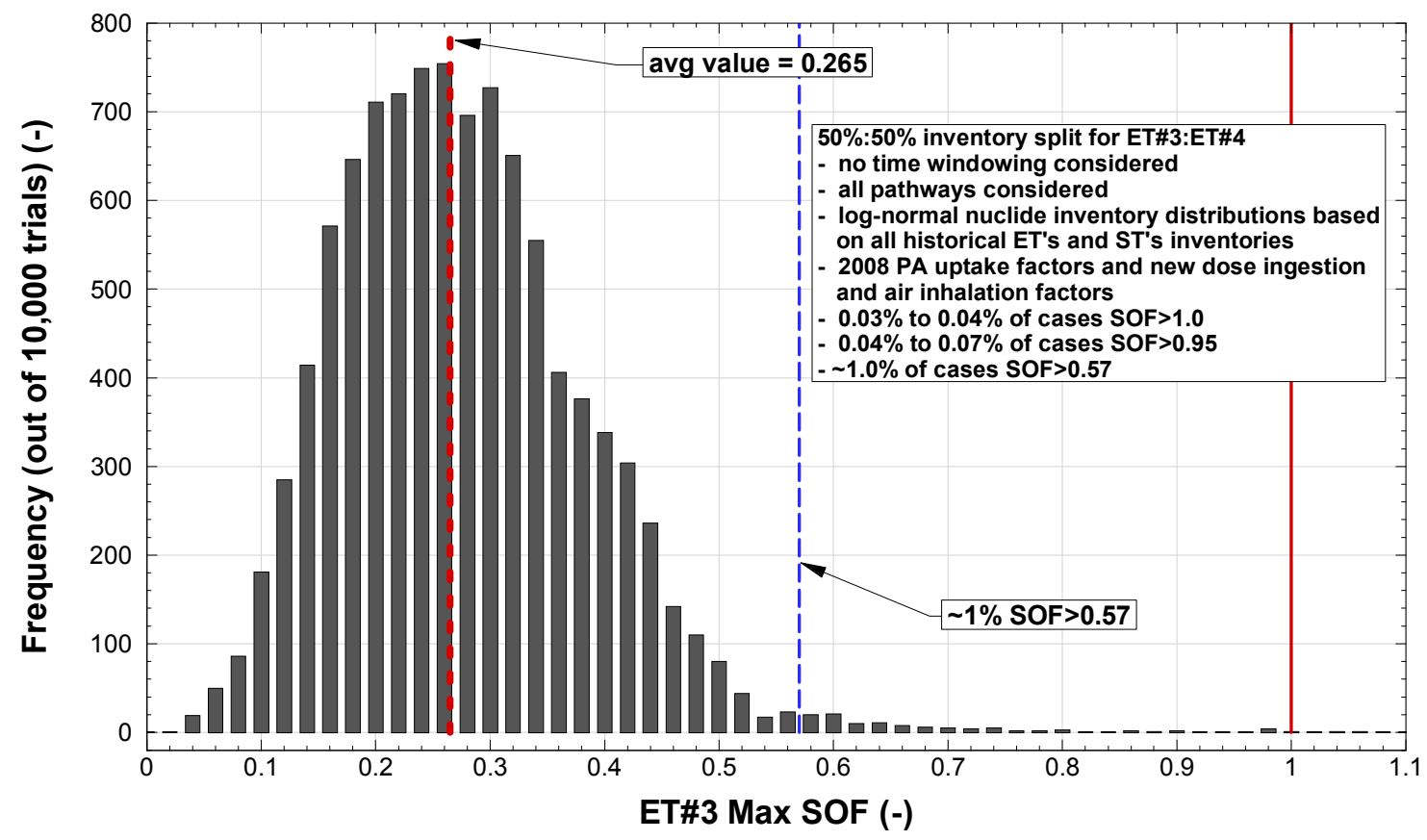

Figure 1-1 Max SOF histogram plot (no time windowing option) based on a 10,000 trial simulation. 
SRNL-STI-2013-00393, REV. 0

\subsection{INTRODUCTION}

\subsection{Background}

SWM requested (see UDQ Screening provided in the Appendix) SRNL: (1) create an assessment report to assist SWM in determining the future E-Area footprint for ET\#3 based on four potential options and once a preferred option had been selected by SWM, (2) determine the new ET\#3 PA disposal limits. In 2012 SWM selected the existing ST\#12 position (i.e., Option 3 in the UDQ Screening) inside E-Area as the future location of ET\#3 based on the site alternatives study performed by Collard and Hamm (2012). SWM is also considering the location of ST\#13 (i.e., Option 2 in the UDQ Screening) as the future site of ET\#4. To accomplish the second request, an UDQE has been performed to assess the expected performance of ET\#3 relative to the existing ST\#12 inventory limits. Based on the analyses presented in this report, the current ST\#12 disposal limits are considered to be acceptable surrogates for use in operating the new ET\#3 disposal unit and as such a standard Special Analysis (SA) is not required.

The current disposal limits for ST\#12 were established in the 2008 PA (WSRC, 2008) and amended by the trench limits SA (Swingle, 2012) and air pathway SA (Hiergesell, 2011). SWM communicated the following objectives to SRNL for this assessment:

- Evaluate whether the existing ST\#12 limits could be used as surrogates for the new ET\#3,

- Assume an equal allocation of allowable inventory between the future ET\#3 (ST\#12 position) and ET\#4 (ST\#13 position) locations in determining if ST\#12 limits are acceptable,

- Focus detailed transport calculations on seven key parent nuclides in the GW pathway to minimize the level of effort (Sink, 2013), and,

- Consider only the new information and model simulation techniques since the 2008 PA that were evaluated in UDQE prepared by Flach (2013) and use Flach's approach to estimate the influence of this new information on the sum-of-fractions (i.e., a perturbation analysis) for the seven key nuclides.

The factors appearing in the perturbation analysis performed in this report were previously analyzed in the UDQE prepared by Flach (2013) for all currently operating Slit and Engineered Trenches and, overall, the impact appeared to be favorable. The perturbation analysis approach was carried out and preliminary results were obtained. However, a concern arose when the results of this effort were reviewed. Increases in sorption $\left(K_{d}\right)$ for key radionuclides in combination with the assumed placement of an interim closure runoff cover over the ET\#3 waste much sooner after burial (i.e., 12 years uncovered for ET\#3 versus 30 years uncovered for ET\#1 before interim closure), shifted peak concentrations for the highly mobile species (Mo-93, Tc-99, C-14 and I-129) from very early times to much later times. This meant that direct comparison of ST\#12 limits and new ET\#3 limits was not possible because of the lack of plume super-positioning between the 2008 PA and new ET\#3 models. For example, the peak concentration for Tc-99 shifted from about 14 years in the 2008 PA to almost 700 years in the revised analysis. The disposal limit for Tc-99 changed 
from being GW beta-gamma maximum contaminant level (MCL) limited to being GW ingestion dose (All-Pathways) limited.

Careful evaluation of the results from the perturbation analysis led to the conclusion that the perturbation approach had to be abandoned in favor of a stochastic analysis that relied on the overall performance of ET\#3 rather than deterministically evaluating the behavior of individual radionuclides. This approach was deemed possible because of the existence of 18 years of historical Slit and Engineered Trench disposal inventories. Fortunately, much of the ET\#3 flow and transport calculations had already been performed as part of the perturbation analysis which also required determining peak concentrations at the point of assessment.

The new "stochastic" approach is philosophically different than that used to set prior inventory limits because it does not rigorously ensure performance objectives at the individual parent nuclide level for ET\#3. Instead, it relies on the expectation that the final ET\#3 inventory distribution will not be significantly different from historical Slit and Engineered Trench disposal compositions. In addition, if a future analysis determined that the ET\#3 SOFs were greater than 1.0 then ET\#4 disposal limits could be reduced prior to the start of operations. Based on engineering judgment, it was believed that the increased risk associated with this proposed approach would be small. Part of the proposed approach was to confirm that this risk was indeed small and acceptable for this specific disposal unit.

\subsection{General Modeling Approach}

This section presents a brief overview of the approach used for modeling GW and non-GW pathways and performing the stochastic analysis. This report is organized into the following chapters:

- New key inputs and assumptions resulting from this evaluation are listed in Chapter 3 ,

- The flow and transport modeling approach used to compute ET\#3 concentration histories at the 100-meter boundary are described in Chapter 4 (vadose zone) and Chapter 5 (aquifer),

- Consideration of the interaction between the contaminant plume from ET\#3 and plumes from ET\#4 and adjacent Slit Trenches and ILV is discussed in Chapter 6,

- The methodology and dosimetry used in the calculation of estimated new ET\#3 inventory limits ${ }^{2}$ along with results are presented in Chapter 7 ,

- The stochastic analysis approach is described and the results are presented in Chapter 8.

- The UDQE questions are answered in Chapter 9,

- The summary conclusions of the analysis are presented in Chapter 10, and,

- The UDQ Screening is shown in the Appendix.

A radionuclide screening methodology was employed in the 2008 PA in order to reduce the number of parent radionuclides to be considered in detailed transport analyses. This GW

\footnotetext{
${ }^{2}$ The term "estimated new ET\#3 limits" is used throughout this document because most of the prospective ET\#3 limits calculated in this UDQE are based on approximations rather than explicit analysis. For example ET\#3 GW and All-Pathways limits calculated for 31 of the $38 \mathrm{GW}$ parent nuclides are based on extrapolation of 2008 PA modeling results.
} 
screening process yielded 38 parent radionuclides that were subsequently evaluated in detailed groundwater modeling in the PA. A separate inadvertent intruder screening yielded 78 nuclides (including the 38 groundwater parents) subsequently evaluated for intruder disposal limits. Four nuclides out of the 78 have no ELLWF trench inventory after 18 years and have been eliminated from this evaluation (specifically, Bk-249, Ca-41, W-185, and W188). The remaining 74 nuclides are described as "parent nuclides" in this UDQE and are listed in Table 2-1.

For GW pathways only the "generic" disposal limits for these 38 parent nuclides are considered for ET\#3. The "special waste forms" that were addressed in the 2008 PA and subsequent SA's are not considered here because no special waste forms will be buried within ET\#3 (See key inputs and assumptions in Chapter 3).

Table 2-1 Parent nuclides evaluated in this UDQE.

\begin{tabular}{|c|c|c|c|}
\hline $\begin{array}{c}\text { Parent } \\
\text { Nuclide, }\end{array}$ & Parent Nuclide & Parent Nuclide & Parent Nuclide \\
\hline Ac-227 & Cm-245 & Ni-59 & Sm-151 \\
\hline Ag-108m & Cm-246 & Ni-63 & Sn-121m \\
\hline Al-26 & Cm-247 & Np-237 & Sn-126 \\
\hline Am-241 & Cm-248 & Pa-231 & Sr-90 \\
\hline Am-242m & Co-60 & Pb-210 & Tc-99 \\
\hline Am-243 & Cs-134 & Pd-107 & Th-228 \\
\hline Ar-39 & Cs-135 & Pu-238 & Th-229 \\
\hline Ba-133 & Cs-137 & Pu-239 & Th-230 \\
\hline Bi-207 & Eu-152 & Pu-240 & Th-232 \\
\hline C-14 & Eu-154 & Pu-241 & U-232 \\
\hline Cd-113m & Eu-155 & Pu-242 & U-233 \\
\hline Cf-249 & H-3 & Pu-244 & U-234 \\
\hline Cf-250 & I-129 & Ra-226 & U-235 \\
\hline Cf-251 & K-40 & Ra-228 & U-236 \\
\hline Cf-252 & Kr-85 & Rb-87 & U-238 \\
\hline Cl-36 & Mo-93 & S-35 & W-181 \\
\hline Cm-242 & Na-22 & Sb-125 & Zr-93 \\
\hline Cm-243 & Nb-93m & Sc-46 & \\
\hline Cm-244 & Nb-94 & Se-79 & \\
\hline
\end{tabular}

a Those parent nuclides that passed the GW screen (38 nuclides) are highlighted in orange.

$\mathrm{b}$ The seven key GW parent nuclides requiring detailed transport analyses are provided in bold.

The analysis in this UDQE follows essentially the same methodology used in the 2008 PA (WSRC, 2008). Below is an overview of the analysis methodology:

Transport Methodology for the Seven Key GW Parent Nuclides

- Seven key GW radionuclides were chosen for full modeling of vadose and aquifer transport from ET\#3 to the point of assessment (Sink, 2013). The parent radionuclides chosen for their typically significant contribution to the SOF for Slit Trench disposal were: H-3, C-14, I-129, Sr-90, Mo-93, Tc-99, and Np-237.

- Transport through ET\#3 and the associated vadose zone of a nominal one gram-mole of each parent radionuclide was calculated using the PORFLOW vadose zone model. 
Vadose zone transport calculations produced contaminant fluxes to the water table which were used as input to the PORFLOW aquifer transport model.

- The aquifer transport model was run and the maximum groundwater concentration at the 100 -m point of assessment for each parent nuclide was saved as a function of time for dose calculations.

Transport Methodology for the Remaining 31 Key GW Parent Nuclides

- The remaining 31 parent GW radionuclides were not included in the ET\#3 transport analysis. Groundwater concentrations at the $100-\mathrm{m}$ point of assessment from the 2008 PA analysis of the west set of Slit Trenches (SLITw) were used.

- The SLITw 100-m boundary concentrations were adjusted for each parent nuclide to take into account impacts associated with going from the SLITw group to the individual ST\#12 unit (these adjustments include the source term adjustment made in the most recent Slit Trench SA (Swingle, 2012). The 2008 PA (WSRC, 2008) aquifer results for the intact scenarios were used because non-crushable containers are being excluded from ET\#3.

Plume Interaction and GW Limit Calculations for All 38 GW Parent Nuclides

- In the 2008 PA methodology, inventory limits were computed individually for each unique disposal unit or group of units such as SLITw. The initial step was the calculation of maximum well concentration profiles (in isolation from neighboring disposal units) that were then adjusted based on a separate plume interaction analyses. For assessing/comparing inventory limits between the current ST\#12 and the new ET\#3, updated plume interaction factors (PIFs) were calculated. This was a result of the fact that current PIFs exist for Slit Trench groups (i.e., SLITw, etc.) and not for any of their individual components (e.g., ST\#12).

- Results from the PORFLOW aquifer transport analysis produced concentrations at the point of assessment in terms of $\mathrm{pCi} / \mathrm{L} /(\mathrm{Ci}$ of parent buried). For each applicable $\mathrm{GW}$ pathway, doses were calculated and new estimated ET\#3 inventory limits were produced using the peak groundwater concentrations in each time window for each parent nuclide (including its progeny where applicable).

Non-GW Limit Calculations for All 74 Parent Nuclides

- The non-GW pathway disposal limits were calculated for ET\#3.

- Dose parameter inputs to the automated Inadvertent Intruder Application (Koffman, 2006) used in the 2008 PA were updated based on the new information considered in Flach's UDQE (2013) before calculating ET\#3 intruder limits.

- ET\#3 disposal unit geometry was factored into the comparisons with the 2008 PA air and radon calculations.

New Stochastic Analysis for All 74 Parent Nuclides

- The above analyses produced a full set of expected GW and non-GW limits for the new ET\#3 (i.e., all pathways and their associated time windows for all 74 parent nuclides) which were then used in the stochastic analysis that lead to the conclusion that it is highly unlikely that waste disposal in ET\#3 would result in an SOF greater than one.

- In the stochastic analysis, it was assumed that the waste that would be disposed in ET\#3 would be similar in composition to that disposed historically in other Slit and 
Engineered Trenches. Historical inventories for the 74 parent nuclides listed in Table 2-1 were obtained for ET\#1, ET\#2 and all operating and closed ST's (Sink, 2012). The mean trench waste composition and standard deviation about the mean were calculated and these stochastic parameters were fit to an assumed log-normal distribution for each parent nuclide.

- Each of the above historical nuclide distributions for the 74 parents were randomly sampled in a "Monte Carlo" like process to arrive at unique final inventory compositions in 10,000 independent trial runs. Each of these 10,000 sets of compositions represented a potential final ET\#3 inventory distribution whose probability of occurrence is log-normal. The inventory composition for each run was represented as "curie fractions" obtained by dividing each individual nuclide's inventory by the total inventory from the trial run.

- Each inventory composition generated above was then scaled to produce the actual inventory that would yield a SOF of unity based on the current ST\#12 inventory limits.

- Given these individual "ST\#12 compliant" inventories the final step was to compute the SOF based on the new estimated ET\#3 limits calculated earlier in this analysis to determine if the ST\#12 SOF was limiting or not for this particular inventory distribution.

All transport analyses highlighted above were performed using PORFLOW (ACRi, 2010), a commercial multidimensional flow and transport code, employing the most recent QA'ed version, 6.30.2 (Whiteside, 2010). The transport analyses used in the current ST\#12 disposal limits were based on an earlier version 5.97 (Hang, 2007 and Aleman, 2007).

The following changes to the modeling approach have been incorporated into this analysis based on new information obtained since the 2008 PA and considered by Flach (2013):

- For the seven key GW parents (and their progeny) updated soil adsorption coefficients $\left(\mathrm{K}_{\mathrm{d}}\right)$ reported by Kaplan (2010) are used in the analysis. The $\mathrm{K}_{\mathrm{d}}$ for carbon has been further updated as reported by Roberts and Kaplan (2013). It is now also recommended that Cellulose Degradation Product (CDP) factors not be applied to modify $\mathrm{K}_{\mathrm{d}}$ values in the presence of cellulosic waste material (Roberts and Kaplan, 2013). However, to be consistent with previous analysis, for the remaining $31 \mathrm{GW}$ parents (and their progeny) disposal limits for ET\#3 considered $\mathrm{K}_{\mathrm{d}}$ values with CDP present and CDP absent.

- The final closure cap has been revised to a composite barrier approved for use at the Saltstone Disposal Facility and in F- and H-Tank Farms by the Nuclear Regulatory Commission (NRC), Environmental Protection Agency (EPA) and South Carolina Department of Health and Environmental Control (SCDHEC). The composite barrier consists of a high-density polyethylene geo-membrane overlying a geo-synthetic clay liner. This cap reduces infiltration through the waste material from that used in previous modeling. The interim closure runoff cover design was the same as the one employed in the 2008 PA.

- Radionuclide properties such as half-life and decay branching fractions were updated to use the latest available information (ICRP, 2008). These changes are relatively 
minor and would be expected to have little impact on calculated doses. The newer dose coefficients are consistent with these newer radionuclide properties.

- Ingestion dose coefficients for the radionuclides considered in this analysis were updated to use the latest available information from Jannik and Stone (2013). During the course of this work, it was discovered that updated values for bioaccumulation and transfer factors have been reported by Jannik et al. (2010). These factors, which impact the dose from ingestion of vegetables, milk and meat, were not updated in this study; however, a new UDQ Screening has been initiated for further evaluation by SRNL.

- A one year half-life cutoff was assumed for establishing each parent nuclides abbreviated chain members. The 2008 PA assumed a five year cutoff while subsequent SA's half-life cutoff values ranged from one to three year. For dose calculations all remaining radionuclides were assumed to be in secular equilibrium with their nearest parent in the full chain.

Only the new information that was incorporated into the recent UDQE by Flach (2013) was considered in this report. 
SRNL-STI-2013-00393, REV . 0

\subsection{KEY INPUTS AND ASSUMPTIONS}

The following key inputs and assumptions apply for this ET\#3 UDQE and supplement all other key inputs and assumptions presented in the 2008 PA (WSRC, 2008), subsequent SA's, and the Closure Plan (Phifer, et al. 2009).

1. Operational Assumption: The following restrictions apply for waste disposal operations in ET\#3:

a. Existing ST\#12 special waste forms in the ELLWF disposal limits database (Swingle, 2012b) are excluded from this assessment and therefore must either be adjusted to the generic limit, adjusted to zero, or prohibited in the Waste Information Tracking System (WITS).

b. No waste is to be directly disposed in the sloping sides of ET\#3. However, occasional slumping of boxes into the slide slope is acceptable.

c. No non-crushable containers are to be disposed of in ET\#3.

d. No operational stormwater runoff covers will be installed prior to installation of the interim closure runoff cover in 2025 .

e. ET\#3 waste disposal operations begin no sooner than September 1, 2013.

2. Operational Assumption: Future inventory allocation is assumed to be evenly divided between ET\#3 (currently being constructed where ST\#12 was planned) and ET\#4 (planned for the ST\#13 footprint). Because of essentially 100\% GW plume overlap between the two locations, an accurate assessment of ET\#3 inventory impacts will be necessary prior to opening ET\#4. ST\#13 limits cannot be used as surrogates for ET\#4 limits without this detailed assessment of ET\#3. Therefore, prior to opening ET\#4 (or ST\#13), a full special analysis will be performed that explicitly accounts for actual ET\#3 inventory (or projected inventory at closure) and incorporates all new information known at that time in establishing limits for ET\#4.

\section{Modeling Assumptions:}

a. The analysis relies on the aggregate performance of the disposal unit assuming a historical trench composition rather than ensuring performance objectives are met at the individual parent nuclide level.

b. The stochastic analysis evaluates overall peak doses irrespective of existing time intervals in the ELLWF disposal limits database (Swingle, 2012b). 


\subsection{VADOSE ZONE ANALYSIS}

\subsection{Vadose Zone Conceptual Model}

Two vadose zone conceptual models apply in this set of analyses: (1) the original 2D model employed in establishing the Slit Trench limits for the 2008 PA and (2) a new 2D model that reflects the expected geometry of the proposed ET\#3 being overlaid on the original footprint of ST\#12 located in the west set of Slit Trenches. The transport results obtained from the 2008 PA SLITw are employed for all of the GW parent nuclides except those seven key parents selected for additional consideration. For those seven parent nuclides, a new model was generated that reflects the proposed geometry of ET\#3 and incorporates the new PA information considered by Flach (2013). The remainder of this chapter is a discussion of this new vadose zone model and results for the seven key groundwater parents.

Figure 4-1 is a close-up view of the north-west section of ELLWF where the original footprint for ST\#12 (outlined in a thin brown line) has been overlaid with the proposed footprint for ET\#3 (i.e., rectangle in the bold solid red line). The area internal to the red rectangular area represents the base of ET\#3 and, similarly, the base of future ET\#4 is defined by the green rectangular box. Coordinates for ET\#3, ET\#4 and NRCDA were provided by SWM for the ET\#3 site selection study (Collard and Hamm, 2012) as amended by Fox (2012) and Tempel (2012). One vertical slice through ET\#3 was chosen to represent the "average" geometry of the 2D vadose zone model. The location of this single slice was placed at the mid-section of the ET\#3 footprint as shown by the magenta line in Figure 4-1. The actual sloped sidewall regions surrounding both ET\#3 and ET\#4 is shown by the red dashed curve. Also shown are the estimated footprints for the interim and final covers (i.e., dashed blue and black curves, respectively). 
SRNL-STI-2013-00393, REV. 0

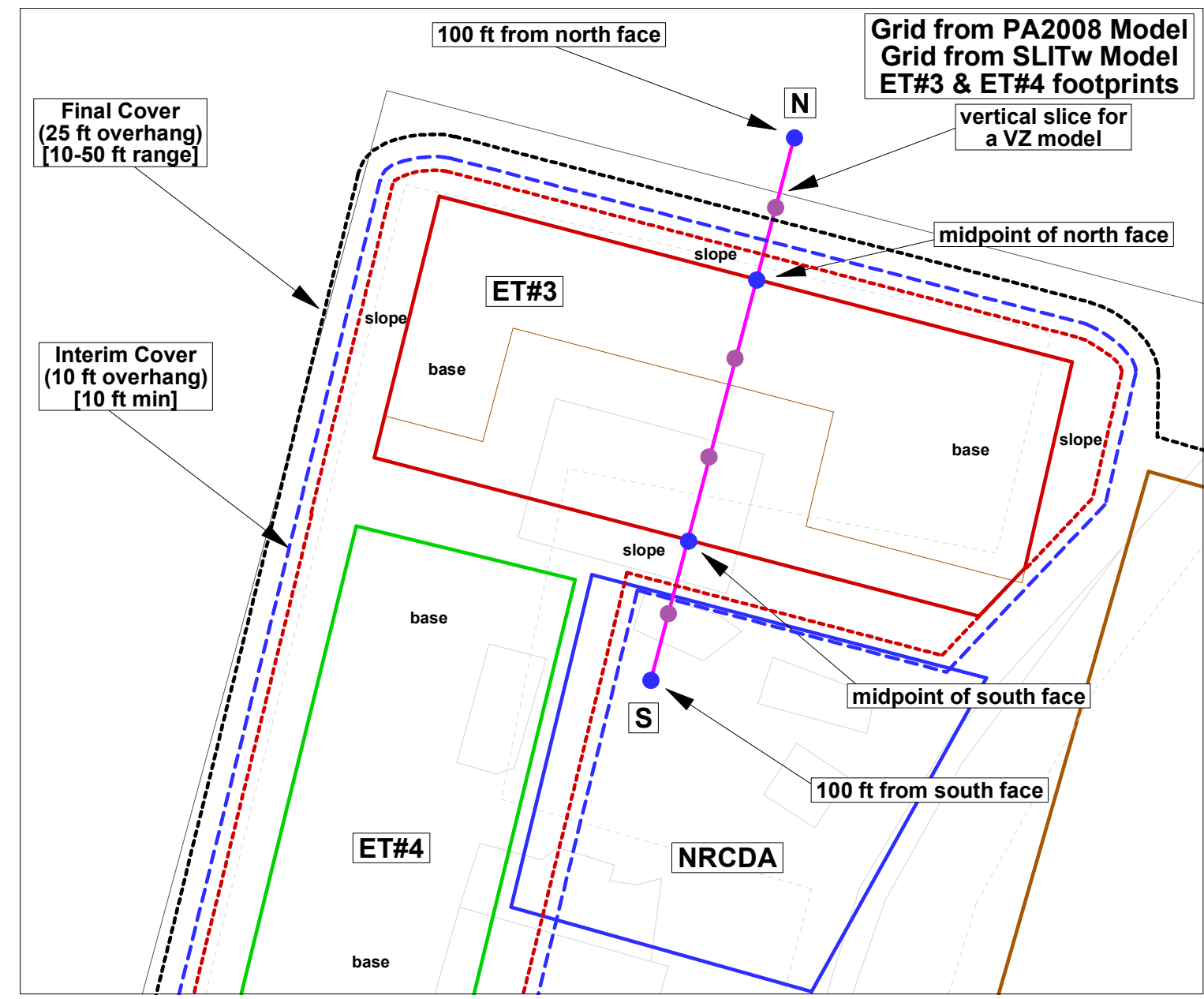

Figure 4-1 Close-up view of proposed ET\#3 footprint showing the vertical cross-section chosen to represent the ET\#3 vadose zone conceptual model.

The vertical slice as shown in Figure 4-1 is also shown in Figure 4-2 where the geometrical details of the material zones are provided. The unexcavated ground surface, depth to the water table, and depth of the clayey region are consistent with the prior ET\#3 down-select models discussed in Collard and Hamm (2012).

The main differences in the ET\#3 model employed here versus the ones employed in the down-select process (Collard and Hamm, 2012, see Figure 2-1 for example) are:

- For the trench base a uniform drop in elevation by approximately three feet from its southern point to its northern point;

- The unexcavated ground surface was employed;

- The northern trench slope ( $1 \frac{1}{2}: 1$ foot rise) does not begin at the bottom of the waste zone but starts approximately 10 feet higher;

- A sloped backfill is added to reflect the estimated slope of the subsequent covers where this backfill region is not present prior to the placement of either cover.

- No subsidence aspects were included;

- Interim and final covers with finite extent were employed (i.e., $10 \mathrm{ft}$ for interim and $25 \mathrm{ft}$ for final covers). 


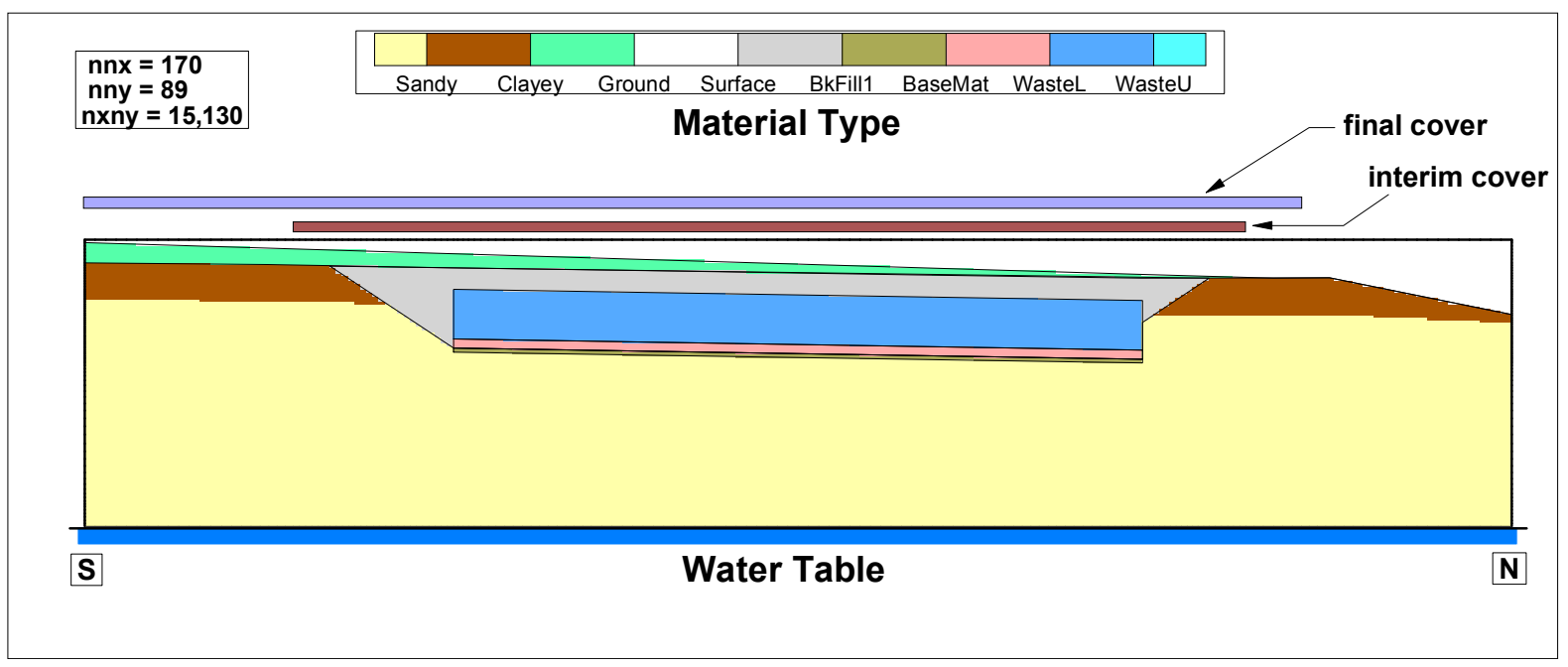

Figure 4-2 2D vadose zone model of ET\#3 showing material zones and the coverage of both the interim and final covers.

\subsection{ET\#3 Vadose Zone Flow Model}

Because ET\#3 operations will be limited to crushable waste containers, only intact scenarios must be considered (i.e., the possibility for localized subsidence due to catastrophic failure of non-crushable containers is eliminated because all waste is assume to be crushed to the maximum extent practical during the dynamic compaction phase prior to the placement of the final cover). The placement of an "operational" cover has also been eliminated; thus from the hydraulic perspective there are only three major time periods of interest:

- The uncovered trench segment prior to placement of the interim cover (before SIC);

- The interim cover period that is institutionally controlled (during IC); and

- The final cover period (after EIC);

where the acronyms are:

- SIC - start of institutional control

- IC - institutional control

- $\quad$ EIC - end of institutional control

During each of these three main time periods hydraulic properties change for various material regions. The majority of these properties were also employed in the previous 2008 PA effort (WSRC, 2008).

In the $2008 \mathrm{PA}$, inventory limits were generated for multiple dose pathways and partitioned out over selected time windows. In this UDQE, the existing analyses extracted from the earlier 2008 PA effort and new ET\#3 analyses will be combined. In order to have consistent time windows, careful consideration was given to burial timing differences. A listing of the ET\#3 timeline in terms of absolute time as well as relative time to the 2008 PA effort is provided in Table 4-1. E-Area Slit Trench operations started in ST\#1 on 12/21/1995 and the entire ELLWF Slit and Engineered Trench burials were assumed to occur on that date 
including ST\#12. The start date for ET\#3 operations is set to 10/1/2013 (an approximately 17.8 year shift from the original 2008 PA trench burial date).

Table 4-1 ET\#3 timeline in terms of absolute versus relative timing.

\begin{tabular}{|c|c|c|c|}
\hline Event & Date & Time & Relative \\
\hline Start of ST\#1 & $12 / 21 / 1995$ & 1995.97 & 0 \\
\hline Start of ET\#3 & $10 / 1 / 2013$ & 2013.75 & 17.8 \\
\hline SIC & $12 / 20 / 2025$ & 2025.97 & 30.0 \\
\hline EIC & $12 / 21 / 2125$ & 2125.97 & 130.0 \\
\hline EPP & $12 / 29 / 3125$ & 3125.97 & 1130.0 \\
\hline End & $1 / 5 / 4126$ & 4125.97 & 2130.0 \\
\hline
\end{tabular}

Table 4-1 also lists the end of performance period (EPP) and the end of the transport analysis runs. EPP is 1,000 years beyond the EIC. An additional 1,000 years of transport simulations were performed for determining potential concentration peak locations.

The time-dependent flow solution was approximated by a series of steady-state time intervals representing the ET\#3 model:

- before SIC,

- during IC, and

- after EIC.

An example of the overall flow results for the first time period (i.e., before SIC without the presence of a cover) is shown below in Figure 4-3. Without the cover, infiltration moves relatively uniformly and rapidly through the waste zone and into the aquifer.

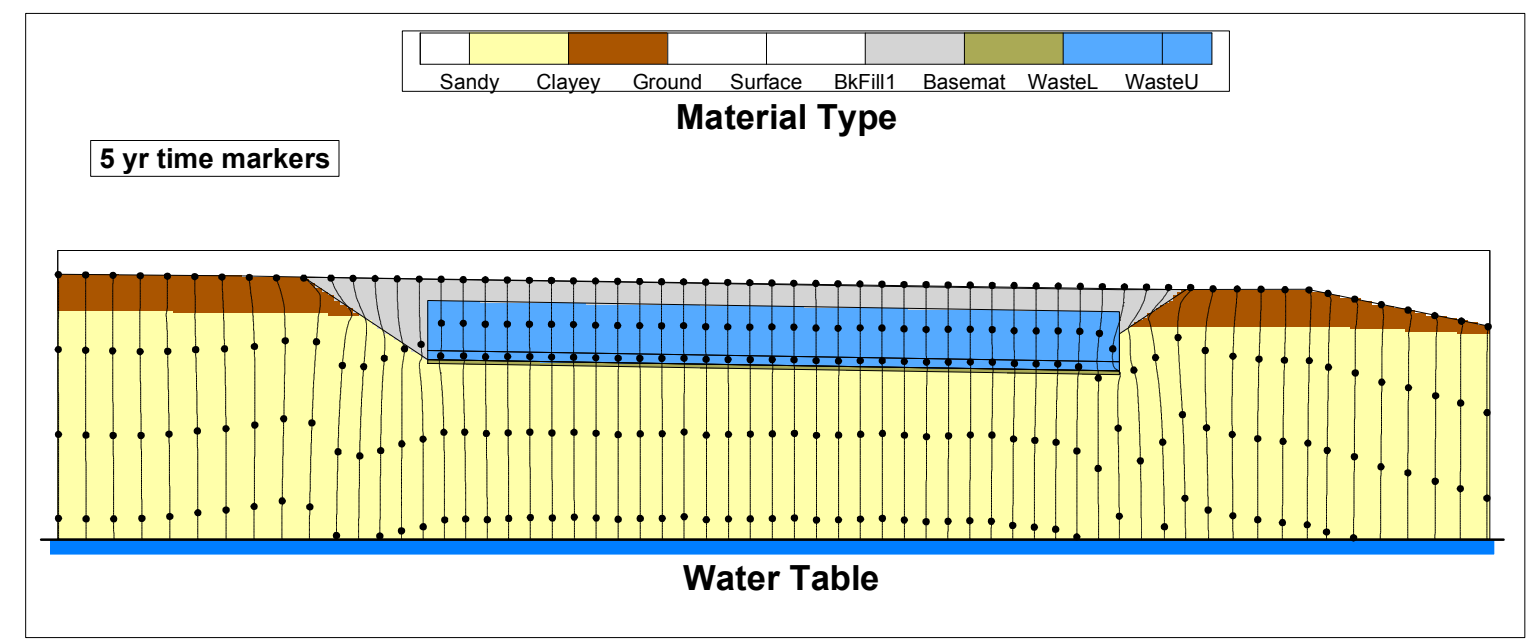

Figure 4-3 Flow results (streamlines) for the ET\#3 model before SIC (i.e., no cover present).

An example of the overall flow results for the second time period (i.e., during IC with a maintained interim cover) is shown below in Figure 4-4. The impact of having a finite interim cover whose overhang is ten feet is clearly present. 


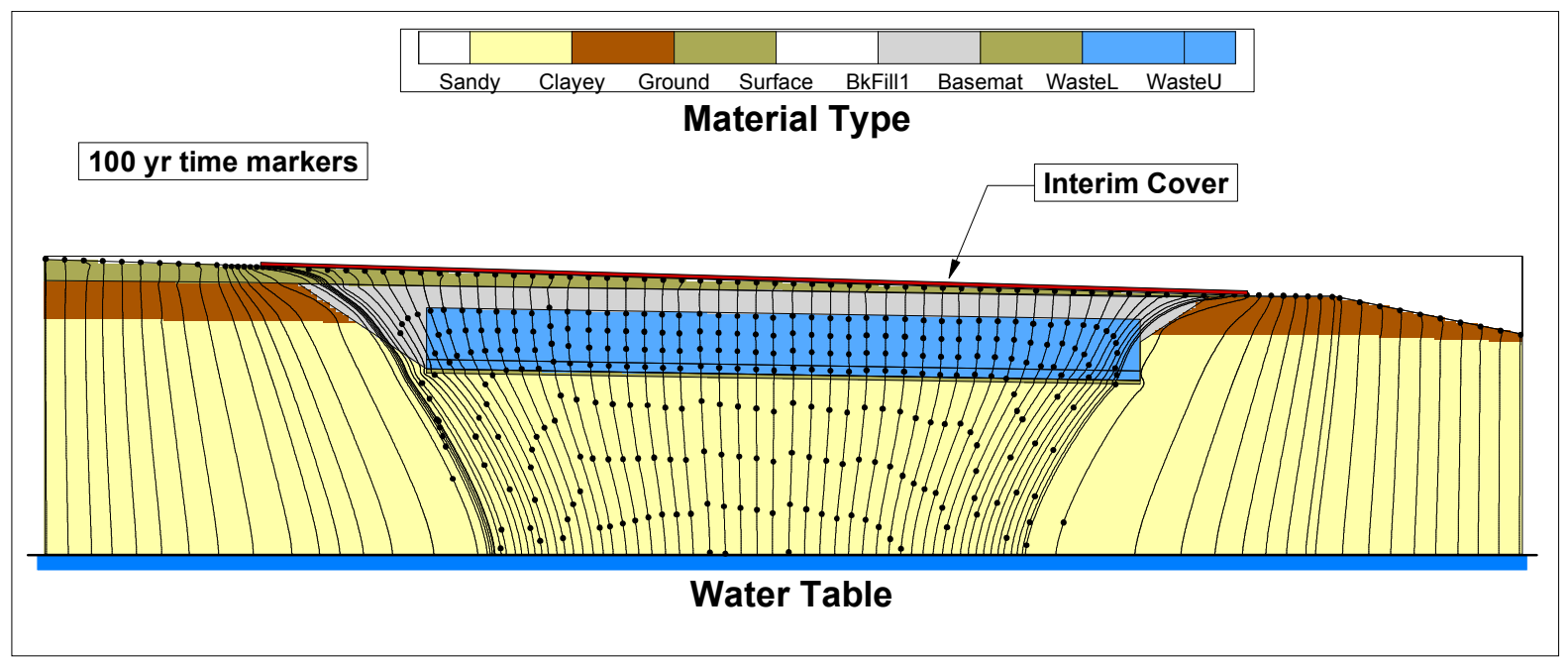

Figure 4-4 Flow results (streamlines) for the ET\#3 model during IC (the application of the interim cover).

An example of the overall flow results for the third time period (i.e., 0-5 years after EIC with a degrading final cover) is shown below in Figure 4-5. The impact of having a finite final cover whose overhang is 25 feet is clearly present. Also, the initial infiltration rate is greatly reduced when compared with the interim cover value. Due to the gradual cover degradation, this third time period was broken up into a total of 25 time intervals. Thus, a total of 27 time periods was employed to cover the entire performance period (i.e., start of ET\#3 operations to EPP).

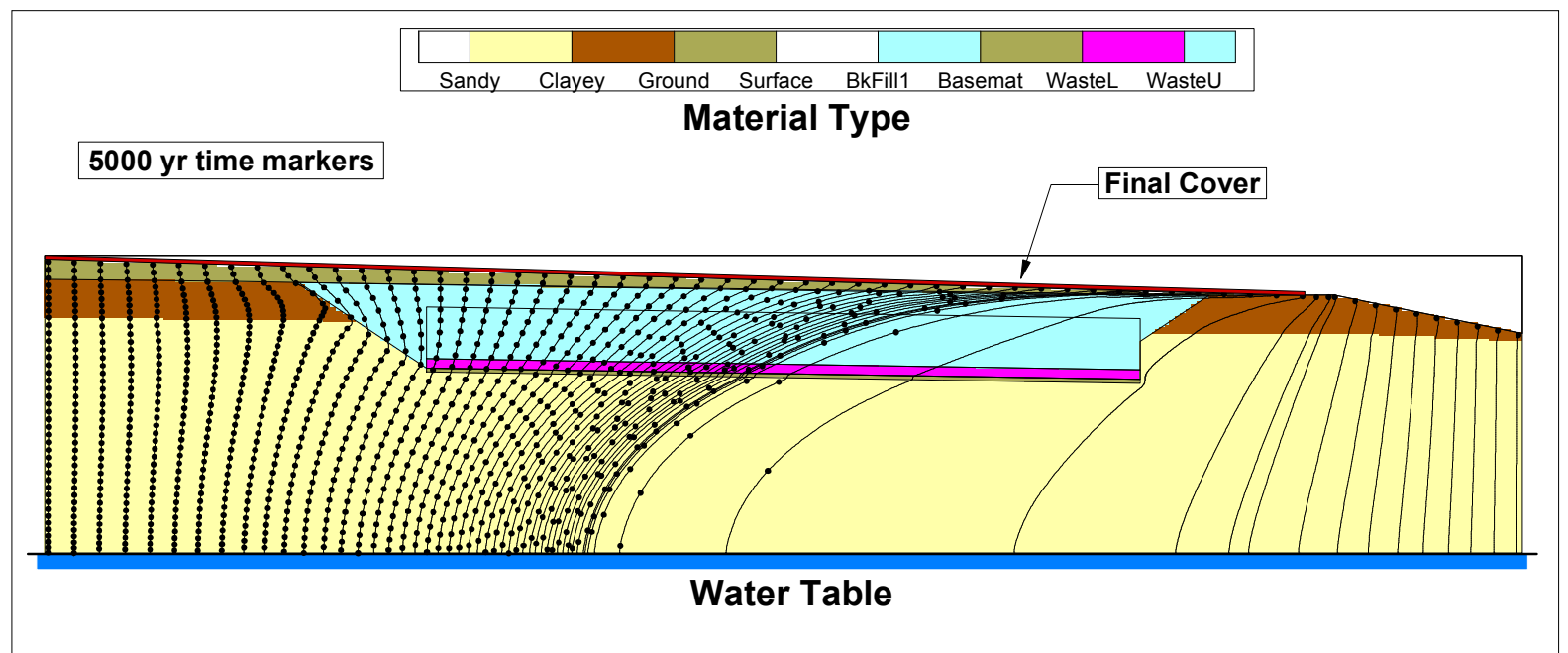

Figure 4-5 Flow results (streamlines) for the ET\#3 model after EIC (i.e., 0-5 years after the application of the final cover).

The background colors for all time slices shown are set to the initial material zone colors as shown in the prior geometry figure (Figure 4-2). Time markers associated with travel times based on the computed pore velocity fields are provided. Different marker timing is employed depending on the overall travel time for each time slice. 
Figures 4-4 and 4-5 indicate that the edge effects on the effectiveness of the interim and final covers can be significant. Note that a cover overhang of approximately 10 feet has been employed for the interim cover (and 25 feet for the final cover) and that all runoff leaving the covers is assumed to have been carried away by supporting drainage systems.

\subsection{ET\#3 Vadose Zone Transport Model}

\subsubsection{Vadose Zone Transport Methodology}

Following the 2008 PA approach, 2D vadose zone transport analyses were performed using a nominal inventory of one gmole for each of the seven key parent nuclides of interest to obtain source terms used in subsequent aquifer transport simulations. These source terms were generated as mass fluxes (gmole/year) to the water table for each nuclide in the parent nuclide's abbreviated chain (half-life greater than one year).

After establishing the infiltration rates, the transport time intervals were set equal to the flow time periods for modeling purposes (i.e., 27 in total up to EPP plus 21 more to search for peaks). Those time intervals included the initial uncapped period, the interim cap period, and multiple time intervals for the final degrading (but intact) cap period.

Each parent was assumed to be disposed of uniformly at the start of unit operation on $10 / 01 / 2013$. For the vadose zone transport model, a nominal inventory of one gmole was modeled. Because results vary in a linear fashion with inventory, the actual inventory limit is computed later during the limits and doses calculation step.

ET\#3 transport analyses were performed for only the seven selected parent nuclides (Sink, 2013):

- C-14, H-3, I-129, Mo-93, Np-237, Sr-90 and Tc-99.

For the remaining $31 \mathrm{GW}$ parent nuclides the original 2008 PA results taken from the SLITw group were employed. Note that for all Slit Trenches in E-Area a single vadose zone model was employed in the 2008 PA effort (i.e., a "standard" geometry was assumed).

For the seven parent nuclides considered, a total of ten nuclides are involved counting chain members. A listing of the $\mathrm{K}_{\mathrm{d}}$ values for these ten chain members is provided in Table 4-2. Highlighted in orange are those elements whose $\mathrm{K}_{\mathrm{d}}$ values have been updated since the 2008 PA (Kaplan, 2010 and for C-14 specifically, Roberts and Kaplan, 2013). 
Table 4-2 $K_{d}$ values employed in ET\#3 transport analyses.

\begin{tabular}{|c|c|c|c|c|c|c|}
\hline source & new & new & PA2008 & PA2008 & PA2008 & PA2008 \\
\hline CDP & na & na & off & off & on & on \\
\hline soil & sand & clay & sand & clay & sand & clay \\
\hline C & 1 & 30 & 0 & 0 & 0 & 0 \\
\hline H & 0 & 0 & 0 & 0 & 0 & 0 \\
\hline I & 0.3 & 0.9 & 0 & 0.6 & 0 & 0.3 \\
\hline Mo & 1000 & 1000 & 0 & 0 & 0 & 0 \\
Nb & 0 & 0 & 0 & 0 & 0 & 0 \\
\hline Np & 3 & 9 & 0.6 & 35 & 1 & 58.1 \\
U & 200 & 300 & 200 & 300 & 378 & 567 \\
Th & 900 & 2000 & 900 & 2000 & 459 & 1020 \\
\hline Sr & 5 & 17 & 5 & 17 & 9.45 & 32.13 \\
\hline Tc & 0.6 & 1.8 & 0.1 & 0.2 & 0.05 & 0.1 \\
\hline
\end{tabular}

\subsubsection{Vadose Zone Transport Results}

Vadose zone modeling results consist of fluxes to the water table for each radionuclide in the parent's abbreviated chain (i.e., a one year half-life cutoff was assumed). Only results for the above seven selected nuclides are provided below. For the remaining 31 nuclides, see the 2008 PA report (WSRC, 2008). For the 2008 PA four cases were run for every parent nuclide: (1) intact cover without CDP; (2) intact cover with CDP; subsided cover without CDP; and subsided cover with CDP. Below only one case is being shown for the ET and ST 2008 PA (i.e., the intact cover without CDP and referred to as "PA2008 ET and ST models", respectively) versus the new ET\#3 (i.e., referred to as "New ET\#3 model"), because crossover can be seen for many of the seven nuclides considered. The original comparison of the PA2008 ET versus ST flux to water table curves demonstrated that many of the parent nuclides experience cross-over (i.e., max flux values swap between ET and ST within various time windows). These cross-overs among various time windows is a key motivation for considering a "stochastic" versus "deterministic" approach to assessing performance measures as discussed in Chapter 8.

To better understand and gain insight, a tracer analysis was also performed (i.e., a tracer neither decays nor is sorbed onto the soil). A comparison of the ET\#3 tracer results to tracer results for the 2008 PA is shown in Figure 4-6. Both sets of analysis are shown based on relative time after each unit's first burial (i.e., 1995 for the 2008 PA results and 2013 for the ET\#3 results). The main feature to notice here is that nuclides with low $\mathrm{K}_{d}$ values (i.e., typically referred to as "mobile" nuclides in previous PA and SA reports) are no longer as mobile as before. In the new VZ model, burial occurs $\sim 12.2$ years before the placement of the interim cover, whereas in the 2008 PA burial occurs $~ 30$ years before cover placement. As Figure 4-6 illustrates, the tracer plume is chopped off by installation of the interim cover prior to reaching its peak value for the ET\#3 configuration. 
SRNL-STI-2013-00393, REV . 0

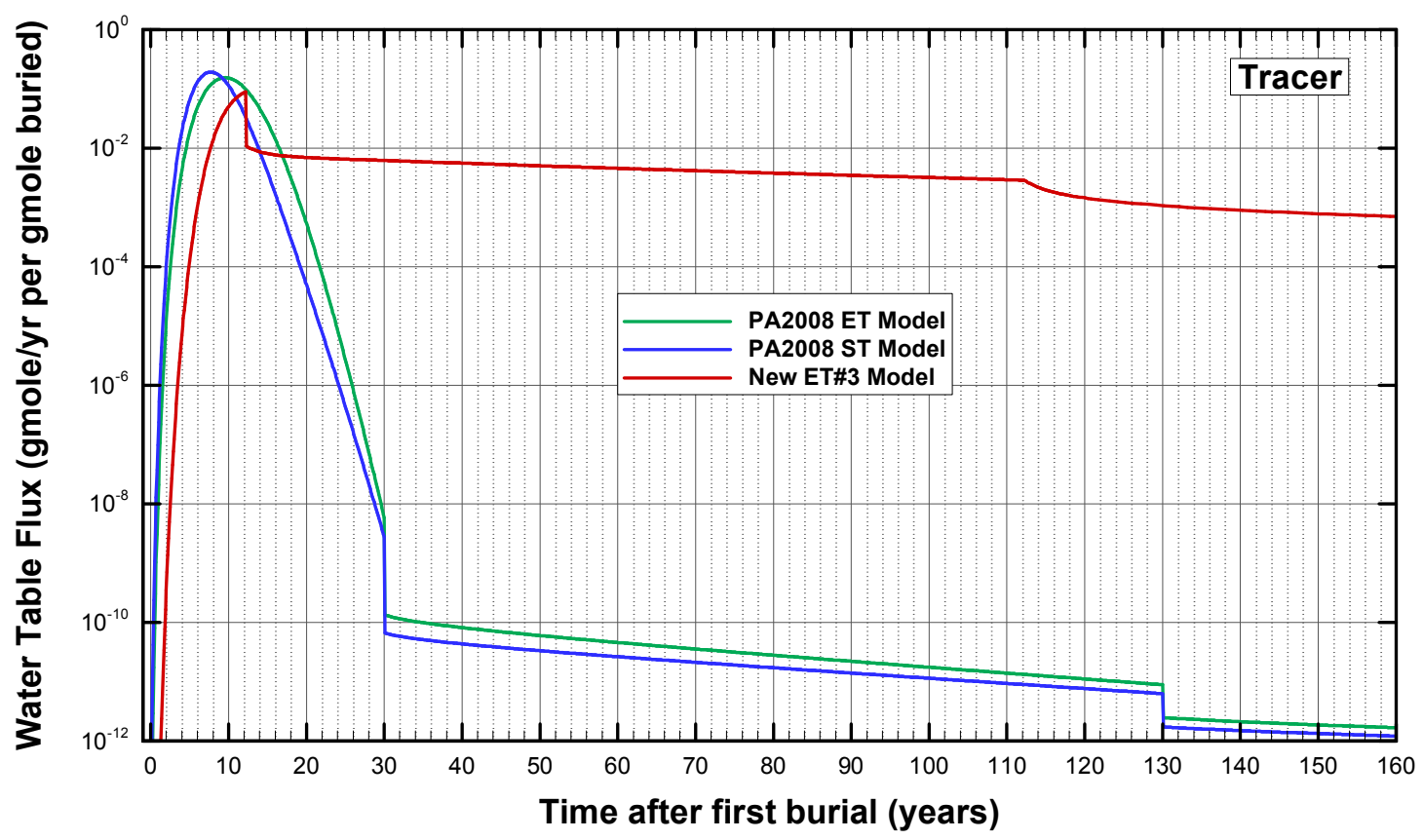

Figure 4-6 Comparison of transport results (flux to water table) for a tracer.

Figures 4-7 to 4-13 provide the flux to the water table for the seven parent nuclides. The original mobile's (C-14, I-129, Mo-93, Tc-99) are no longer peaking at times prior to the SIC. C-14 and Mo-93 are delayed even more due to increased $\mathrm{K}_{\mathrm{d}}$ values as listed in Table 42. H-3 would demonstrate the same behavior except that, with a short half-life of 12.3 years, it decays away prior to reaching the EIC.

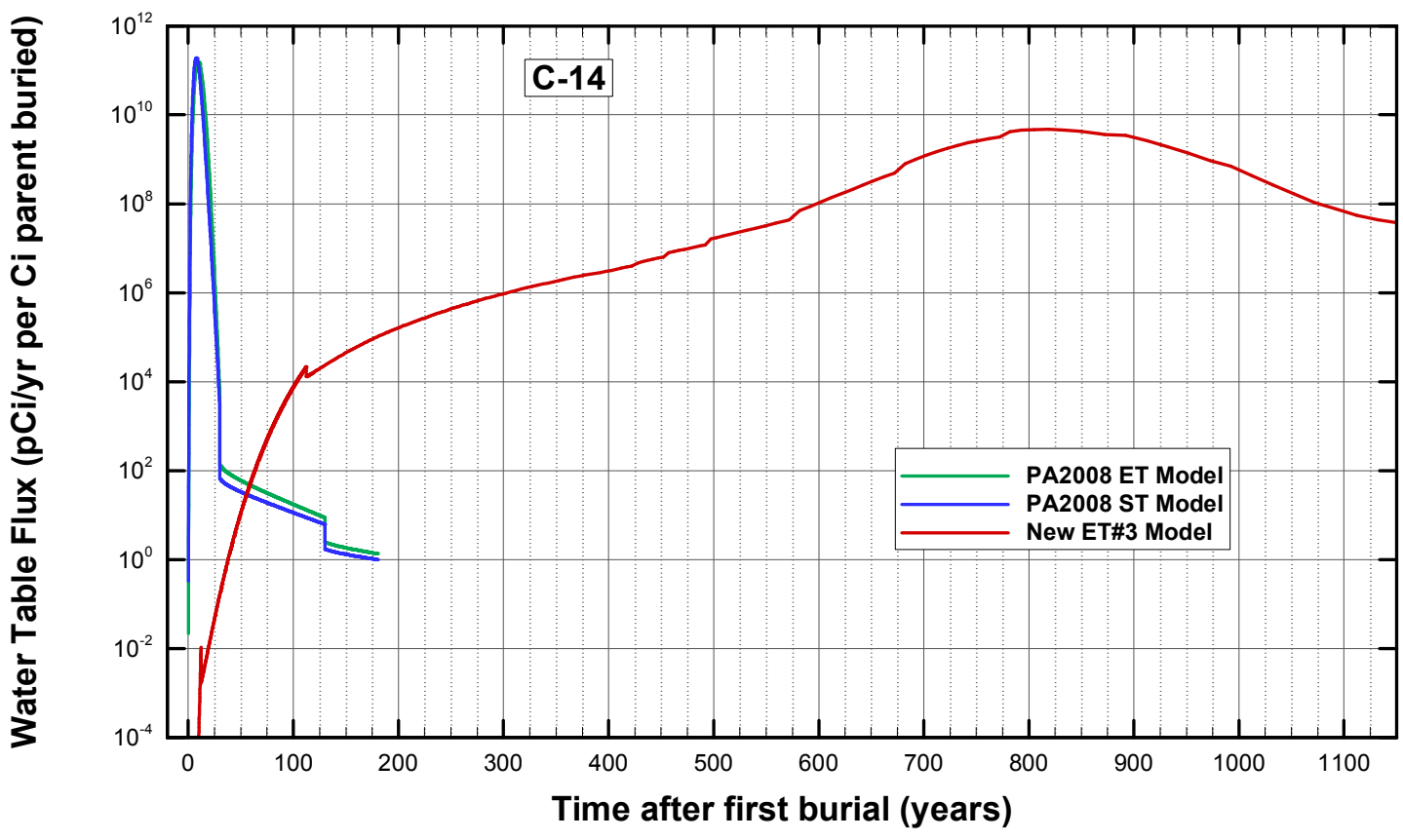

Figure 4-7 Comparison of transport results (flux to water table) for C-14. 
SRNL-STI-2013-00393, REV. 0

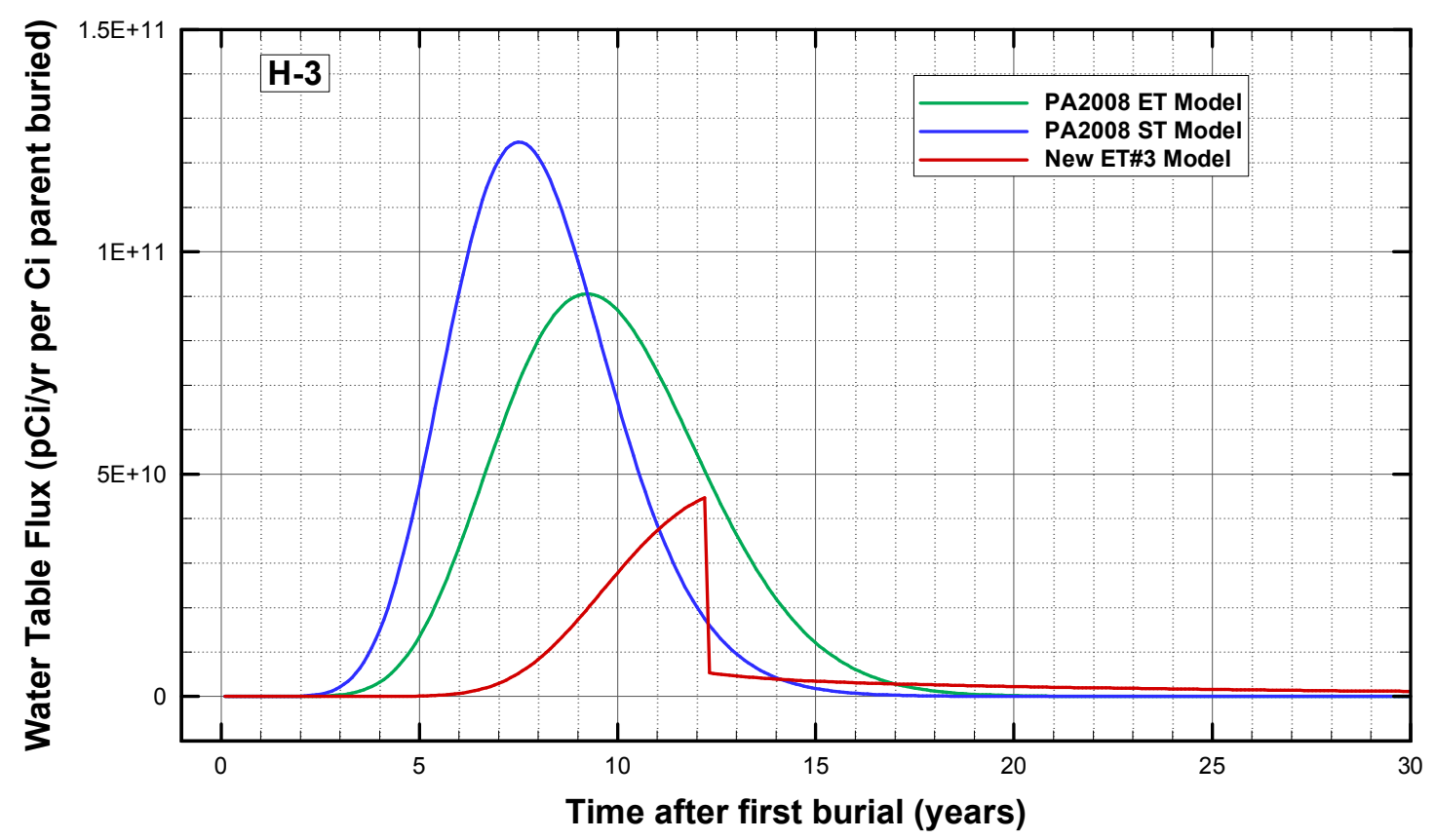

Figure 4-8 Comparison of transport results (flux to water table) for H-3.

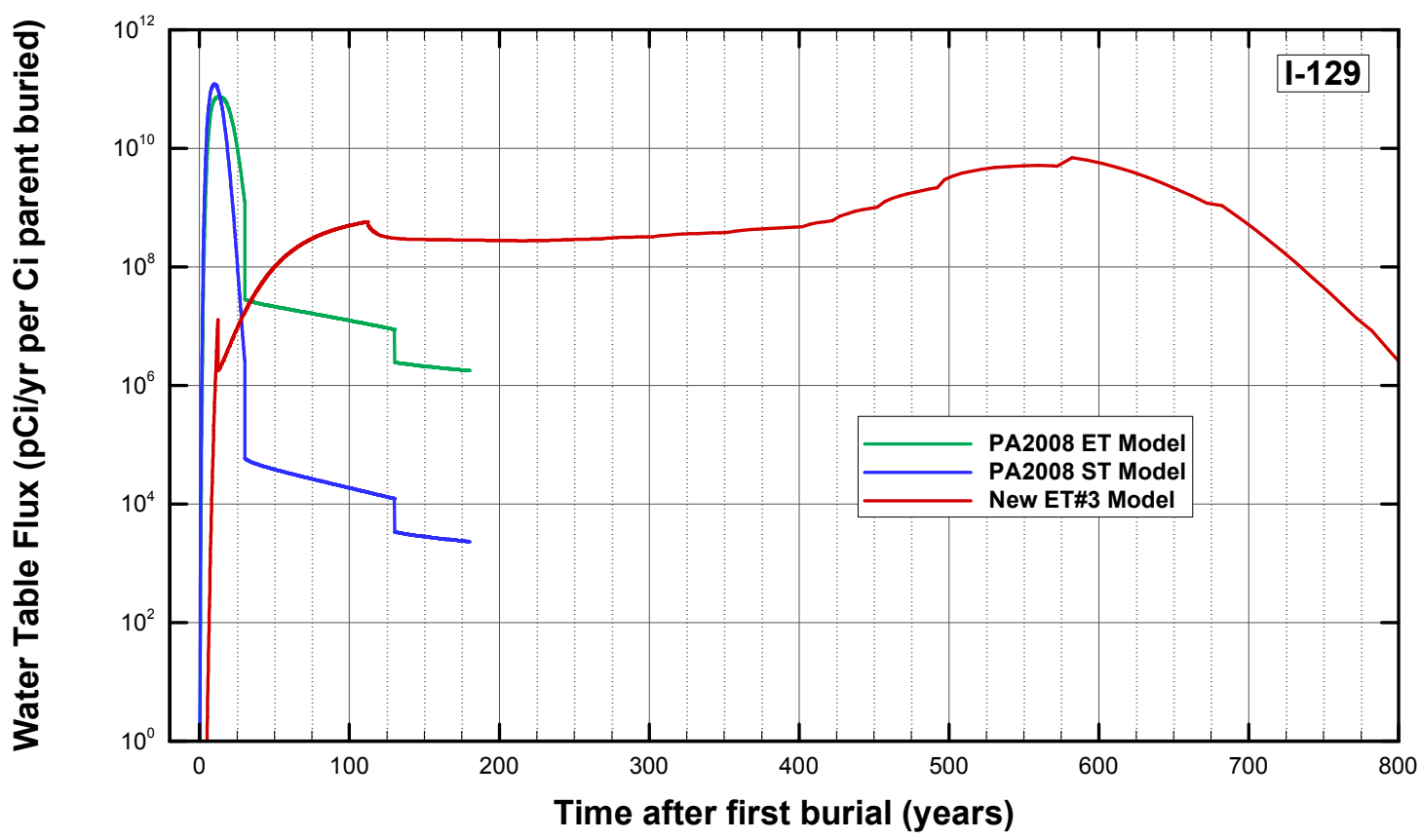

Figure 4-9 Comparison of transport results (flux to water table) for I-129. 
SRNL-STI-2013-00393, REV. 0

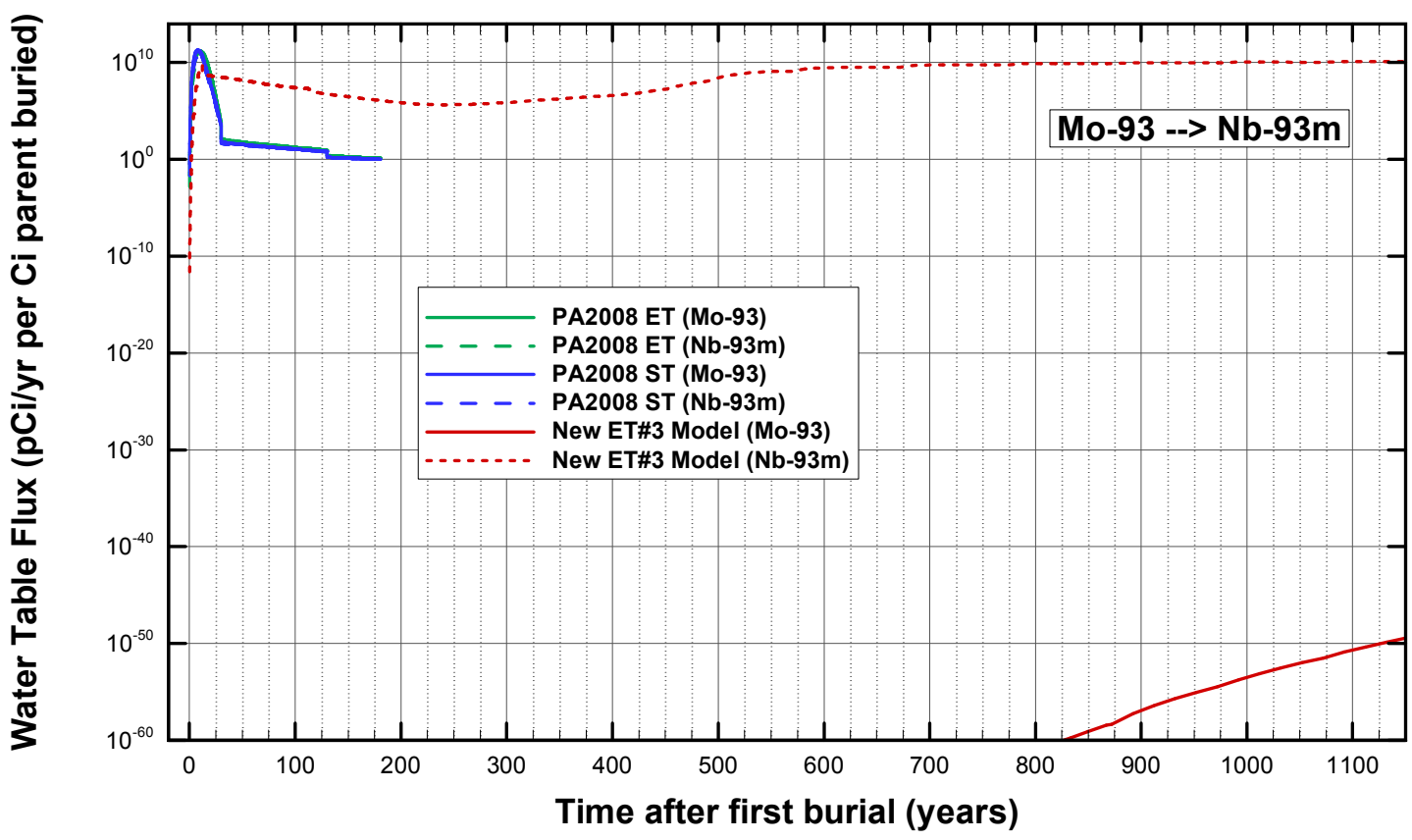

Figure 4-10 Comparison of transport results (flux to water table) for Mo-93.

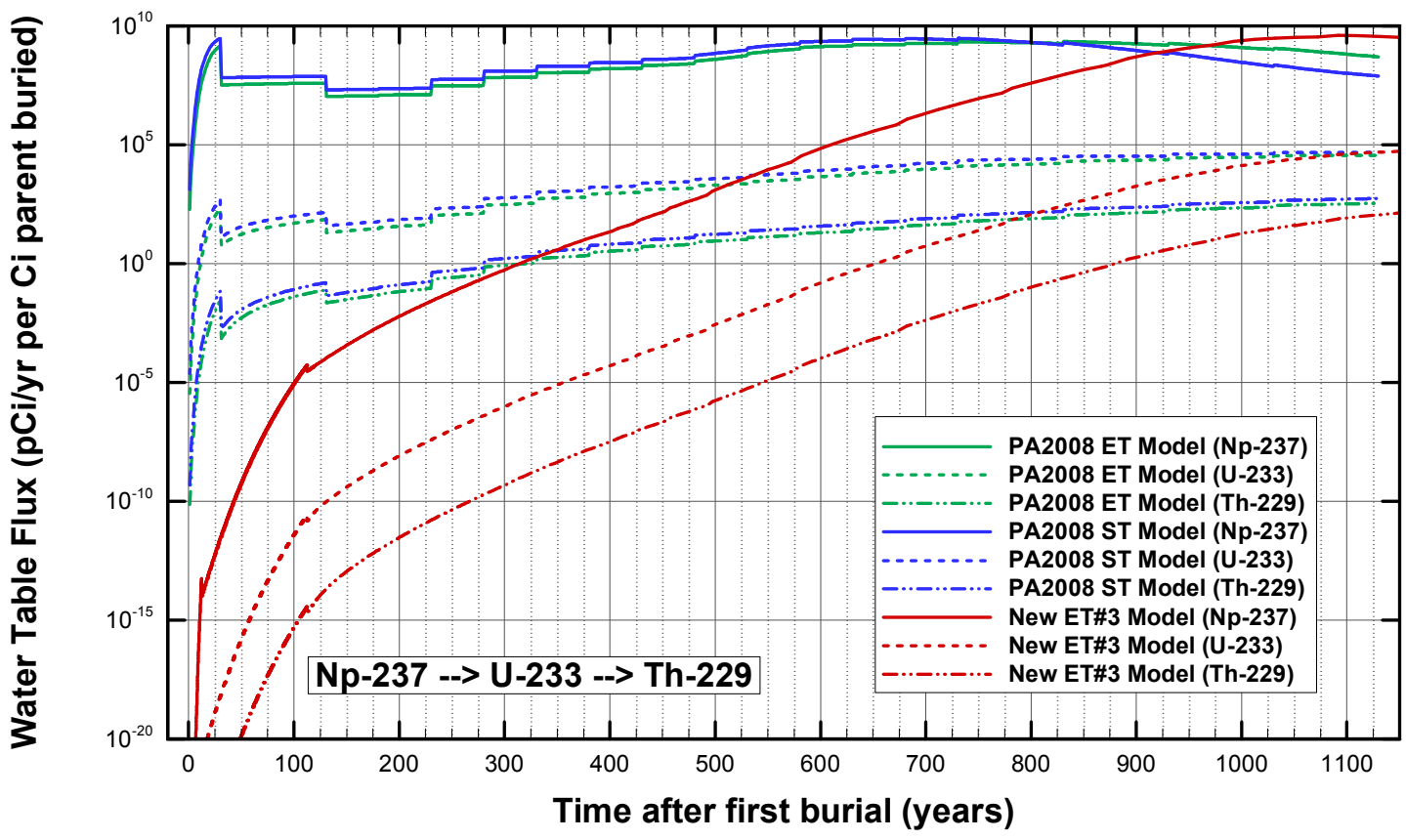

Figure 4-11 Comparison of transport results (flux to water table) for Np-237. 


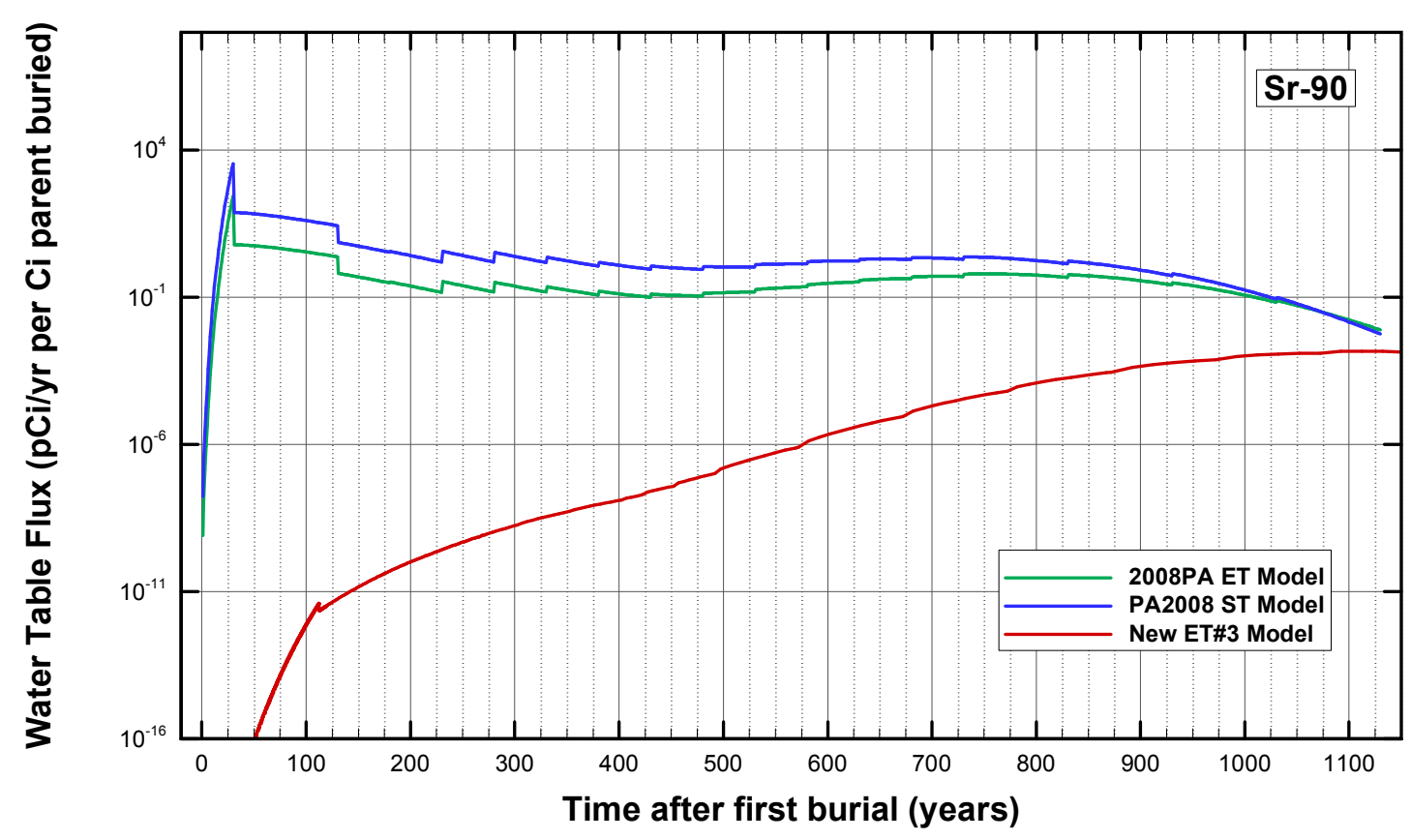

Figure 4-12 Comparison of transport results (flux to water table) for Sr-90.

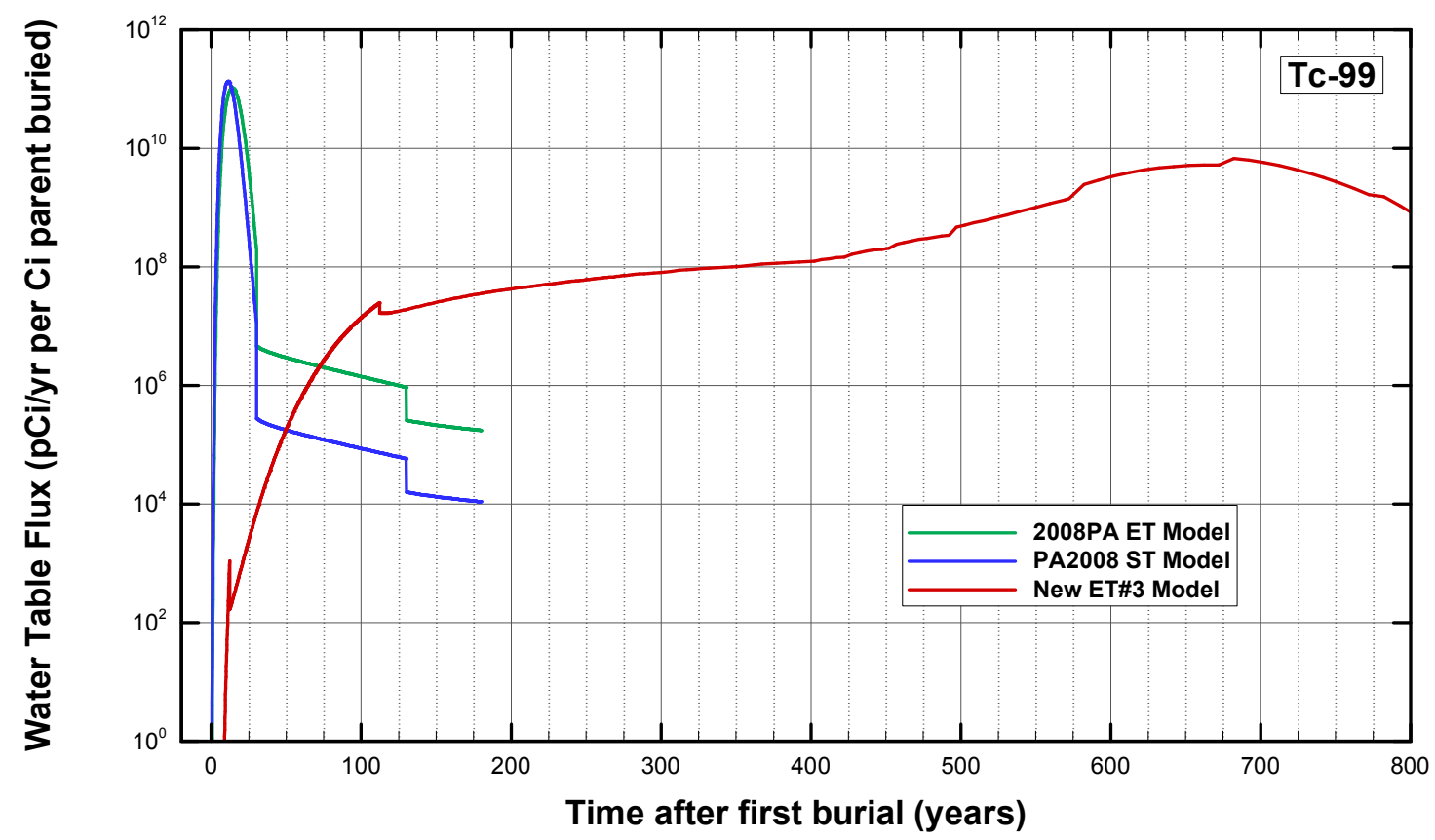

Figure 4-13 Comparison of transport results (flux to water table) for Tc-99.

The fractional flux to water table curves shown in Figures 4-7 through 4-13 are used as unit source terms to the following ET\#3 aquifer transport analyses. Unit source term implies one gmole of parent buried uniformly within the waste zone of the $2 \mathrm{D}$ vadose zone model. As shown in the aquifer results, these nuclides have 100-m boundary well concentration peaks at drastically different times than those predicted during the 2008 PA. 
SRNL-STI-2013-00393, REV . 0

\subsection{AQUIFER ANALYSIS}

All $38 \mathrm{GW}$ parent nuclides were considered in the aquifer analysis. These nuclide parents were broken up into two categories and handled differently based on SWM's request to focus detailed transport calculations on only seven key parent nuclides in the GW pathway to minimize the level of effort:

- Seven nuclides addressed by computing their 100-m boundary concentrations using the new ET\#3 PORFLOW aquifer model.

- The remaining 31 nuclides are addressed by adjusting the 2008 PA SLITw 100-m boundary concentrations to take into account impacts associated with going from the SLITw group to the individual ST\#12 unit (referred to as adjustment or correction factors).

Consistent with the 2008 PA methodology, both aquifer models mentioned above were generated by extracting time-averaged flow fields from a sub-region of the General Separations Area flow model by use of a "cookie-cutting" procedure (Flach, 2007).

To provide maximum well concentration histories for subsequent performance evaluation analyses as discussed in Chapter 7, a set of base cases was considered:

- For the seven selected parent nuclides, updated $\mathrm{K}_{\mathrm{d}}$ values were employed (Kaplan, 2010 and Roberts and Kaplan, 2013). Only the intact cap case was considered where the impact from options of full and reduced dispersion tensors in the modeling were addressed.

- For the remaining 31 nuclides the 2008 PA (WSRC, 2008) aquifer results were chosen for only the intact case but both CDP on and CDP off cases were included because $\mathrm{K}_{\mathrm{d}}$ values were not updated.

For aquifer transport analyses, the 2008 PA results were obtained using PORFLOW version 5.97 (Hang, 2007 and Aleman, 2007). For the new ET\#3 set of analyses the newest QA'd version 6.30.2 (Whiteside, 2010) was employed. Details and results for each category of parent nuclides are presented below.

\subsection{Aquifer Model Geometry}

For the seven selected parent nuclides the aquifer transport analyses relied on a new aquifer flow model geometry. An aerial view of this new ET\#3 aquifer model is shown in Figure 5-1. The model domain encompasses all of the disposal units that were originally grouped into the west set of Slit Trenches. For the remaining 31 parent nuclides SRNL applied the original 2008 PA aquifer model results adjusted to account for new information (e.g., new DCF's) and isolation of ST\#12 impacts (e.g., PIF's). SRNL considered this a reasonable ET\#3 approximation for these less important nuclides.

The original and updated footprints for all the disposal units are shown in Figure 5-1. The original units ST\#12 and ST\#13 have been drawn using dashed green lines while the remaining SLITw ST units are shown as solid green lines (i.e., ST\#8 through ST\#11). The updated footprints for ET\#3 (replacing ST\#12) and ET\#4 (replacing ST\#13) are shown in red. The Naval Reactor Component Disposal Area (NRCDA) is shown in blue while the 
Intermediate Level Vault is shown in black. To the right and outside the mesh domain are ST\#1 through ST\#4 (shown in orange) which are part of the center set of Slit Trenches.

The outline of the 100-m boundary is shown in black along with the actual node locations within the PORFLOW mesh where this boundary is discretely applied (i.e., small circles filled with orange shading). The average aquifer flow direction underneath the ET\#3 and ET\#4 units is shown as a large blue arrow. Details on the 2008 PA aquifer flow model for SLITw can be found in WSRC report (2008).

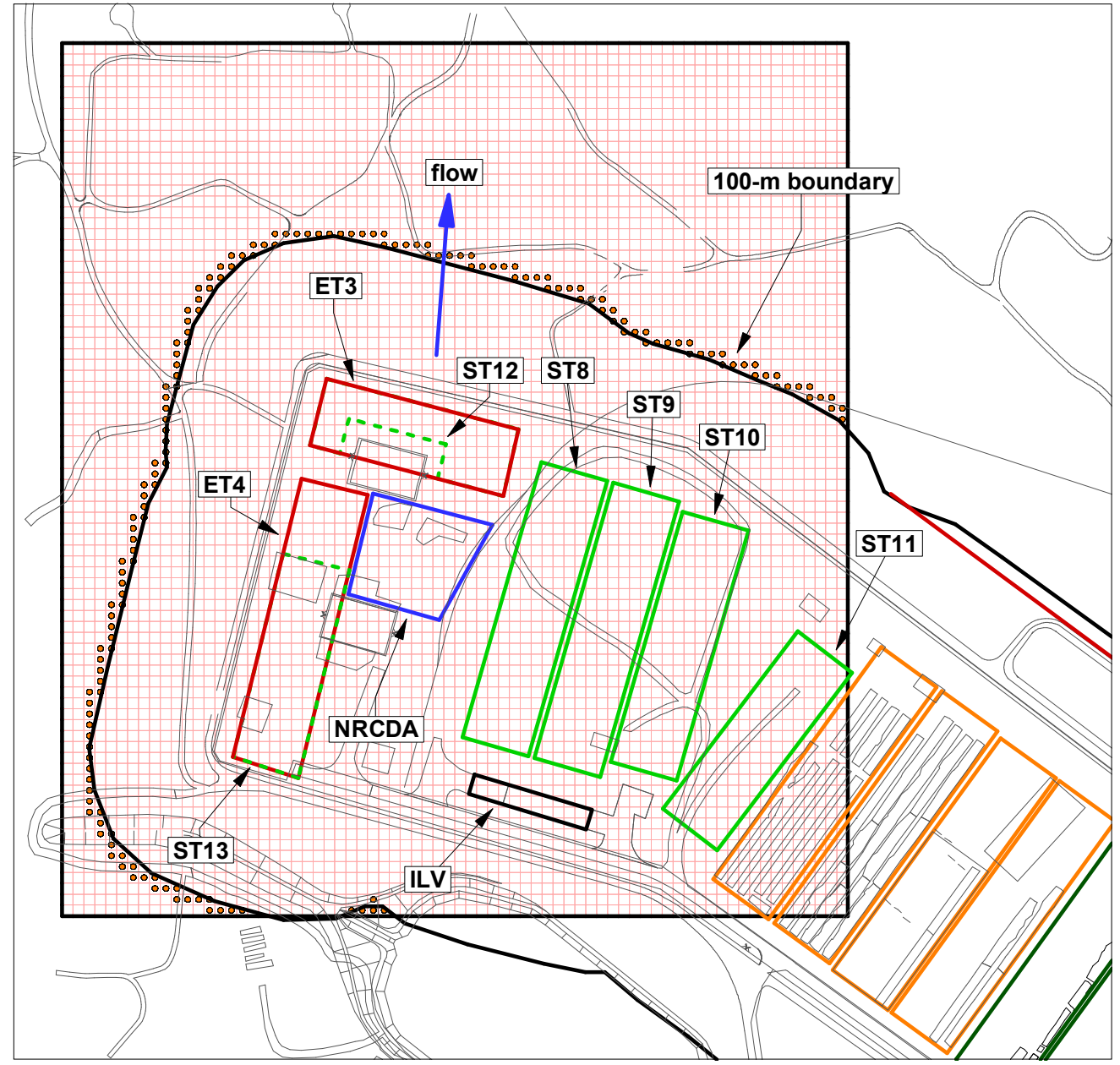

Figure 5-1 New 3D Aquifer flow model used for analyzing ET\#3.

\subsection{Aquifer Model Results}

Aquifer model results are concentrations versus time for every nuclide in the abbreviated chain. At requested time intervals, PORFLOW (ACRi, 2010) records peak well concentrations from the set of cells outside the 100-m boundary and the location of that cell. Only those chain members with half-lives greater than one year are explicitly modeled. PostPORFLOW processing, discussed in Chapter 7, expands these abbreviated chains into their full chains by assuming secular equilibrium between short half-life nuclides and their nearest parents for the purpose of calculating doses. Also, during post-PORFLOW processing, plume interactions factors are applied. 
Well concentration plots are presented in units of $\mathrm{pCi} / \mathrm{L}$ per $\mathrm{Ci}$ of parent buried. The source terms provided to the aquifer analyses come from prior vadose zone analyses (discussed in Chapter 4) where a single gmole of the parent nuclide is buried. The PORFLOW results are first converted from units of gmole $/ \mathrm{ft}^{3}$ (per gmole of parent nuclide buried) to $\mathrm{pCi} / \mathrm{L}$ (per $\mathrm{Ci}$ of parent nuclide buried). For chain members (i.e., progeny of the parent nuclide) a conversion of $\mathrm{Ci} /$ gmole must also be included.

For the seven key parent nuclides, the new aquifer model concentrations had to be adjusted to account for the new PROFLOW dispersion model. This adjustment is described in Section 5.2.2 below. For the ST\#12 concentrations based on the prior 2008 PA aquifer analyses an adjustment was required to account for the Interim Measures (IM) Correction Factor from the 2013 SA (Swingle, 2013). This adjustment is described in Section 5.2.3.

\subsubsection{Dispersion Tensor Correction Factors}

The 2008 PA assumed a traditional, two-parameter, dispersion tensor model which was the only option available in the PORFLOW code (version 5.97) at that time. The two parameters are longitudinal dispersivity and transverse dispersivity. When both parameters are turned on the model is operating in full tensor mode allowing contaminant plume dispersion in all directions in the aquifer. Because of numerical difficulties experienced during the 2008 PA simulations for some nuclides, the vertical velocity contribution to dispersion was set to zero (reduced tensor option) for both Slit and Engineered Trenches. Non-conservative aspects of concentrating the plume in this manner in the model were addressed by Flach (2013).

A more robust dispersion tensor model was used in the most recent versions of PORFLOW such as version 6.30.2. The newer model handles vertically induced dispersion such that the need to set the vertical dispersion to zero was no longer expected. However, during the aquifer analyses using the new ET\#3 aquifer model and PORFLOW version 6.30.2, numerical difficulties were again encountered for some nuclides. To account for these numerical difficulties, both full tensor and reduced tensor runs were made, then graphically viewed, and a correction factor was estimated. The tensor factor is nuclide dependent and the computed values for the seven special parent nuclides are provided in Table 5-1. As Table 5-1 indicates, all tensor factors are greater than unity implying that the reduced tensor option yields more artificial dispersion than intended.

Table 5-1 Tensor factors for the seven special parent nuclides.

\begin{tabular}{|c|c|}
\hline $\begin{array}{c}\text { Tensor } \\
\text { Factor }\end{array}$ & Parent Nuclides \\
\hline 1.16 & $\mathrm{H}-3$ \\
\hline 1.12 & Sr-90 \\
\hline 1.20 & C-14, I-129, Tc-99, Mo-93, Np-237 \\
\hline
\end{tabular}

\subsubsection{Interim Measures Correction Factors}

In the process of performing an earlier SA for the SLITw group, SRNL modelers recognized that the different size, geometry and orientation of the Slit Trench units in that group were not adequately represented by the application of a single set of GW limits. These differences 
can readily be seen in Figure 5-1. SRNL concluded in an Interim Measures assessment that adjustments needed to be made to GW limits (Butcher and Hiergesell, 2012) to account for these differences.

In the 2008 PA methodology, inventory limits were established for a group of trenches rather than for each individual trench unit within that group. For example, SLITw had a single set of inventory limits that applied for every unit within that group (i.e., ST\#8 through ST\#13) irrespective of size, geometry or orientation. Embedded within this group concept was the computational constraint of uniform waste distribution.

To arrive at the 2008 PA group inventory limits, a standard-sized trench unit concept was employed. The six units comprising the SLITw group (i.e., ST\#8 through ST\#13) total up to 4.95 standard-sized trench units on an aerial footprint basis. To arrive at the units of $\mathrm{pCi} / \mathrm{L}$ (per $\mathrm{Ci}$ of parent buried) within a standard-sized trench unit, the $2008 \mathrm{PA}$ aquifer concentration results had to be multiplied by 4.95 . The resulting concentration profiles reflect the 100-m boundary response to burial of $1 \mathrm{Ci}$ within a standard-sized trench unit and not any specific ST unit within the SLITw group. Thus, an adjustment factor is required to establish the ST\#12 specific GW concentrations (or inventory limits) for the 31 parent nuclides when looking at the original 2008 PA standard-sized trench unit GW concentrations (or inventory limits). Non-GW limits are unaffected by this specific GW limit adjustment.

In this report an IM correction factor is applied to the maximum well concentrations to reflect the aquifer response to these geometry considerations. This IM factor accounts for geometry differences within the PORFLOW aquifer model between the actual ST\#12 unit and the standard-size trench unit. See Butcher and Hiergesell (2012) for a description of how the correction factors were calculated and Swingle (2012) for the final correction factors applied to GW limits. Table 5-2 lists the IM factors (for inventory) for all six units in SLITw.

Table 5-2 IM Inventory Factor for each disposal unit in SLITw.

\begin{tabular}{|c|c|}
\hline Trench Unit & IM Factor \\
\hline $\mathbf{8}$ & 0.80 \\
\hline $\mathbf{9}$ & 0.78 \\
\hline $\mathbf{1 0}$ & 0.78 \\
\hline $\mathbf{1 1}$ & 0.79 \\
\hline $\mathbf{1 2}$ & 1.16 \\
\hline $\mathbf{1 3}$ & 0.64 \\
\hline
\end{tabular}

Note that the two adjustment factors being applied here are: (1) the 4.95 factor to set concentrations for the standard-size trench unit based on SLITw and (2) the IM factors provided in Table 5-2 to adjust the standard-size trench unit concentrations to reflect each specific trench unit. The ST\#12 adjustment is highlighted in orange.

Throughout the remainder of this report, the new inventory limits and corresponding well concentrations established as a result of the IM Assessment (Butcher and Hiergesell, 2012) and subsequent SA (Swingle, 2012) will be referred as IM2012 limits or GW concentrations 
in order to distinguish them from 2008 PA results, where appropriate. IM2012 GW limits are the current GW limits in the ELLWF disposal limits database (Swingle, 2012b).

\subsubsection{Maximum Well Concentration Comparisons}

In Figures 5-2 through 5-8 the predicted maximum well concentrations for the seven special parent nuclides are shown. The correction factors discussed above were applied to the aquifer results where appropriate. Both the IM2012 and new ET\#3 results are plotted in each figure. For the IM2012 results only the intact cases with and without CDP present are required because the potential for subsidence has been eliminated.

The main differences between the IM2012 and new ET\#3 aquifer results are:

- Peak well concentrations for the IM2012 analyses are typically greater than for the new ET\#3 analyses.

- Peak well concentrations are greatly delayed for the new ET\#3 due to a combination of higher updated $\mathrm{K}_{\mathrm{d}}$ values, shorter time being uncovered, and a lower infiltration rate for the final cover.

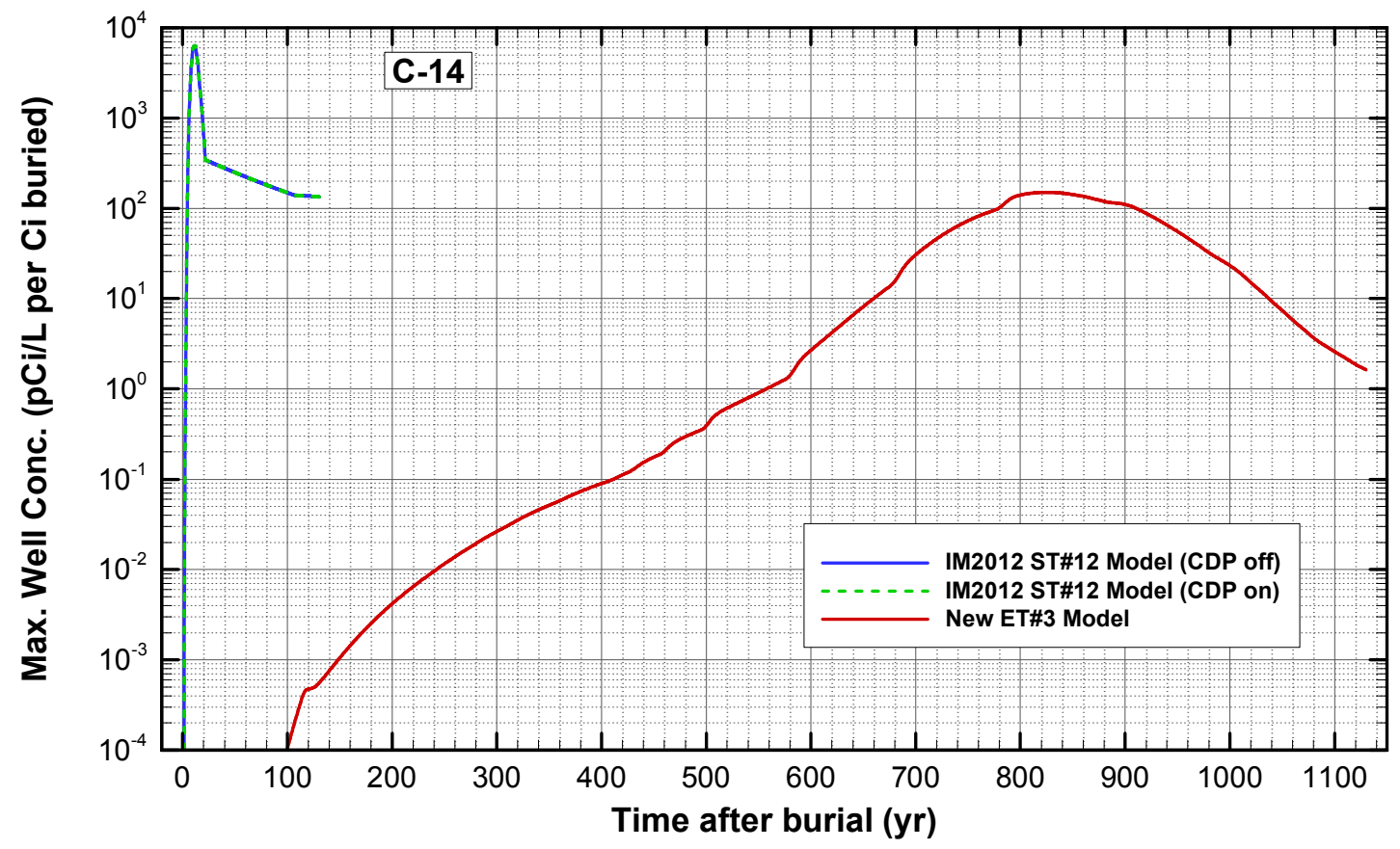

Figure 5-2 Well concentrations for C-14 in ST\#12 (IM 2012) and ET\#3 (new) aquifer analyses (intact case only). 
SRNL-STI-2013-00393, REV. 0

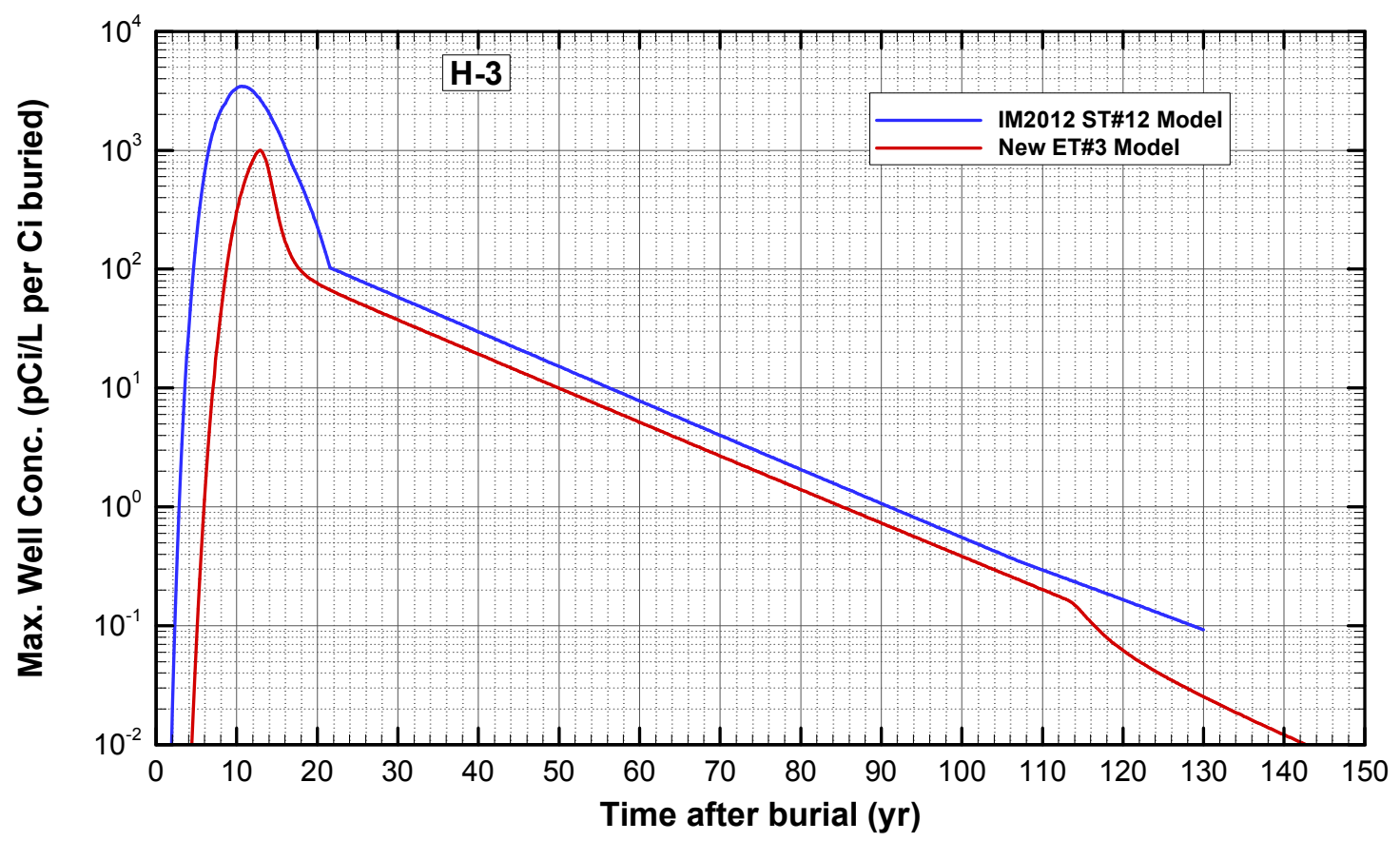

Figure 5-3 Well concentrations for H-3 in ST\#12 (IM 2012) and ET\#3 (new) aquifer analyses (intact case only).

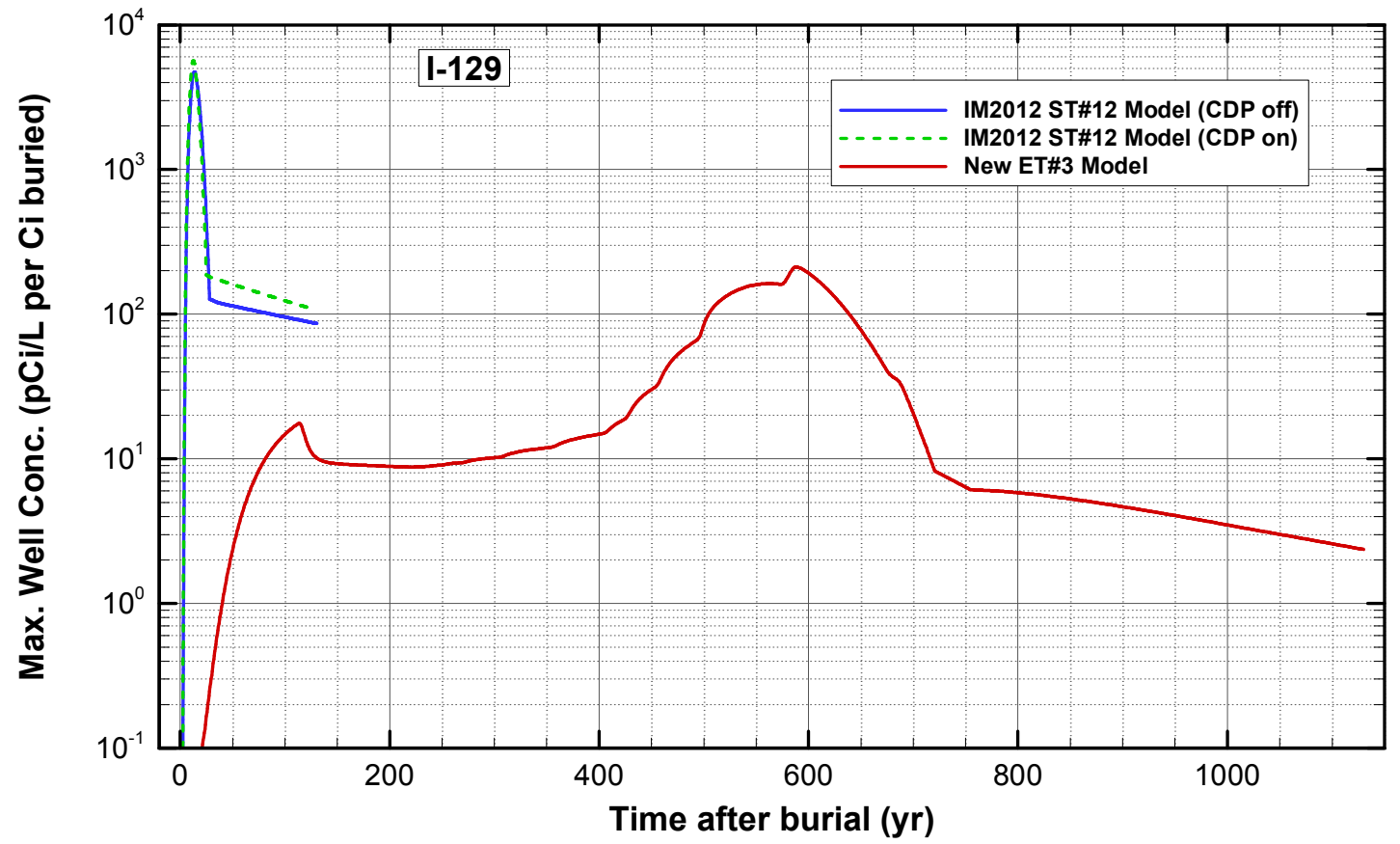

Figure 5-4 Well concentrations for I-129 in ST\#12 (IM 2012) and ET\#3 (new) aquifer analyses (intact case only). 
SRNL-STI-2013-00393, REV. 0

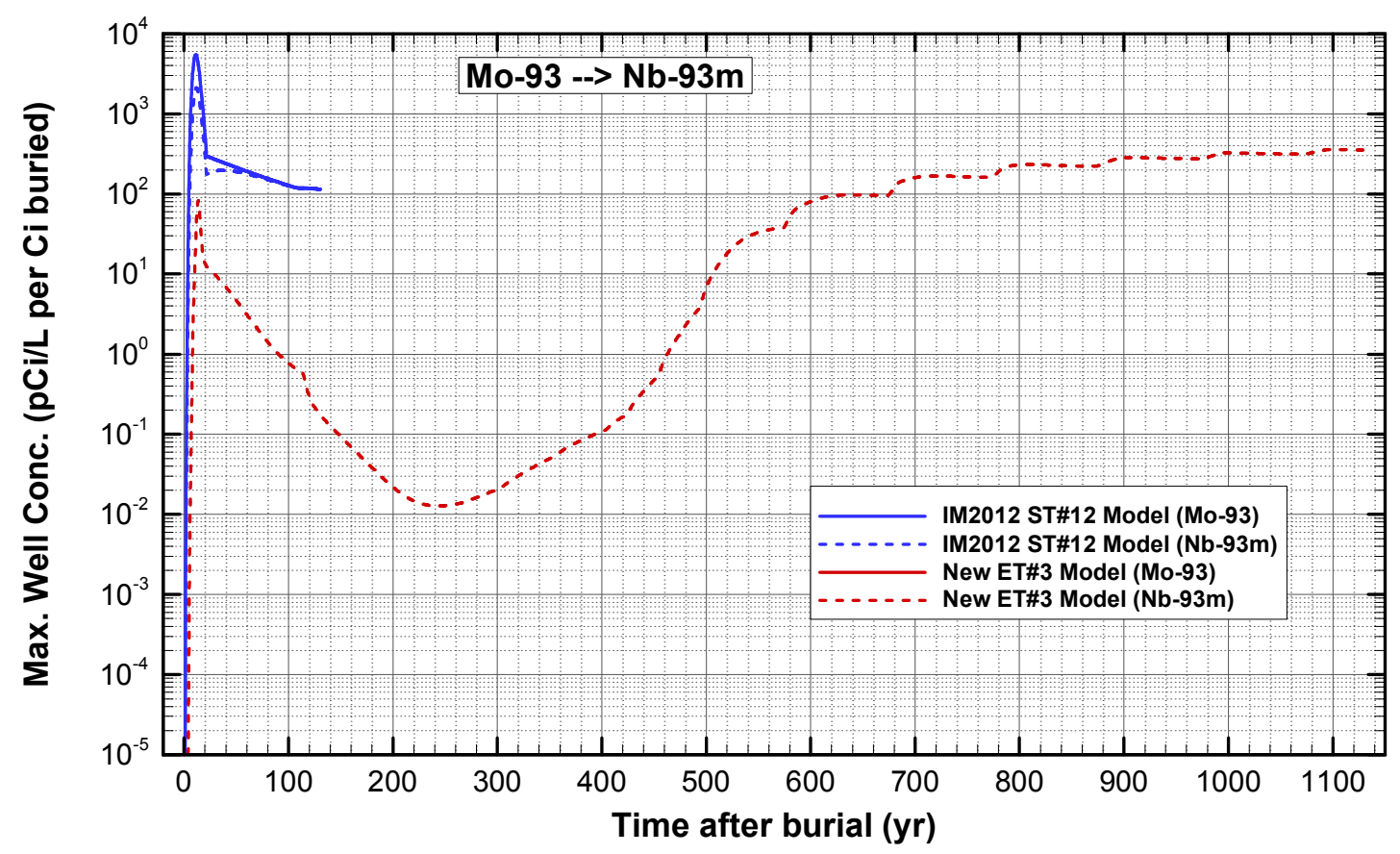

Figure 5-5 Well concentrations for Mo-93 in ST\#12 (IM2012) and ET\#3 (new) aquifer analyses (intact case only).

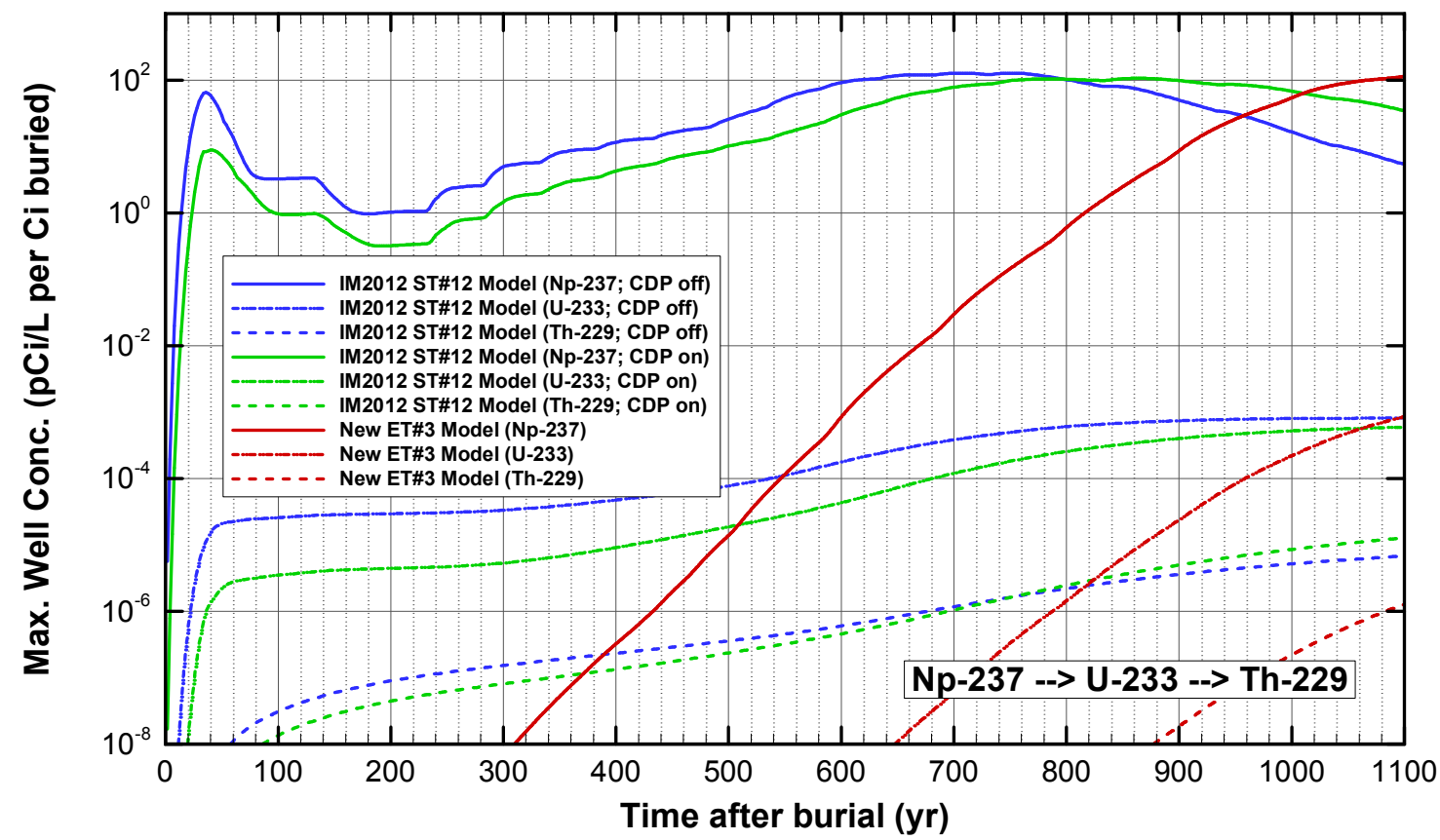

Figure 5-6 Well concentrations for Np-237 in ST\#12 (IM2012) and ET\#3 (new) aquifer analyses (intact case only). 
SRNL-STI-2013-00393, REV. 0

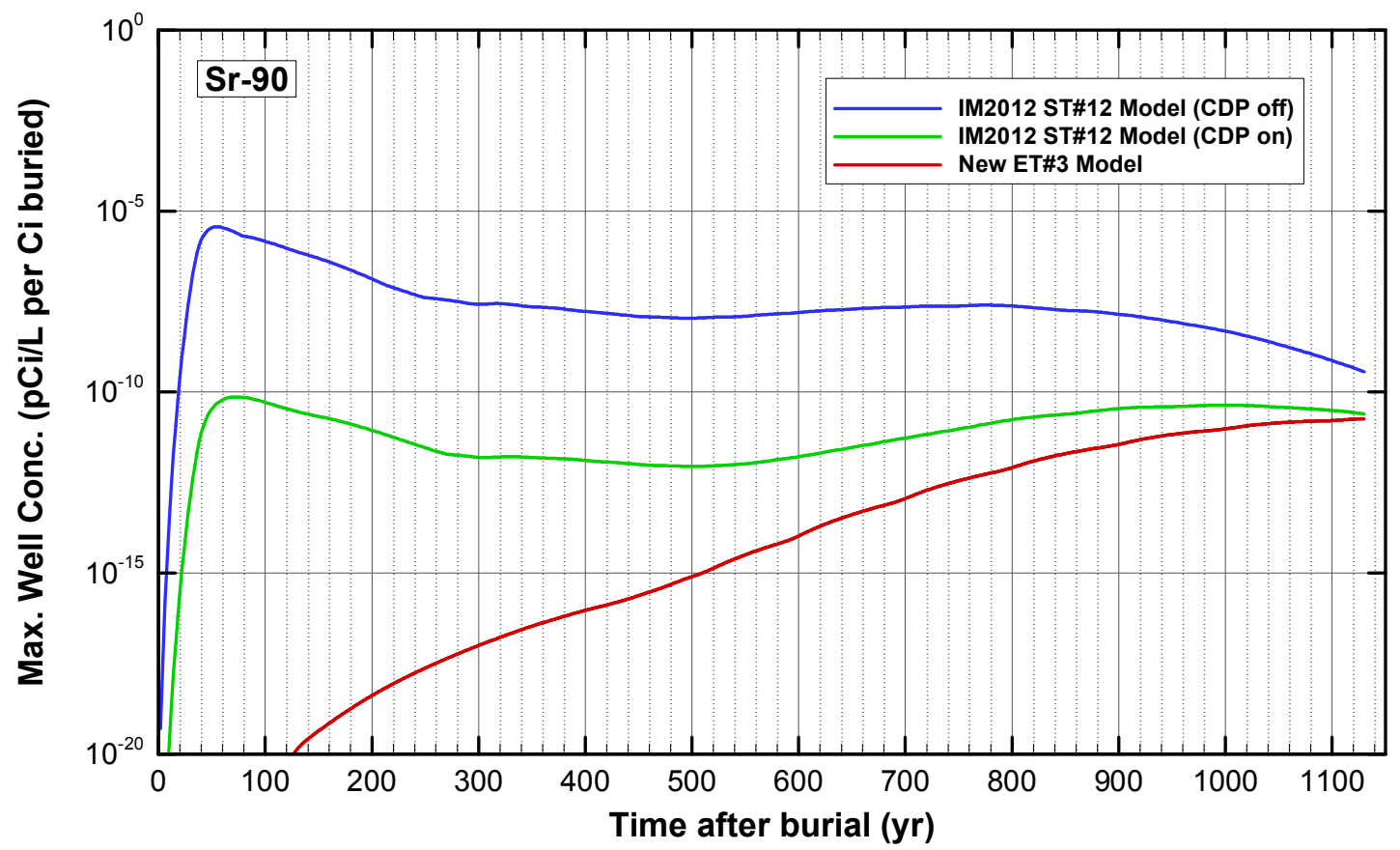

Figure 5-7 Well concentrations for Sr-90 in ST\#12 (IM2012) and ET\#3 (new) aquifer analyses (intact case only).

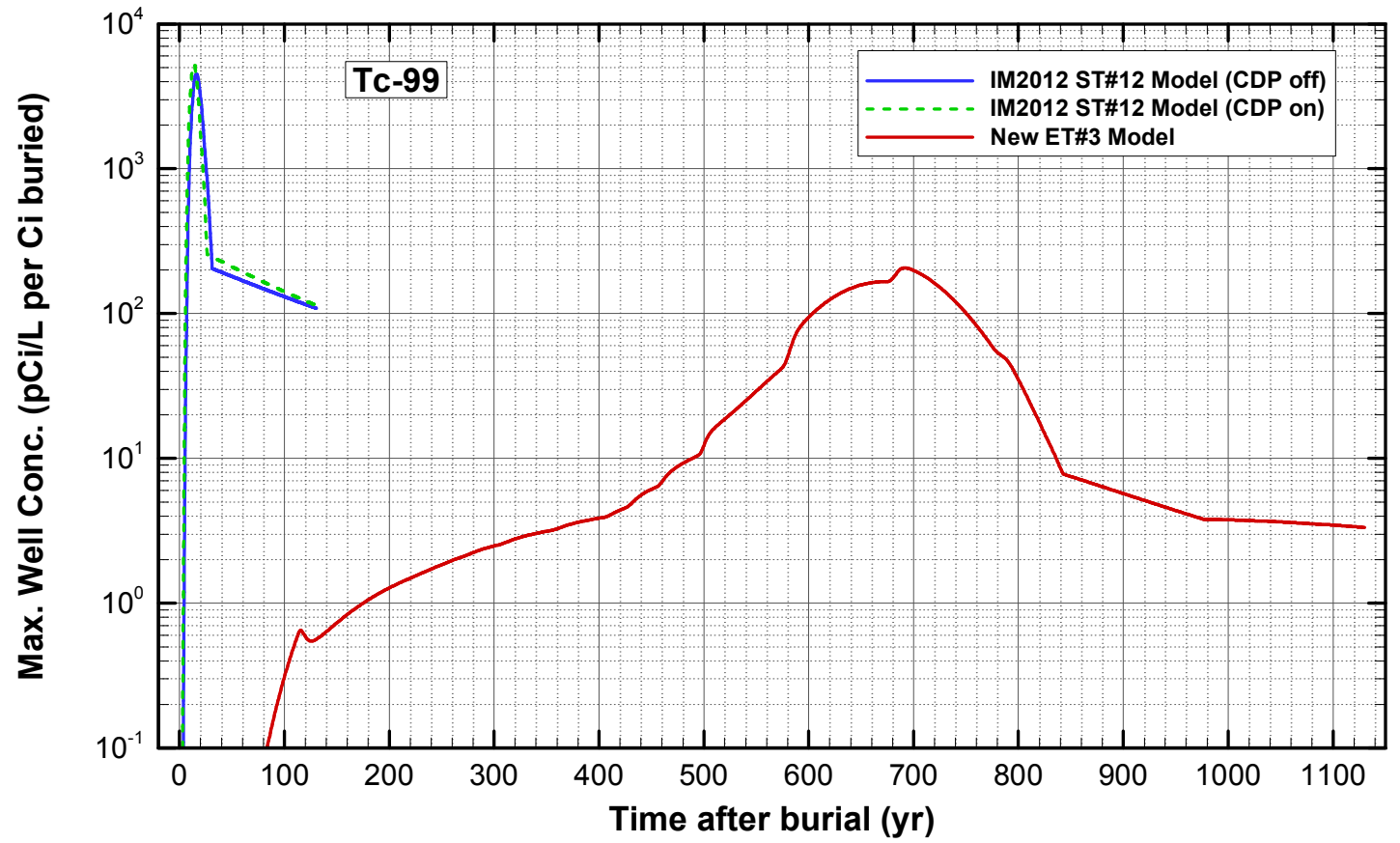

Figure 5-8 Well concentrations for Tc-99 in ST\#12 (IM2012) and ET\#3 (new) aquifer analyses (intact case only). 
SRNL-STI-2013-00393, REV . 0

\subsection{PLUME INTERACTION}

Plume interaction must be accounted for in the groundwater analysis because of the close proximity of ELLWF disposal units resulting in commingling of adjacent plumes due to plume dispersion and direction of groundwater flow. For assessing/comparing inventory limits between the current ST\#12 and the new ET\#3, updated plume interaction factors were needed. This is because the current PIFs exist for Slit Trench groups (i.e., SLITw, SLITc, SLITe) and not for any of their individual group members. In addition, assessing new information with regard to dispersion aspects is warranted. Both of these aspects are addressed within this chapter.

\subsection{PA Methodology}

In the 2008 PA report (WSRC, 2008) a methodology was established where an individual disposal unit or group of disposal units (e.g., SLITw) were modeled separately from all of the other disposal units making up the E-Area. Thus, there are seven unique ELLWF models:

- Intermediate Level Vault (ILV) - modeled as one separate unit

- Low Activity Waste Vault (LAWV) - modeled as one separate unit

- Engineered Trenches (ET) - ET\#1 and ET\#2 units were modeled as a group

- Center Slit Trenches (SLITc) - ST\#1 through ST\#7 were modeled as a group

- West Slit Trenches (SLITw) - ST\#8 through ST\#13 were modeled as a group

- East Slit Trenches (SLITe) - ST\#14 through ST\#21 were modeled as a group

- Component-in-Grout Trenches (CIG) - CIG\#1 and CIG\#2 units were modeled as a group

The location of these various individual disposal units and some of the key groups (in dashed circles) are shown in Figure 6-1 where 3D streamlines emanating out from their footprint centroids are also provided.

In the 2008 PA methodology, inventory limits are computed individually for each entity above (i.e., either a group or unique disposal unit). The initial step was the calculation of maximum well concentration profiles that were then adjusted based on a separate plume interaction analyses. The plume interaction analysis involved the entire set of disposal units contained within E-Area as shown in Figure 6-1.

The basic scheme employed made use of a conservative tracer under a steady-state constant source. For each group, a uniform constant source was applied over the entire group's footprint. Details of this approach can be found in Chapter 6 of the 2008 PA report (WSRC, 2008). To assess several refinements to modeling techniques and assumptions affecting plume dispersion, a separate plume interaction analysis was performed. Application of the updated plume interaction model to ET\#3 and ET\#4 inventory limits is discussed in this chapter. 


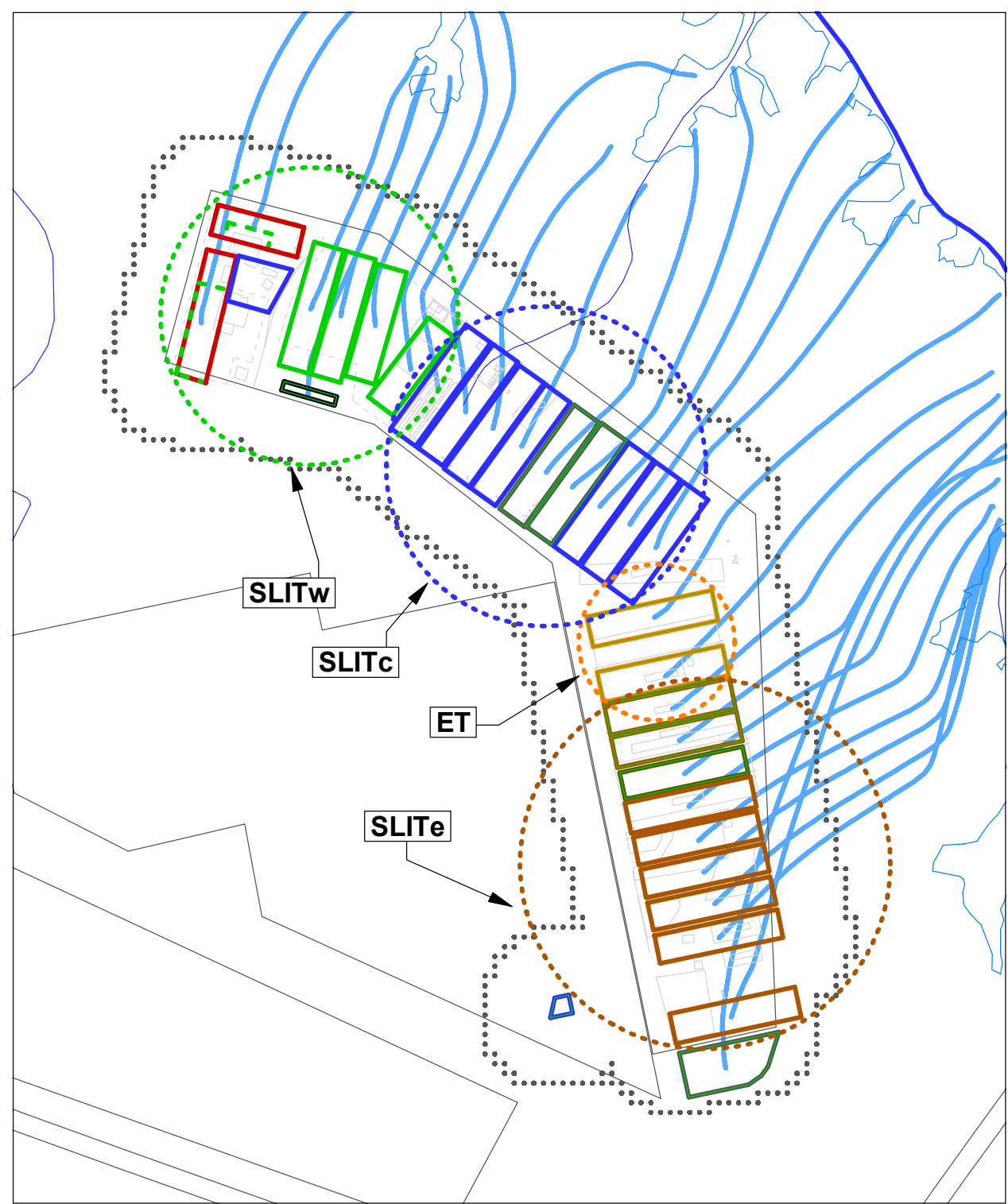

Figure 6-1 Disposal units in E-Area showing basic streamline paths from the centroid of each unit.

\subsection{Plume Interaction Concept}

To illustrate the basic plume interaction factor concept, we will focus on the SLITw plume interaction with the ILV unit. As mentioned above, a constant source conservative tracer is employed where the PIF is determined based on steady-state concentration profiles. For the conservative tracer, an arbitrary concentration limit was established as $1.0 \times 10^{-8} \mathrm{gmole} / \mathrm{L}$ to serve as a hypothetical "tracer" performance measure. The objective is to calibrate source strengths in individual units or groups of units to just achieve this concentration at the 100-m point of assessment. This process allows us to calculate a PIF based on the contribution of each unit or group of units to the concentration at this boundary. 
To clearly see the relative contribution of GW concentrations from each disposal unit or group of units, the maximum concentrations from each entity are plotted versus the arclength (i.e., distance) along the 100-m boundary from the down-gradient northwest end to the southeast end of E-Area (see Figure 6-1) in Figure 6-2. For example, the maximum tracer concentration for the SLITw group is plotted in blue, ILV in pink, SLITc in green, etc. The total maximum concentration is shown in black (i.e., sum of all unit or group contributions).

Focusing our attention on the SLITw group in Figure 6-2, we see that significant plume overlap occurs between SLITw (dark blue line) and ILV (pink line). Only a marginal plume overlap is observed between SLITw and SLITc. Essentially no plume overlap occurs between SLITw and the remaining entities.

When looking at the SLITw curve a double hump can be seen. This double hump is the result of some degree of plume separation within the SLITw group of units. Specifically, ST\#12 and ST\#13 have plumes that are somewhat separated from the other units within SLITw. Also, the pink curve representing the ILV appears to be somewhat separated from ST\#12 and ST\#13. Note the large amount of margin between the ST\#12 and ST\#13 concentration peak on the left side of the figure and the tracer performance measure of $1 \mathrm{E}-08$ gmole/L.

In replacing ST\#12 and ST\#13 Slit Trenches with ET\#3 and ET\#4 Engineered Trenches, the SLITw group must be broken up into finer groupings. The observations made above suggest that the ET\#3 and ET\#4 units will have little plume overlap with the remaining units in the west. However, based on the aquifer flow direction these two engineered trench units will experience significant plume overlap with each other. In the next section new plume interaction factors for these two units are addressed.

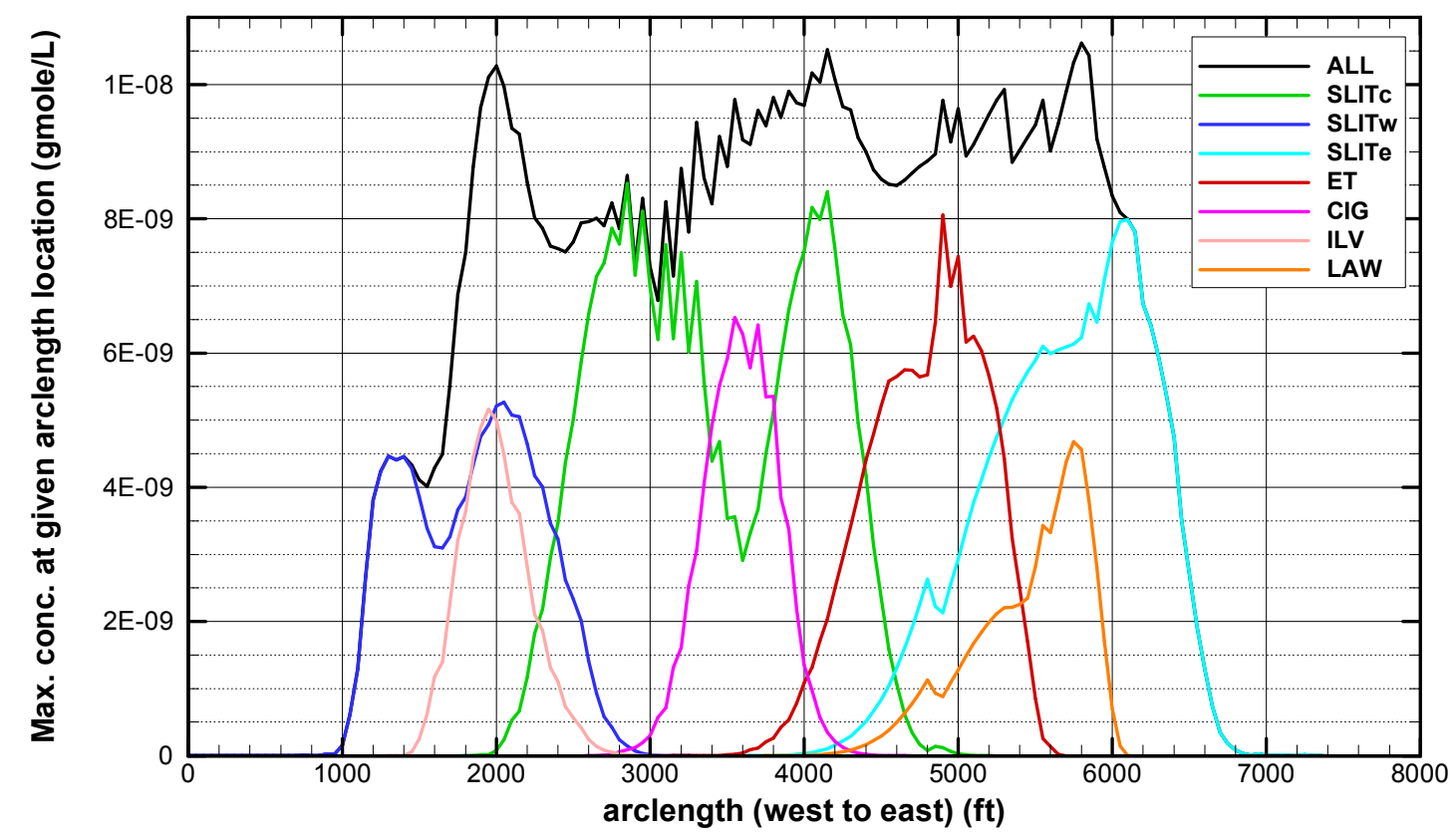

Figure 6-2 Maximum tracer concentration profile along 100-m boundary for each unique entity (i.e., group or unit). 
Table 6-1 lists the PIF's that were calculated for the specific set of tracer source strengths employed in the 2008 PA.

Table 6-1 2008 PA Plume Interaction Factors.

\begin{tabular}{|c|c|c|}
\hline Entity & Parent & PIF \\
\hline SLITc & all & 1.17 \\
\hline SLITw & I-129 & 1.02 \\
\hline SLITw & All but I-129 & 1.90 \\
\hline SLITe & all & 1.25 \\
\hline ET & all & 1.24 \\
\hline CIG & all & 1.53 \\
\hline ILV & all & 1.94 \\
\hline LAW & all & 2.14 \\
\hline
\end{tabular}

Peak radionuclide concentrations at the 100-meter boundary obtained by modeling individual units (e.g., LAWV) or groups of units (e.g., SLITw) in isolation were multiplied by these PIF's to obtain the final GW concentrations used to calculate limits in the 2008 PA. Note that the PIFs listed above result in a source strength combination that yields maximum concentrations (black curve in Figure 6-2) that do not exceed the tracer limit (i.e., 1.0x10-8 gmole/L) except slightly in three locations as shown in Figure 6-2. Technically, the intent was to set these PIFs such that the limit was reached but not exceeded at any location.

\subsection{ET\#3 and ET\#4 Plume Interaction Factors}

As discussed in Chapter 5, a new aquifer model was created for the ET\#3 and ET\#4 analyses (i.e., for both plume interaction factors and inventory limit calculations). The main differences from the 2008 PA model are that the mesh was refined to reduce numerical dispersion and source term placement, and the dispersion model was improved because it is available in the newer PORFLOW version 6.30.2.

The observations of plume interaction described in the previous section provided the motivation to perform a similar set of plume interaction analyses as was done in the 2008 PA effort. The main differences in this new set of analyses and the original 2008 PA set are:

- A new aquifer model using the newer PORFLOW version with a footprint that only covers the northwest region of E-Area. The new model addresses dispersion issues focusing on their resolution.

- The ET\#3 and ET\#4 units are broken out from the remaining SLITw units so that a relationship can be establish for their PIFs based on allocation of allowable inventory between the two units. This allows predicting adjustments in ET\#4 inventory limits that might arise from future analysis updates.

The footprint of the new ET\#3 aquifer model is shown in Figure 5-1. Each of the various disposal units contained within this model are labeled. For the plume interaction analyses presented in this section, only the footprints for ET\#3 and ET\#4 are considered (i.e., the ST\#12 and ST\#13 footprints are shown only for information purposes). Specifically, for the plume interaction analyses performed here the following unique entities are considered: 
- ST\#8-11 (group containing ST\#8 through ST\#11)

- ILV (individual unit)

- ET\#3 (individual unit)

- ET\#4 (individual unit)

- ALL (all of the above units combined for validation purposes)

Figure 6-3 illustrates the plume separation in the west set of disposal units using the new ET\#3 aquifer model for one set of steady-state tracer source strengths. A clear plume separation can be seen between the ET\#3-ET\#4 grouping and the remaining disposal units. Significant plume overlap is present between ET\#3 and ET\#4 and between ILV and ST\#811. Lower concentration contours not plotted in Figure 6-3 would reveal plume overlap but are not shown because they have minor impacts.

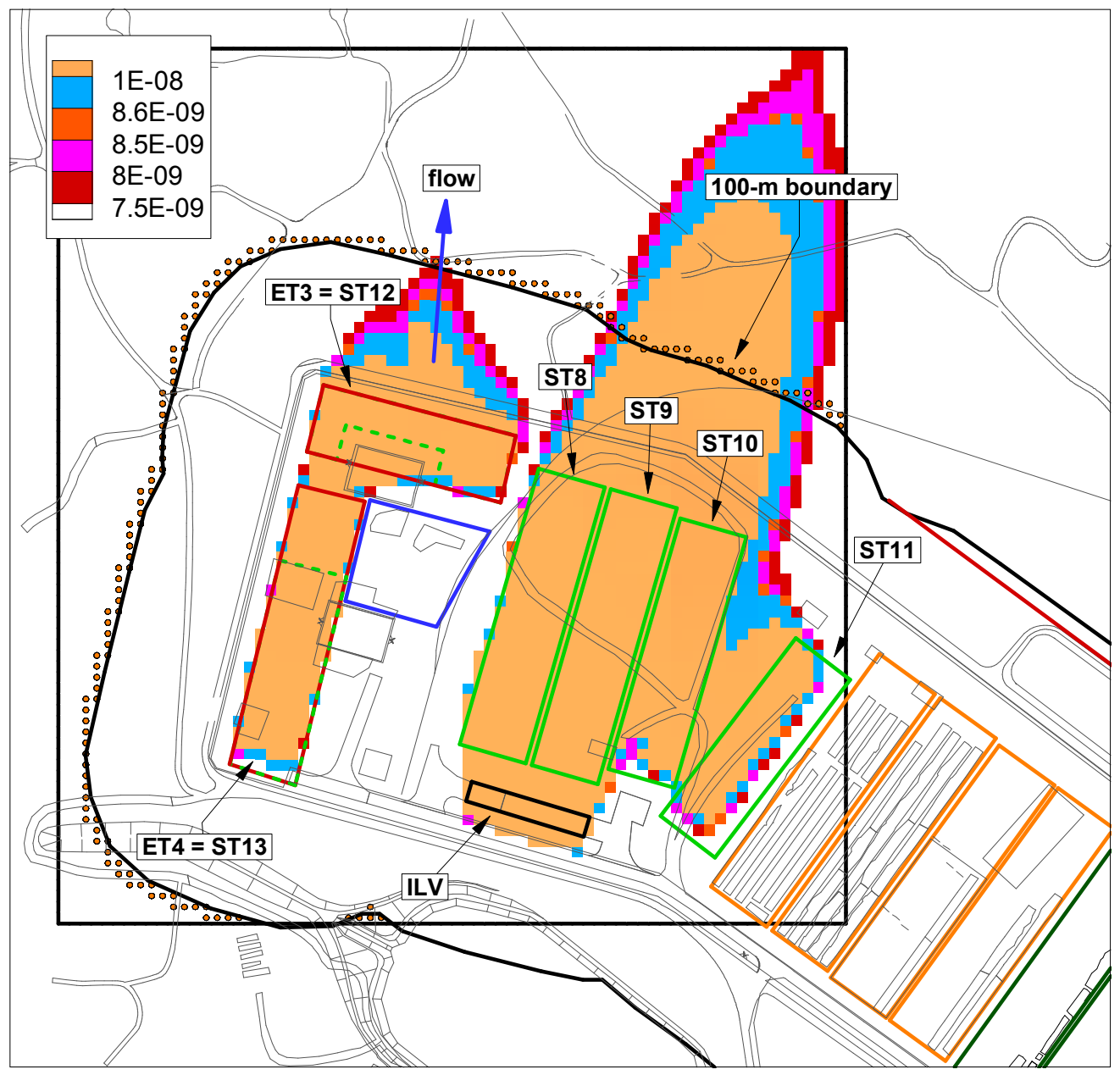

Figure 6-3 Maximum tracer concentration profile based on one set of source strengths.

No attempt was made to adjust the source strengths employed in the analysis shown in Figure 6-3 to match the tracer limit. Based on the linearity of the transport equations these source 
strengths can be varied independently to reach any desired composite response along the 100-m boundary.

For example, if a $50 \%$ to $50 \%$ distribution split of allowable inventory is made for ET\#3 versus ET\#4 the corresponding maximum tracer concentration profile along the $100-\mathrm{m}$ boundary is plotted in Figure 6-4. Each entity's concentration profile is plotted along with the total concentration. The total concentration equals the tracer performance measure at two specific locations along the 100-m boundary (i.e., one downstream of the ET\#3 plus ET\#4 and one downstream of ST\#8-11 plus ILV). These two total concentration peaks are essentially independent of each other (i.e., significant plume separation).

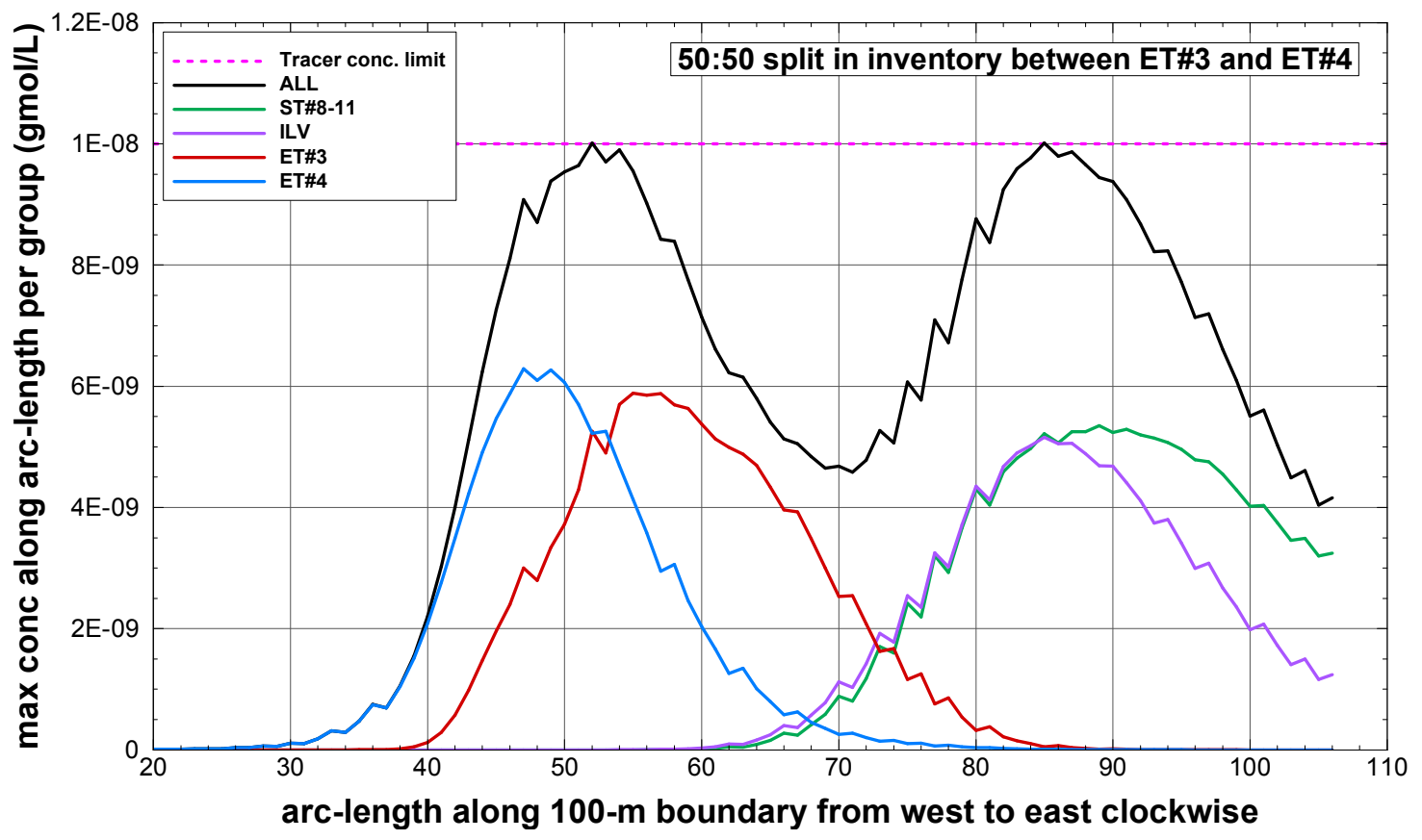

Figure 6-4 Maximum tracer concentration profile along the 100-m boundary for a 50\% ET\#3 and 50\% ET\#4 inventory distribution.

The ratio of source strengths when each unit is modeled in isolation to just equal the tracer performance measure (i.e., 1E-08 gmole/L) and then run in combination (i.e., ET\#3 plus ET\#4) results in a PIF for each disposal unit. For a 50:50 split of ET\#3 and ET\#4 inventory (i.e., source strength) the following PIFs apply:

- $\quad$ For ET\#3 - PIF $=1.70$

- For ET\#4 - PIF = 1.59

These PIFs are directly incorporated into the stochastic analyses presented in Chapter 8 . 
SRNL-STI-2013-00393, REV . 0

\subsection{PERFORMANCE EVALUATION}

\subsection{Exposure Pathways and Dose Factors}

The exposure pathways considered in this analysis along with their respective DOE 435.1 performance measure/objective and associated time windows are shown in Table 7-1 below:

Table 7-1 All E-Area pathways being considered and their current time windows.

\begin{tabular}{|c|c|c|c|}
\hline Category & Pathway & $\begin{array}{l}\text { Performance } \\
\text { Criterion }\end{array}$ & Time Window ${ }^{a}$ \\
\hline \multirow[t]{13}{*}{ Groundwater } & \multirow[t]{3}{*}{ Beta-Gamma } & \multirow[t]{3}{*}{4 mrem/yr } & $0-12$ \\
\hline & & & $12-100$ \\
\hline & & & $100-1130$ \\
\hline & \multirow[t]{3}{*}{ All Pathway } & \multirow[t]{3}{*}{$25 \mathrm{mrem} / \mathrm{yr}$} & $130-200$ \\
\hline & & & $200-1000$ \\
\hline & & & $1000-1130$ \\
\hline & \multirow[t]{3}{*}{ Gross Alpha } & \multirow[t]{3}{*}{$15 \mathrm{pCi} / \mathrm{L}$} & $0-1000$ \\
\hline & & & $1000-1120$ \\
\hline & & & $1120-1130$ \\
\hline & \multirow{3}{*}{$\begin{array}{c}\text { Radium } \\
(\text { Ra-226 + Ra- } \\
\text { 228) }\end{array}$} & \multirow[t]{3}{*}{$5 \mathrm{pCi} / \mathrm{L}$} & $0-1000$ \\
\hline & & & $1000-1120$ \\
\hline & & & $1120-1130$ \\
\hline & Uranium & $30 \mu \mathrm{g} / \mathrm{L}$ & $0-1130$ \\
\hline \multirow{5}{*}{$\begin{array}{c}\text { Non- } \\
\text { Groundwater } \\
\text { (non-GW) }\end{array}$} & $\begin{array}{l}\text { Intruder: } \\
\text { Resident }^{\text {b }}\end{array}$ & $\begin{array}{l}100 \mathrm{mrem} / \mathrm{yr} \\
\text { (chronic) }\end{array}$ & $130-1130$ \\
\hline & $\begin{array}{c}\text { Intruder: } \\
\text { Post-drilling }\end{array}$ & $\begin{array}{c}100 \mathrm{mrem} / \mathrm{yr} \\
\text { (chronic) }\end{array}$ & $130-1130$ \\
\hline & \multirow[t]{2}{*}{ Air Pathway } & $\begin{array}{c}10 \mathrm{mrem} / \mathrm{yr} \\
\text { (at Site Boundary) }\end{array}$ & $30-130$ \\
\hline & & $\begin{array}{c}10 \mathrm{mrem} / \mathrm{yr} \\
\text { (at } 100-\mathrm{m} \text { Boundary) }\end{array}$ & $130-1130$ \\
\hline & $\begin{array}{c}\text { Radon Pathway } \\
\text { (Rn-222) }\end{array}$ & $20 \mathrm{pCi} / \mathrm{m}^{2}-\mathrm{s}$ & $0-1130$ \\
\hline
\end{tabular}

a All times in years relative to the start of ELLWF operations of SLIT1 in 1995 (i.e., 12/21/1995).

b Chronic exposures were considered limiting relative to acute exposures in the 2008 PA.

The time windows provided correspond to the 2008 PA timing where the start of burial in SLIT\#1 was set to 12/21/1995 (in absolute terms 1995.97 years). The key points in time for the ST\#12 and ET\#3 units are provided in Table 4-1 along with the absolute and relative timing for comparison to ST\#12. The timing for the new ET\#3 dose calculations and inventory limits are shifted to correspond to the same absolute times employed in the 2008 PA (i.e., which are also employed in the current ELLWF disposal limits database [Swingle, 2012b] time windows).

The performance criteria defined in terms of dose (mrem/yr) in Table 7-1 (i.e., Beta-Gamma, All Pathways, Inadvertent Intruder, and Air Pathways) require the use of dose conversion factors (DCF's) to translate peak concentrations at the point of assessment into inventory limits. Depending on the pathway or scenario, exposure to radionuclides can include ingestion, inhalation, and/or external exposure (gamma shine). For the GW pathway only 
ingestion is considered. The GW all-pathways calculation, which considers all uses of groundwater, includes the following ingestion pathways:

- Water Ingestion

- Vegetable Consumption

- Milk Consumption

- Meat Consumption

\subsection{Groundwater Pathway}

The previous 2008 PA analysis of the Slit Trenches and Engineered Trenches considered four cases in the aquifer transport calculations:

1. All crushable waste packages without CDP present (intact scenario)

2. All non-crushable waste packages without CDP present (10\% subsided scenario)

3. All crushable waste packages with CDP present (intact scenario)

4. All non-crushable waste packages with CDP present (10\% subsided scenario)

Results from analysis of crushable and non-crushable waste were blended $(90 \%$ and $10 \%$, respectively) to represent the expected fraction of each type of waste package in the disposal unit (i.e., up to a 10\% non-crushable limit). Finally, at each time step, the greatest concentration for each radionuclide (the parent and all of its full chain progeny) was selected from among the four cases to produce a worst-case concentration file. These concentrations were then used to calculate doses.

Two changes have occurred that are reflected in the new ET\#3 transport calculations: 1) SWM has committed that non-crushable waste packages will not be buried in ET\#3, and 2) SRNL has eliminated the use of CDP factors (Roberts and Kaplan, 2013). Thus, for the seven key parent nuclides and their progeny, the groundwater conceptual model reduced to a single case (i.e., Case \#1 above) for which new PORFLOW transport calculations were performed.

The remaining $31 \mathrm{GW}$ parent nuclides were included in the ET\#3 analysis by using PORFLOW results from the 2008 PA with the appropriate adjustments as described in Chapter 5 (Section 5.2.2). The 2008 PA cases were selected for this analysis as follows:

- Based on SWM's commitment to exclude non-crushable waste, the results for the blended (non-crushable waste) 2008 PA cases were not used.

- Both CDP-impacted $K_{d}$ values and non-impacted $K_{d}$ values (i.e., no CDP present) were included in determining a worst case scenario. CDP impacts were accounted for in the 2008 PA by multiplying $\mathrm{K}_{d}$ values by their $\mathrm{K}_{\mathrm{d}}$-specific CDP factor. The CDPimpacted $K_{d}$ values were included to account for the fact that updated $K_{d}$ values were not used (they were not reanalyzed) for the 31 parent nuclides. In some cases new $\mathrm{K}_{\mathrm{d}}$ values increased while in other cases $K_{d}$ values decreased.

Dose calculations were performed for all 38 parent nuclides listed in Table 7-2 as follows:

- Ideal files, representing the maximum concentrations of the radionuclides at the 100$\mathrm{m}$ point of assessment, were created from the PORFLOW output. To accomplish 
this, abbreviated chain concentration histories generated by PORFLOW are expanded into full chain "ideal" files by using the FORTRAN code "IdealFile_PlumeInteractionV2".

- The "ideal" files are then used as input to the "LimitsAndDoses" FORTRAN code (see Collard, 2011) that automates the overall process of computing limits and doses for the GW pathways listed above within the time windows used in the ELLWF disposal limits database (Swingle, 2012b). In this case, an inventory of one Curie of each radionuclide was used in the limits calculation.

- Finally, a plume interaction factor is applied assuming a 50-50 split in inventory allocation between ET\#3 and ET\#4. The description of the PIF process is described in Chapter 6. The expected inventory was applied in the stochastic analysis described in Chapter 8

To verify the dose calculation, PORFLOW results from the 2008 PA SLITw analysis for the 38 parent nuclides considered in this study were run through the dose calculations using the old dose parameters. This verification calculation successfully reproduced the SLITw disposal limits reported in the 2008 PA.

New estimated ET\#3 inventory limits are listed in Table 7-3 at the end of this chapter.

Table 7-2 List of GW parent nuclides for ST\#12 highlighting those that require further transport analysis consideration.

\begin{tabular}{|c|c|c|c|}
\hline Parent Nuclide & Parent Nuclide & Parent Nuclide & Parent Nuclide \\
\hline Am-241 & Cm-248 & Pu-239 & Th-230 \\
\hline Am-243 & H-3 & Pu-240 & Th-232 \\
\hline C-14 & I-129 & Pu-241 & U-233 \\
\hline Cf-249 & K-40 & Pu-242 & U-234 \\
\hline Cf-251 & Mo-93 & Pu-244 & U-235 \\
\hline Cl-36 & Nb-94 & Ra-226 & U-236 \\
\hline Cm-244 & Ni-59 & Se-79 & U-238 \\
\hline Cm-245 & Np-237 & Sn-126 & Zr-93 \\
\hline Cm-246 & Pd-107 & Sr-90 & \\
\hline Cm-247 & Pu-238 & Tc-99 & \\
\hline
\end{tabular}

\subsection{Non-Groundwater Pathways}

Non-groundwater pathway doses to the public associated with ET\#3 are via the Atmospheric Release pathway, Radon pathway, and the Inadvertent Intruder pathway. The Inadvertent Intruder includes an analysis of the Resident Intruder and the Post-Drilling scenario. These analyses are summarized below.

\subsubsection{Atmospheric Pathway}

The current disposal limits for the Atmospheric Release pathway are established in the report by Hiergesell (2011). Disposal limits are calculated based on the DOE 435.1 performance objective for the atmospheric pathway which is a dose to a representative member of the public of $10 \mathrm{mrem} / \mathrm{yr}$. The $2011 \mathrm{SA}$ documents the development of a GoldSim model which 
was utilized to evaluate the release of all potentially volatile radionuclides from the different types of ELLWF disposal facilities. A key finding was that of all the potentially volatile radionuclides simulated only $\mathrm{C}-14$ and $\mathrm{H}-3$ produce any flux at the land surface over the 1000-year period that was simulated. These radionuclides, therefore, are the only ones for which a disposal limit is established.

The GoldSim Atmospheric Release Model simulates migration of volatile radionuclides from the waste zone to the ground surface and computes a surface flux for the radionuclides of interest over a specified area. The rate of transport of the source radionuclide through the subsurface is proportional to the concentration gradient in the vapor-filled pore space. Whether a unit-area-sized waste zone (e.g., $1 \mathrm{~m}^{2}$ surface area) or a full-sized trench waste zone is evaluated using a unit source term, the radionuclide release rate at the land surface (curies/yr) is the same in both cases. Because both the ET\#3 closure cap construction features and waste zone thickness (z-dimension) are essentially the same as for STs and ETs evaluated in the 2011 SA (Hiergesell), the surface flux for ET\#3 would be the same as determined by that analysis.

Assuming this surface release rate (Ci/yr), the Hiergesell SA (2011) used dose release factors (DRF's, mrem/Ci) to obtain dose impacts (mrem/yr) for a receptor at the point of assessment (POA). The calculation of the DRF for the 100-m POA for an area source takes into account disposal unit distance to the POA relative to the length of the disposal unit. A comparison was made of the DRF's for C-14 and H-3 by disposal unit in Lee (2006). The comparison showed that the DRFs are all within an order of magnitude for each radionuclide. Because the atmospheric pathway is not the controlling limit for C-14 and H-3 in SLITw by many orders of magnitude (groundwater beta-gamma limit is six orders of magnitude smaller for C-14 and 18 orders smaller for H-3), these small differences could be ignored. Therefore the West Slit Trench Group atmospheric pathway limits for C-14 and H-3 were used in the stochastic analysis in Chapter 8 of this report. The SLITw inventory limits for the air pathway are shown below and in Table 7-3 at the end of this chapter.

- $\mathrm{C}-14$-- $1.9 \mathrm{E}+05 \mathrm{Ci}$

- $\mathrm{H}-3$-- $2.8 \mathrm{E}+18 \mathrm{Ci}$

\subsubsection{Radon Pathway}

The radon analysis conducted for ELLWF disposal units generates disposal limits for five radionuclides whose decay chains ultimately lead to the ingrowth of Rn-222. The modeling analysis of Rn-222 migration in the subsurface is the same as the analysis of the other potentially volatile radionuclides that are evaluated in the Atmospheric pathway analysis. In fact, the same model is utilized for both analyses. However, the performance objective for $\mathrm{Rn}-222$ release is defined differently than the performance objective for the Atmospheric Release pathway. The Rn-222 performance objective is defined in terms of an actual surface emanation rate or flux at the land surface rather than a maximum permissible exposure to a member of the public for atmospheric pathway radionuclides, which is calculated at a downwind point of exposure. The Rn-222 performance objective is defined as an average flux of $20 \mathrm{pCi} / \mathrm{m}^{2}-\mathrm{sec}$ at the surface of the disposal facility. 
The flux of Rn-222 from the Slit and Engineered Trenches was evaluated for two separate time periods and the maximum flux was then compared to the USDOE performance objective. The first time period evaluated covers the operational and institutional control periods, during which a minimum four-foot operational soil cover overlies the waste. The second time period evaluated covers the post-closure compliance period, after final closure cap installation. The initial conditions for the model also assumed a one curie inventory for each parent nuclide uniformly spread over the waste zone. This condition would result in a higher subsurface concentration and surface flux rate for disposal units with a smaller footprint. Therefore, all other things being equal the relative radon flux is directly proportional to trench surface area.

The surface area of ET\#3 has been computed as $7877 \mathrm{~m}^{2}$ (using the surveyed corner point coordinates) compared to the $6098 \mathrm{~m}^{2}$ area associated with a standard ST. Based on the relative size of the surface area over which surface emanation of Rn-222 occurs, it is clear that the 2008 PA radon pathway disposal limits computed for a ST are bounding for ET\#3.

Limits can easily be estimated for ET\#3 by multiplying the 2008 PA radon modeling results for a unit surface area by the ratio of the calculated surface area of ET\#3 to that for a standard ST. When this calculation is performed the following parent nuclide disposal limits are computed:

- $\mathrm{Pu}-238$-- 9.9E+12 Ci

- Ra-226 -- $2.9 \mathrm{E}+04 \mathrm{Ci}$

- $\mathrm{Th}-230--5.4 \mathrm{E}+05 \mathrm{Ci}$

- $\mathrm{U}-234--9.3 \mathrm{E}+08 \mathrm{Ci}$

- $\mathrm{U}-238--7.9 \mathrm{E}+12 \mathrm{Ci}$

These estimated limits, also shown in Table 7-3 at the end of this chapter, are used in the stochastic analysis in Chapter 8 of this report.

\subsubsection{Intruder Scenarios}

A list of 78 parent nuclides was obtained from an intruder screening in the 2008 PA (WSRC, 2008). These 78 parents were reduced to the 74 considered in this analysis by eliminating four nuclides having no prior historical inventory in E-Area. The list of parents is found in Table 2-1.

In the 2008 PA a single set of Intruder disposal limits were established for all Slit Trenches assuming a standard-sized ST footprint. Because ET\#3 directly overlays the location of the previously planned ST \#12, an analysis was performed to determine if Intruder disposal limits calculated in the 2008 PA were bounding for ET\#3. In this analysis, the Automated Inadvertent Intruder Application (Koffman, 2006) was used. The first step in employing this program was to demonstrate that the 2008 PA results could be duplicated and this was successfully achieved. 
Since the 2008 PA new dose parameters have been published as discussed in Section 7.1. These factors include new ingestion and inhalation dose coefficients published by DOE (USDOE, 2011) and utilized by Jannik and Stone (2013). Input files to the Koffman (2006) Automated Inadvertent Intruder Application were updated with these new dose coefficients along with new disposal unit inputs consistent with the ET\#3 geometry. New Intruder limits were calculated for both the Resident and Post-Drilling Intruder scenarios. The result of these changes is that some Intruder limits have increased while some have decreased.

The estimated ET\#3 Intruder disposal limits are shown in Table 7-3 at the end of the chapter and are used in the stochastic analysis in Chapter 8 of this report.

\subsection{Disposal Limits}

Table 7-3 lists all the new estimated ET\#3 inventory limits based on the following:

- For GW pathways - New limits from ET\#3 vadose zone and aquifer transport runs for the seven selected key parent nuclides, and estimated limits for the remaining 31 parents based on the adjusted 2008 PA analyses. The same plume interaction factor is applied to all 38 parents (i.e., for $\mathrm{ET \#} 3$ a $\mathrm{PIF}=1.70$ in value).

- For non-GW pathways - New limits are listed which account for the ET\#3 geometry and the latest dose coefficients.

Table 7-4 lists the baseline ST\#12 inventory limits for all nine pathways to which the new estimated ET\#3 limits can be compared. The limits in Table 7-4 are the current ST\#12 inventory limits in the ELLWF disposal limits database (Swingle, 2012b). The current ST\#12 inventory limits derive from the following sources;

- 2012IM GW SA limits (Swingle, 2012a)

- 2012 Air pathway SA limits (Hiergesell, 2012)

- 2008 PA inventory limits for all other pathways (WSRC, 2008)

The most limiting pathway for each parent nuclide is shown shaded in blue in both tables. The main conclusions from the limits analysis are:

- Tables 7-3 and 7-4 show that while, in some cases, specific new estimated ET\#3 GW disposal limits are lower than the corresponding ST\#12 limits in the ELLWF disposal limits database, in all cases the 2008 PA gives the minimum GW disposal limit and is therefore bounding.

- In many cases the limiting dose pathway shifted between the current ST\#12 limits and the ET\#3 analyses. This was caused by three factors: 1) changes in $\mathrm{K}_{\mathrm{d}}, 2$ ) changes in ingestion dose coefficients, and 3) the change in interim cover timing.

- In all cases, Air Pathway and Radon limits determined by the ET\#3 analysis are equal to or greater than current ST\#12 limits.

- The Resident Intruder limits determined by the ET\#3 analysis are all lower than the current ST\#12 limits because of the net impact of increasing the waste volume and geometry factor (a dimensionless unit that represents a probability of the home basement footprint being entirely over the waste) when going from Slit Trench to ET\#3 geometry. The ET\#3 Post-Drilling Intruder limits go in both directions depending on the change in the ingestion and inhalation dose coefficients. 
SRNL-STI-2013-00393, REV. 0

\section{Table 7-3 New estimated inventory limits ${ }^{a}$ for $\mathbf{E T} \# 3^{\mathrm{b}, \mathrm{c}}$}

\begin{tabular}{|c|c|c|c|c|c|c|c|c|c|c|c|c|c|c|c|c|c|}
\hline \multirow[b]{2}{*}{ Radionuclide } & \multicolumn{3}{|c|}{ Beta-Gamma (Ci) } & \multicolumn{3}{|c|}{ Gross Alpha (Ci) } & \multicolumn{3}{|c|}{ Radium (Ci) } & \multirow{2}{*}{$\begin{array}{c}\text { Uranium (Ci) } \\
\text { All Years } \\
\end{array}$} & \multicolumn{3}{|c|}{ All-Pathways Limits (Ci) } & \multicolumn{2}{|c|}{ Intruder Limits (Ci) } & \multirow{2}{*}{\begin{tabular}{|c|} 
Air Pathway \\
(Ci)
\end{tabular}} & \multirow{2}{*}{$\begin{array}{l}\text { Radon Pathway } \\
\text { (Ci) }\end{array}$} \\
\hline & $0-12 \mathrm{yrs}$ & $12-100 \mathrm{yrs}$ & $100-1130 \mathrm{yrs}$ & $0-1000 \mathrm{yrs}$ & $1000-1120 \mathrm{yrs}$ & $1120-1130 \mathrm{yrs}$ & $0-1000 \mathrm{yrs}$ & $1000-1120 \mathrm{yrs}$ & $1120-1130 \mathrm{yrs}$ & & $130-200 \mathrm{yrs}$ & $200-1000 \mathrm{yrs}$ & $1000-1130 \mathrm{yrs}$ & Resident & Post-drilling & & \\
\hline Ac-227 & --- & -- & -- & -- & --- & --- & \begin{tabular}{|l|}
--- \\
\end{tabular} & --- & -- & --- & -- & -- & --- & $2.6 \mathrm{E}+07$ & $1.1 \mathrm{E}+04$ & --- & --- \\
\hline $\mathrm{Ag}-108 \mathrm{~m}$ & --- & --- & --- & --- & --- & --- & --- & --- & --- & --- & --- & --- & --- & $3.0 \mathrm{E}+01$ & $2.7 \mathrm{E}+03$ & --- & --- \\
\hline $\mathrm{Al}-26$ & --- & --- & --- & --- & --- & --- & --- & --- & --- & --- & --- & --- & --- & $3.3 \mathrm{E}+00$ & $2.1 \mathrm{E}+03$ & $-\ldots$ & $-\ldots$ \\
\hline Am-241 & $1.1 \mathrm{E}+09$ & $1.6 \mathrm{E}+06$ & $1.2 \mathrm{E}+04$ & $5.9 \mathrm{E}+02$ & $8.3 \mathrm{E}+02$ & $1.3 \mathrm{E}+03$ & --- & --- & --- & $1.8 \mathrm{E}+12$ & $3.0 \mathrm{E}+06$ & $1.7 \mathrm{E}+03$ & $2.4 \mathrm{E}+03$ & $5.2 \mathrm{E}+05$ & $7.4 \mathrm{E}+03$ & --- & --- \\
\hline Am-242m & --- & --- & --- & --- & --- & --- & --- & --- & --- & --- & --- & --- & --- & $1.4 \mathrm{E}+05$ & $6.9 \mathrm{E}+03$ & --- & --- \\
\hline Am-243 & --- & $5.4 \mathrm{E}+16$ & $1.0 \mathrm{E}+09$ & $9.2 \mathrm{E}+08$ & $7.3 \mathrm{E}+08$ & $7.3 \mathrm{E}+08$ & $-\ldots$ & $-\ldots$ & --- & $-\ldots$ & $6.8 \mathrm{E}+15$ & $5.9 \mathrm{E}+08$ & $4.7 \mathrm{E}+08$ & $3.3 \mathrm{E}+02$ & $5.3 \mathrm{E}+03$ & $-\ldots$ & --- \\
\hline Ar-39 & --- & -- & -- & -- & --- & --- & --- & --- & --- & --- & -- & -- & --- & --- & $4.7 \mathrm{E}+07$ & --- & --- \\
\hline Ba-133 & -- & --- & -- & --- & --- & --- & --- & --- & -- & -- & -- & -- & --- & $3.6 \mathrm{E}+09$ & $9.0 \mathrm{E}+06$ & --- & --- \\
\hline Bi-207 & -- & --- & -- & --- & --- & --- & --- & --- & -- & --- & --- & --- & --- & $8.2 \mathrm{E}+04$ & $3.1 \mathrm{E}+04$ & $-\ldots$ & $-\ldots$ \\
\hline C-14 & --- & $7.2 \mathrm{E}+07$ & $6.5 \mathrm{E}+00$ & --- & --- & --- & --- & --- & --- & --- & $3.4 \mathrm{E}+05$ & $6.1 \mathrm{E}+00$ & $2.9 \mathrm{E}+01$ & --- & $2.3 \mathrm{E}+03$ & $1.9 \mathrm{E}+05$ & --- \\
\hline Cd-113m & --- & --- & --- & --- & --- & --- & --- & --- & -- & -- & -- & -- & --- & $-\ldots$ & $6.6 \mathrm{E}+04$ & $\ldots$ & $\ldots$ \\
\hline Cf-249 & $2.8 \mathrm{E}+16$ & $2.8 \mathrm{E}+12$ & $6.2 \mathrm{E}+05$ & $3.7 \mathrm{E}+04$ & $3.1 \mathrm{E}+04$ & $3.1 \mathrm{E}+04$ & --- & --- & --- & $1.0 \mathrm{E}+14$ & $2.7 \mathrm{E}+12$ & $1.1 \mathrm{E}+05$ & $9.2 \mathrm{E}+04$ & $3.1 \mathrm{E}+02$ & $4.1 \mathrm{E}+03$ & --- & --- \\
\hline Cf-250 & --- & --- & --- & --- & --- & --- & --- & --- & -- & --- & --- & --- & --- & $3.1 \mathrm{E}+13$ & $1.1 \mathrm{E}+06$ & --- & --- \\
\hline Cf-251 & --- & --- & $4.4 \mathrm{E}+15$ & $8.6 \mathrm{E}+14$ & $7.7 \mathrm{E}+12$ & $5.2 \mathrm{E}+12$ & --- & --- & --- & --- & --- & $6.7 \mathrm{E}+14$ & $4.3 \mathrm{E}+12$ & $1.1 \mathrm{E}+03$ & $4.2 \mathrm{E}+03$ & --- & --- \\
\hline Cf-252 & --- & --- & --- & --- & --- & --- & --- & --- & -- & --- & --- & --- & --- & $6.2 \mathrm{E}+11$ & $2.8 \mathrm{E}+08$ & --- & --- \\
\hline $\mathrm{Cl}-36$ & $8.7 \mathrm{E}-02$ & $9.0 \mathrm{E}-02$ & $3.7 \mathrm{E}+00$ & --- & --- & --- & --- & --- & --- & --- & $1.4 \mathrm{E}+00$ & $1.4 \mathrm{E}+00$ & $1.4 \mathrm{E}+00$ & --- & $2.2 \mathrm{E}+01$ & --- & --- \\
\hline $\mathrm{Cm}-242$ & -- & --- & -- & --- & --- & --- & --- & --- & -- & --- & --- & -- & --- & $2.2 \mathrm{E}+09$ & $3.0 \mathrm{E}+06$ & $-\ldots$ & --- \\
\hline $\mathrm{Cm}-243$ & -- & --- & -- & --- & --- & --- & --- & --- & -- & --- & -- & --- & --- & $3.4 \mathrm{E}+07$ & $9.3 \mathrm{E}+04$ & --- & --- \\
\hline $\mathrm{Cm}-244$ & --- & --- & --- & --- & --- & --- & --- & --- & --- & --- & --- & --- & --- & $3.6 \mathrm{E}+11$ & $4.6 \mathrm{E}+05$ & --- & --- \\
\hline $\mathrm{Cm}-245$ & $4.0 \mathrm{E}+12$ & $9.7 \mathrm{E}+08$ & $1.4 \mathrm{E}+04$ & $7.4 \mathrm{E}+02$ & $7.0 \mathrm{E}+02$ & $7.3 \mathrm{E}+02$ & 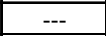 & --- & --- & $1.9 \mathrm{E}+12$ & $1.1 \mathrm{E}+09$ & $2.2 \mathrm{E}+03$ & $2.1 \mathrm{E}+03$ & $2.0 \mathrm{E}+03$ & $4.0 \mathrm{E}+03$ & --- & --- \\
\hline $\mathrm{Cm}-246$ & --- & --- & $4.7 \mathrm{E}+17$ & $5.5 \mathrm{E}+14$ & $3.8 \mathrm{E}+12$ & $2.5 \mathrm{E}+12$ & $3.8 \mathrm{E}+16$ & $5.1 \mathrm{E}+15$ & $4.5 \mathrm{E}+15$ & --- & --- & $8.6 \mathrm{E}+14$ & $3.9 \mathrm{E}+12$ & $8.6 \mathrm{E}+10$ & $7.8 \mathrm{E}+03$ & --- & $-\cdots$ \\
\hline $\mathrm{Cm}-247$ & --- & --- & $3.8 \mathrm{E}+10$ & $3.6 \mathrm{E}+10$ & $2.4 \mathrm{E}+10$ & $2.4 \mathrm{E}+10$ & --- & --- & --- & --- & $1.5 \mathrm{E}+19$ & $2.3 \mathrm{E}+10$ & $1.5 \mathrm{E}+10$ & $6.5 \mathrm{E}+01$ & $5.3 \mathrm{E}+03$ & --- & --. \\
\hline $\mathrm{Cm}-248$ & --- & -- & --- & $5.3 \mathrm{E}+14$ & $3.5 \mathrm{E}+12$ & $2.3 \mathrm{E}+12$ & --- & --- & --- & --- & --- & $2.0 \mathrm{E}+14$ & $8.8 \mathrm{E}+11$ & $4.6 \mathrm{E}+06$ & $2.1 \mathrm{E}+03$ & --- & --- \\
\hline Co-60 & -- & --- & -- & --- & --- & --- & --- & --- & -- & --- & -- & --- & --- & $1.7 \mathrm{E}+09$ & $1.1 \mathrm{E}+09$ & --- & --- \\
\hline Cs-134 & -- & --- & --- & --- & --- & --- & --- & --- & -- & --- & --- & --- & --- & $1.2 \mathrm{E}+19$ & $6.5 \mathrm{E}+17$ & --- & --- \\
\hline Cs-135 & -- & --- & -- & --- & --- & --- & --- & --- & -- & --- & --- & --- & --- & --- & $2.3 \mathrm{E}+04$ & --- & --- \\
\hline Cs-137 & -- & --- & -- & --- & --- & --- & --- & --- & -- & --- & -- & -- & --- & $1.8 \mathrm{E}+06$ & $3.2 \mathrm{E}+04$ & --- & --- \\
\hline Eu-152 & -- & --- & -- & --- & --- & --- & --- & --- & -- & --- & -- & -- & --- & $1.9 \mathrm{E}+06$ & $8.5 \mathrm{E}+05$ & --- & --- \\
\hline Eu-154 & -- & --- & -- & --- & --- & --- & --- & --- & -- & --- & --- & --- & --- & $3.4 \mathrm{E}+07$ & $1.5 \mathrm{E}+07$ & --- & --- \\
\hline Eu-155 & -- & -- & -- & --- & --- & --- & --- & --- & -- & --- & -- & --- & --- & $3.4 \mathrm{E}+18$ & $3.0 \mathrm{E}+11$ & --- & --- \\
\hline $\mathrm{H}-3$ & --- & $1.0 \mathrm{E}+01$ & $8.4 \mathrm{E}+03$ & --- & --- & --- & --- & --- & --- & --- & $1.2 \mathrm{E}+06$ & $2.8 \mathrm{E}+08$ & $8.4 \mathrm{E}+08$ & --- & $2.2 \mathrm{E}+06$ & $2.8 \mathrm{E}+18$ & --- \\
\hline I-129 & --- & $4.8 \mathrm{E}-02$ & $2.3 \mathrm{E}-03$ & --- & --- & --- & --- & --- & --- & --- & $1.0 \mathrm{E}+00$ & $8.6 \mathrm{E}-02$ & $5.0 \mathrm{E}+00$ & $6.1 \mathrm{E}+09$ & $3.0 \mathrm{E}+02$ & --- & --- \\
\hline K-40 & $2.2 \mathrm{E}-01$ & $1.6 \mathrm{E}-01$ & $1.8 \mathrm{E}+00$ & --- & --- & --- & --- & --- & --- & --- & $2.7 \mathrm{E}+00$ & $3.7 \mathrm{E}+00$ & $1.9 \mathrm{E}+01$ & $5.6 \mathrm{E}+01$ & $4.1 \mathrm{E}+02$ & --- & --- \\
\hline $\mathrm{Kr}-85$ & -- & --- & -- & --- & --- & --- & --- & --- & -- & --- & -- & -- & --- & $8.2 \mathrm{E}+10$ & $1.5 \mathrm{E}+09$ & --- & --- \\
\hline Mo-93 & --- & $5.9 \mathrm{E}+00$ & $1.4 \mathrm{E}+00$ & --- & --- & --.- & --- & --- & --- & --- & $3.8 \mathrm{E}+03$ & $7.9 \mathrm{E}+00$ & $6.4 \mathrm{E}+00$ & --- & $9.6 \mathrm{E}+04$ & --- & --- \\
\hline $\mathrm{Na}-22$ & --- & --- & --- & --- & --- & --- & --- & --- & --- & --- & --- & --- & --- & $2.3 \mathrm{E}+15$ & $7.4 \mathrm{E}+14$ & 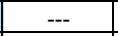 & --.- \\
\hline Nb-93m & --- & --- & --- & --- & --- & --- & --- & --- & --- & --- & --- & --- & --- & --- & $1.3 \mathrm{E}+08$ & --- & --- \\
\hline
\end{tabular}

a Most limiting pathway for each parent nuclide is shown shaded in blue.

b Only 74 out of possible 78 parent nuclides listed (i.e., Bk-249, Ca-41, W-185, and W-188 omitted because no prior historical inventories are available).

c Includes plume interaction factor assuming 50:50 inventory split ET\#3 vs. ET\#4. 
SRNL-STI-2013-00393, REV. 0

Table 7-3 New estimated inventory limits ${ }^{\mathrm{a}}$ for $\mathbf{E T} \# 3^{\mathrm{b}, \mathrm{c}}$ (continued).

\begin{tabular}{|c|c|c|c|c|c|c|c|c|c|c|c|c|c|c|c|c|c|}
\hline \multirow[b]{2}{*}{ Radionuclide } & \multicolumn{3}{|c|}{ Beta-Gamma (Ci) } & \multicolumn{3}{|c|}{ Gross Alpha (Ci) } & \multirow{2}{*}{\multicolumn{3}{|c|}{\begin{tabular}{|c|}
\multicolumn{2}{|c|}{ Radium (Ci) } \\
0-1000 yrs $1000-1120$ yrs $\quad 1120-1130 \mathrm{yrs}$ \\
\end{tabular}}} & \multirow{2}{*}{\begin{tabular}{|c} 
Uranium $(\mathrm{Ci})$ \\
All Years
\end{tabular}} & \multicolumn{3}{|c|}{ All-Pathways Limits (Ci) } & \multicolumn{2}{|c|}{ Intruder Limits (Ci) } & \multirow{2}{*}{$\begin{array}{c}\text { Air Pathway } \\
\text { (Ci) }\end{array}$} & \multirow{2}{*}{$\begin{array}{l}\text { Radon Pathway } \\
\text { (Ci) }\end{array}$} \\
\hline & $0-12 \mathrm{yrs}$ & $12-100 \mathrm{yrs}$ & $100-1130 \mathrm{yrs}$ & $0-1000 \mathrm{yrs}$ & $1000-1120 \mathrm{yrs}$ & $1120-1130 \mathrm{yrs}$ & & & & & $130-200 \mathrm{yrs}$ & $200-1000 \mathrm{yr}$ & $1000-1130 \mathrm{yrs}$ & Resident & Post-drilling & & \\
\hline $\mathrm{Nb}-94$ & $9.6 \mathrm{E}-02$ & \begin{tabular}{|c|}
$9.9 \mathrm{E}-02$ \\
\end{tabular} & $4.1 \mathrm{E}+00$ & --- & --- & --- & --- & --- & --- & --- & $2.2 \mathrm{E}+00$ & $2.2 \mathrm{E}+00$ & $2.2 \mathrm{E}+00$ & $8.0 \mathrm{E}+00$ & $3.6 \mathrm{E}+03$ & --- & --- \\
\hline $\mathrm{Ni}-59$ & $6.5 \mathrm{E}+17$ & $2.6 \mathrm{E}+09$ & $3.6 \mathrm{E}+00$ & $-\ldots$ & $-\ldots$ & --- & -.- & $\ldots$ & --. & --. & $2.9 \mathrm{E}+11$ & $3.4 \mathrm{E}+03$ & $6.5 \mathrm{E}+02$ & --- & $3.9 \mathrm{E}+05$ & --. & $-\ldots$ \\
\hline $\mathrm{Ni}-63$ & --- & --- & --- & --- & --- & --- & --- & -- & -- & --- & --- & --- & --- & --- & $3.1 \mathrm{E}+05$ & --. & -.- \\
\hline $\mathrm{Np}-237$ & --- & $2.9 \mathrm{E}+17$ & $1.2 \mathrm{E}+00$ & $1.8 \mathrm{E}-01$ & $6.5 \mathrm{E}-02$ & $6.2 \mathrm{E}-02$ & $\ldots$ & --- & --. & $1.5 \mathrm{E}+08$ & $1.0 \mathrm{E}+12$ & $5.3 \mathrm{E}-01$ & $1.8 \mathrm{E}-01$ & $1.4 \mathrm{E}+02$ & $1.3 \mathrm{E}+03$ & $\ldots$ & $\ldots$ \\
\hline $\mathrm{Pa}-231$ & -.- & --- & --- & --- & --- & --- & $\ldots$ & -.- & --. & --- & --- & --- & --- & $6.7 \mathrm{E}+01$ & $3.9 \mathrm{E}+02$ & --- & $\ldots$ \\
\hline $\mathrm{Pb}-210$ & --- & --- & --- & --- & --- & --- & --- & --- & --- & --- & --- & --- & --- & $1.2 \mathrm{E}+11$ & $4.0 \mathrm{E}+03$ & --- & --- \\
\hline Pd-107 & --- & $3.1 \mathrm{E}+11$ & $4.4 \mathrm{E}+02$ & $\ldots$ & $\ldots$ & $\ldots$ & $\ldots$ & $\ldots$ & $\ldots$ & --- & $4.8 \mathrm{E}+11$ & $5.5 \mathrm{E}+03$ & $1.1 \mathrm{E}+03$ & --- & $8.7 \mathrm{E}+05$ & --. & --- \\
\hline Pu-238 & --- & --- & $1.0 \mathrm{E}+07$ & $4.9 \mathrm{E}+05$ & $1.2 \mathrm{E}+05$ & $1.1 \mathrm{E}+05$ & $4.9 \mathrm{E}+05$ & $1.2 \mathrm{E}+05$ & $1.1 \mathrm{E}+05$ & $\ldots$ & $1.4 \mathrm{E}+18$ & $1.1 \mathrm{E}+06$ & $2.6 \mathrm{E}+05$ & $1.1 \mathrm{E}+07$ & $1.5 \mathrm{E}+04$ & $\ldots$ & $9.9 \mathrm{E}+12$ \\
\hline $\mathrm{Pu}-239$ & $2.3 \mathrm{E}+17$ & $6.9 \mathrm{E}+12$ & $1.2 \mathrm{E}+07$ & $9.8 \mathrm{E}+06$ & $9.1 \mathrm{E}+06$ & $9.2 \mathrm{E}+06$ & --- & --- & --- & --- & $1.1 \mathrm{E}+12$ & $6.3 \mathrm{E}+06$ & $5.9 \mathrm{E}+06$ & $3.2 \mathrm{E}+06$ & $6.3 \mathrm{E}+03$ & $-\ldots$ & --- \\
\hline Pu-240 & --- & --- & --- & --- & --- & --- & --. & -.- & $-\ldots$ & --- & --- & --- & --- & $1.0 \mathrm{E}+09$ & $6.3 \mathrm{E}+03$ & --- & $-\ldots$ \\
\hline $\mathrm{Pu}-241$ & $3.6 \mathrm{E}+11$ & $2.3 \mathrm{E}+08$ & $3.6 \mathrm{E}+05$ & $1.8 \mathrm{E}+04$ & $2.5 \mathrm{E}+04$ & $3.9 \mathrm{E}+04$ & --- & $-\ldots$ & --- & $5.4 \mathrm{E}+13$ & $3.3 \mathrm{E}+08$ & $5.3 \mathrm{E}+04$ & $7.4 \mathrm{E}+04$ & $1.5 \mathrm{E}+07$ & $2.2 \mathrm{E}+05$ & $-\ldots$ & $\ldots$ \\
\hline $\mathrm{Pu}-242$ & --- & --- & $1.3 \mathrm{E}+14$ & $8.6 \mathrm{E}+12$ & $1.4 \mathrm{E}+12$ & $1.3 \mathrm{E}+12$ & $8.6 \mathrm{E}+12$ & $1.4 \mathrm{E}+12$ & $1.3 \mathrm{E}+12$ & --- & --- & $2.0 \mathrm{E}+13$ & $3.0 \mathrm{E}+12$ & $5.8 \mathrm{E}+08$ & $6.6 \mathrm{E}+03$ & -.- & -.- \\
\hline Pu-244 & $\ldots$ & $\ldots$ & --- & --- & --- & --- & --- & --- & --- & --- & $\ldots$ & --- & --- & $3.6 \mathrm{E}+01$ & $4.4 \mathrm{E}+03$ & --- & $\ldots$ \\
\hline Ra-226 & $4.7 \mathrm{E}+15$ & $2.0 \mathrm{E}+07$ & $3.2 \mathrm{E}+00$ & $6.1 \mathrm{E}-02$ & $4.2 \mathrm{E}-02$ & $4.2 \mathrm{E}-02$ & $6.1 \mathrm{E}-02$ & $4.2 \mathrm{E}-02$ & $4.2 \mathrm{E}-02$ & --- & $4.2 \mathrm{E}+05$ & $1.4 \mathrm{E}-01$ & $9.7 \mathrm{E}-02$ & $7.6 \mathrm{E}+00$ & $1.1 \mathrm{E}+02$ & $\ldots$ & $2.9 \mathrm{E}+04$ \\
\hline Ra-228 & --- & --- & --- & --- & --- & --- & --- & --- & --- & --- & --- & --- & --- & $1.1 \mathrm{E}+08$ & $1.1 \mathrm{E}+07$ & $\ldots$ & --- \\
\hline Rb-87 & --- & --- & --- & --- & --- & --- & --- & --- & -- & --- & --- & --- & --- & --- & $1.3 \mathrm{E}+04$ & --. & -.- \\
\hline S-35 & -- & - & -- & --- & --- & --- & --- & $-\ldots$ & -- & --- & -- & -- & --- & --- & --- & $\ldots$ & $\ldots$ \\
\hline $\mathrm{Sb}-125$ & -- & -- & --- & --- & --- & --- & --- & --- & -- & --- & -- & -- & --- & $4.1 \mathrm{E}+16$ & $8.4 \mathrm{E}+14$ & -.- & $\ldots$ \\
\hline Sc-46 & --- & --- & --- & --- & --- & --- & --- & --- & --- & --- & --- & --- & --- & --- & --- & --- & -.- \\
\hline Se-79 & -- & -- & -- & -- & -- & -- & -- & -- & -- & -- & -- & -- & -- & - & $1.6 \mathrm{E}+04$ & - & $\ldots$ \\
\hline Sm-151 & - & - & - & -- & - & --- & - & --- & - & -- & -- & -- & --- & $-\ldots$ & $6.0 \mathrm{E}+06$ & $-\ldots$ & $\ldots$ \\
\hline $\mathrm{Sn}-121 \mathrm{~m}$ & --- & --- & --- & --- & --- & --- & --- & --- & --- & --- & --- & --- & --- & --- & $1.7 \mathrm{E}+06$ & --- & --- \\
\hline Sn-126 & --- & -.- & --- & -.- & -.- & --- & --. & -.- & -.- & --- & --- & --- & --- & $7.2 \mathrm{E}+00$ & $2.7 \mathrm{E}+03$ & --- & -.- \\
\hline Sr-90 & --- & --- & $2.1 \mathrm{E}+11$ & $-\ldots$ & $-\ldots$ & $\ldots$ & $\ldots$ & $\ldots$ & $-\ldots$ & $\ldots$ & --- & $8.9 \mathrm{E}+12$ & $4.4 \mathrm{E}+12$ & --- & $2.3 \mathrm{E}+03$ & $-\ldots$ & $\ldots$ \\
\hline Tc-99 & --- & $4.9 \mathrm{E}+03$ & $2.1 \mathrm{E}+00$ & --- & -.- & --- & --- & --- & -.- & --- & $2.7 \mathrm{E}+02$ & $1.4 \mathrm{E}+00$ & $7.6 \mathrm{E}+01$ & $8.7 \mathrm{E}+08$ & $1.4 \mathrm{E}+03$ & --- & -.- \\
\hline Th-228 & -- & --- & --- & --- & -- & -- & -- & -- & -- & -- & --- & --- & --- & $5.5 \mathrm{E}+18$ & $3.8 \mathrm{E}+18$ & --- & $-\ldots$ \\
\hline Th-229 & --- & --- & --- & --- & --- & --- & --- & --- & -- & --- & -- & --- & --- & $7.5 \mathrm{E}+01$ & $4.1 \mathrm{E}+02$ & $-\ldots$ & $-\ldots$ \\
\hline Th-230 & $7.3 \mathrm{E}+18$ & $1.6 \mathrm{E}+10$ & $8.8 \mathrm{E}+00$ & $2.9 \mathrm{E}-01$ & $1.1 \mathrm{E}-01$ & $1.1 \mathrm{E}-01$ & $2.9 \mathrm{E}-01$ & $1.1 \mathrm{E}-01$ & $1.1 \mathrm{E}-01$ & --- & $3.1 \mathrm{E}+08$ & $6.8 \mathrm{E}-01$ & $2.4 \mathrm{E}-01$ & $1.6 \mathrm{E}+01$ & $2.8 \mathrm{E}+02$ & --- & $5.4 \mathrm{E}+05$ \\
\hline Th-232 & $1.0 \mathrm{E}+15$ & $6.4 \mathrm{E}+08$ & $3.1 \mathrm{E}+08$ & $6.5 \mathrm{E}+08$ & $3.6 \mathrm{E}+08$ & $3.1 \mathrm{E}+08$ & $8.7 \mathrm{E}+08$ & $4.8 \mathrm{E}+08$ & $4.2 \mathrm{E}+08$ & $-\ldots$ & $2.9 \mathrm{E}+12$ & $3.7 \mathrm{E}+09$ & $2.5 \mathrm{E}+08$ & $3.6 \mathrm{E}+00$ & $6.5 \mathrm{E}+01$ & --- & -.- \\
\hline U-232 & --- & --- & --- & --- & --- & --- & --- & --- & --- & --- & --- & --- & --- & $2.6 \mathrm{E}+03$ & $1.1 \mathrm{E}+03$ & $\ldots$ & $\ldots$ \\
\hline U-233 & --. & -.- & -.- & --- & -.- & --.- & --- & -.- & --- & --- & --- & --- & --- & $7.7 \mathrm{E}+02$ & $2.6 \mathrm{E}+03$ & --- & -.-- \\
\hline U-234 & --- & $6.0 \mathrm{E}+14$ & $2.6 \mathrm{E}+03$ & $1.1 \mathrm{E}+02$ & $3.1 \mathrm{E}+01$ & $2.9 \mathrm{E}+01$ & $1.1 \mathrm{E}+02$ & $3.1 \mathrm{E}+01$ & $2.9 \mathrm{E}+01$ & --- & $1.1 \mathrm{E}+13$ & $2.6 \mathrm{E}+02$ & $6.8 \mathrm{E}+01$ & $3.2 \mathrm{E}+03$ & $5.9 \mathrm{E}+03$ & --- & $9.3 \mathrm{E}+08$ \\
\hline U-235 & $4.2 \mathrm{E}+08$ & $3.0 \mathrm{E}+04$ & $6.7 \mathrm{E}+00$ & $5.1 \mathrm{E}+00$ & $5.4 \mathrm{E}+00$ & $6.4 \mathrm{E}+00$ & --- & --- & --- & $-\ldots$ & $8.4 \mathrm{E}+03$ & $3.2 \mathrm{E}+00$ & $3.5 \mathrm{E}+00$ & $4.2 \mathrm{E}+02$ & $4.5 \mathrm{E}+03$ & $-\ldots$ & $-\ldots$ \\
\hline U-236 & --- & $3.8 \mathrm{E}+18$ & $3.3 \mathrm{E}+15$ & $5.9 \mathrm{E}+16$ & $3.9 \mathrm{E}+15$ & $3.3 \mathrm{E}+15$ & $7.9 \mathrm{E}+16$ & $5.2 \mathrm{E}+15$ & $4.5 \mathrm{E}+15$ & $-\ldots$ & --- & $4.8 \mathrm{E}+16$ & $2.7 \mathrm{E}+15$ & $2.3 \mathrm{E}+07$ & $6.9 \mathrm{E}+03$ & --- & -.- \\
\hline U-238 & --- & --- & $3.7 \mathrm{E}+06$ & $2.0 \mathrm{E}+05$ & $4.3 \mathrm{E}+04$ & $3.9 \mathrm{E}+04$ & $2.0 \mathrm{E}+05$ & $4.3 \mathrm{E}+04$ & $3.9 \mathrm{E}+04$ & --- & $1.3 \mathrm{E}+18$ & $4.8 \mathrm{E}+05$ & $9.2 \mathrm{E}+04$ & $8.1 \mathrm{E}+02$ & $6.9 \mathrm{E}+03$ & $-\ldots$ & $7.9 \mathrm{E}+12$ \\
\hline W-181 & --- & --- & --- & --- & --- & --- & --- & --- & --- & --- & --- & --- & --- & --- & --- & -.- & --- \\
\hline Zr-93 & $1.4 \mathrm{E}+00$ & $7.2 \mathrm{E}-01$ & $9.0 \mathrm{E}-01$ & --- & --- & --- & --- & --- & --- & --- & $3.4 \mathrm{E}+03$ & $4.7 \mathrm{E}+00$ & $4.3 \mathrm{E}+00$ & --- & $7.4 \mathrm{E}+05$ & --- & --- \\
\hline
\end{tabular}

a Most limiting pathway for each parent nuclide is shown shaded in blue.

b Only 74 out of possible 78 parent nuclides listed (i.e., Bk-249, Ca-41, W-185, and W-188 omitted because no prior historical inventories are available).

c Includes plume interaction factor assuming 50:50 inventory split ET\#3 vs. ET\#4. 
SRNL-STI-2013-00393, REV. 0

\section{Table 7-4 Current inventory limits ${ }^{\mathrm{a}}$ for ST\#12 ${ }^{\mathrm{b}}$.}

\begin{tabular}{|c|c|c|c|c|c|c|c|c|c|c|c|c|c|c|c|c|c|}
\hline \multirow[b]{2}{*}{ Radionuclide } & \multicolumn{3}{|c|}{ Beta-Gamma (Ci) } & \multicolumn{3}{|c|}{ Gross Alpha (Ci) } & \multicolumn{3}{|c|}{ Radium (Ci) } & \multirow{2}{*}{\begin{tabular}{|c} 
Uranium (Ci) \\
All Years \\
\end{tabular}} & \multicolumn{3}{|c|}{ All-Pathways Limits (Ci) } & \multicolumn{2}{|c|}{ Intruder Limits (Ci) } & \multirow{2}{*}{\begin{tabular}{|c|} 
Air Pathway \\
(Ci)
\end{tabular}} & \multirow{2}{*}{$\begin{array}{c}\text { Radon Pathway } \\
\text { (Ci) }\end{array}$} \\
\hline & $0-12 \mathrm{yrs}$ & $12-100 \mathrm{yrs}$ & $100-1130 \mathrm{yrs}$ & $0-1000 \mathrm{yrs}$ & $1000-1120 \mathrm{yrs}$ & $1120-1130 \mathrm{yrs}$ & $0-1000$ yrs & $1000-1120 \mathrm{yrs}$ & $1120-1130 \mathrm{yrs}$ & & $130-200 \mathrm{yrs}$ & $200-1000 \mathrm{yrs}$ & $1000-1130 \mathrm{yrs}$ & Resident & Post-drilling & & \\
\hline Ac-227 & --- & \begin{tabular}{|l|}
-- \\
\end{tabular} & \begin{tabular}{|c|}
-- \\
\end{tabular} & \begin{tabular}{|c|}
-- \\
\end{tabular} & \begin{tabular}{|c|}
-- \\
\end{tabular} & -- & --- & --- & --- & \begin{tabular}{|c|}
-- \\
\end{tabular} & \begin{tabular}{|c|}
-- \\
\end{tabular} & --- & \begin{tabular}{|c|}
-- \\
\end{tabular} & $3.1 \mathrm{E}+07$ & $4.2 \mathrm{E}+03$ & --- & --- \\
\hline $\mathrm{Ag}-108 \mathrm{~m}$ & --- & $-\ldots$ & --- & -- & --- & - & $-\ldots$ & --- & $-\ldots$ & - & --- & --- & --- & $3.6 \mathrm{E}+01$ & $2.3 \mathrm{E}+03$ & $\ldots$ & $-\ldots$ \\
\hline $\mathrm{Al}-26$ & --- & --- & --- & --- & --- & --- & --- & --- & --- & -- & $-\ldots$ & --- & $-\ldots$ & $3.9 \mathrm{E}+00$ & $1.6 \mathrm{E}+03$ &.-- & $-\ldots$ \\
\hline Am-241 & $9.5 \mathrm{E}+08$ & $1.5 \mathrm{E}+06$ & $1.1 \mathrm{E}+04$ & $6.4 \mathrm{E}+01$ & $4.2 \mathrm{E}+01$ & $4.1 \mathrm{E}+01$ & --- & --- & --- & $1.6 \mathrm{E}+12$ & $5.9 \mathrm{E}+02$ & $2.4 \mathrm{E}+01$ & $1.5 \mathrm{E}+01$ & $6.2 \mathrm{E}+05$ & $1.4 \mathrm{E}+03$ & --- & --- \\
\hline Am-242m & --- & --- & --- & -- & --- & --- & --- & --- & --- & --- & --- & --- & --- & $1.6 \mathrm{E}+05$ & $1.4 \mathrm{E}+03$ & --- & 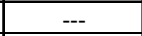 \\
\hline Am-243 & $-\ldots$ & $4.9 \mathrm{E}+16$ & $1.5 \mathrm{E}+02$ & $1.5 \mathrm{E}+01$ & $8.0 \mathrm{E}+00$ & $7.7 \mathrm{E}+00$ & $-\ldots$ & $-\ldots$ & $-\ldots$ & $2.6 \mathrm{E}+11$ & $2.8 \mathrm{E}+10$ & $5.8 \mathrm{E}+00$ & $2.9 \mathrm{E}+00$ & $3.9 \mathrm{E}+02$ & $1.1 \mathrm{E}+03$ & $-\ldots$ & $-\ldots$ \\
\hline Ar-39 & --- & --- & --- & --- & --- & --- & --- & --- & --- & --- & --- & --- & --- & --- & $3.6 \mathrm{E}+07$ & --- & --- \\
\hline Ba-133 & --- & -- & -- & -- & -- & -- & -- & --- & -- & -- & --- & -- & -- & $4.3 \mathrm{E}+09$ & $8.2 \mathrm{E}+06$ & --- & --- \\
\hline Bi-207 & --- & --- & -- & -- & --- & -- & -- & --- & -- & - & --- & --- & - & $9.9 \mathrm{E}+04$ & $2.3 \mathrm{E}+04$ & $-\ldots$ & --- \\
\hline C-14 & $2.2 \mathrm{E}-01$ & $2.3 \mathrm{E}-01$ & $9.6 \mathrm{E}+00$ & $-\ldots$ & $-\ldots$ & $-\ldots$ & $-\ldots$ & $-\ldots$ & $-\ldots$ & $-\ldots$ & $1.1 \mathrm{E}+01$ & $1.1 \mathrm{E}+01$ & $1.1 \mathrm{E}+01$ & --- & $2.0 \mathrm{E}+03$ & $1.9 \mathrm{E}+05$ & --- \\
\hline Cd-113m & --- & --- & --- & --- & --- & --- & --- & --- & --- & --- & --- & --- & --- & 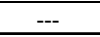 & $3.0 \mathrm{E}+04$ & --- & --- \\
\hline Cf-249 & $2.6 \mathrm{E}+16$ & $2.6 \mathrm{E}+12$ & $1.0 \mathrm{E}+04$ & $7.3 \mathrm{E}+01$ & $4.3 \mathrm{E}+01$ & $4.2 \mathrm{E}+01$ &.-- & $-\ldots$ &.-- & $9.0 \mathrm{E}+13$ & $1.8 \mathrm{E}+06$ & $2.3 \mathrm{E}+01$ & $1.3 \mathrm{E}+01$ & $3.7 \mathrm{E}+02$ & $1.3 \mathrm{E}+03$ &.-- & --- \\
\hline Cf-250 & --- & --- & --- & --- & --- & --- & -- & --- & -- & --- & --- & --- & --- & $3.8 \mathrm{E}+13$ & $2.6 \mathrm{E}+05$ & --- & --- \\
\hline Cf-251 & --- & --- & $5.3 \mathrm{E}+07$ & $3.0 \mathrm{E}+01$ & $1.7 \mathrm{E}+01$ & $1.6 \mathrm{E}+01$ & --- & --- & --- & $1.9 \mathrm{E}+17$ & $5.6 \mathrm{E}+17$ & $8.6 \mathrm{E}+00$ & $4.7 \mathrm{E}+00$ & $1.4 \mathrm{E}+03$ & $1.2 \mathrm{E}+03$ & --- & --- \\
\hline Cf-252 & --- & -- & --- & --- & --- & --- & -- & --- & --- & --- & --- & --- & --- & $7.5 \mathrm{E}+11$ & $5.3 \mathrm{E}+07$ & $-\ldots$ & --- \\
\hline $\mathrm{Cl}-36$ & $7.9 \mathrm{E}-02$ & $8.1 \mathrm{E}-02$ & $3.4 \mathrm{E}+00$ & $-\ldots$ & $-\ldots$ & $-\ldots$ & $-\ldots$ & $-\ldots$ & $-\ldots$ & $-\ldots$ & $2.0 \mathrm{E}+00$ & $2.0 \mathrm{E}+00$ & $2.0 \mathrm{E}+00$ & --- & $2.5 \mathrm{E}+01$ & $-\ldots$ & $-\ldots$ \\
\hline $\mathrm{Cm}-242$ & --- & -- & --- & -- & -- & -- & -- & -- & -- & -- & --- & --- & --- & $2.6 \mathrm{E}+09$ & $7.0 \mathrm{E}+05$ & --- & --- \\
\hline $\mathrm{Cm}-243$ & --- & -- & $-\ldots$ & -- & --- & -- & -- & --- & $-\ldots$ & - & --- & --- & --- & $4.1 \mathrm{E}+07$ & $2.2 \mathrm{E}+04$ & $-\ldots$ & --- \\
\hline $\mathrm{Cm}-244$ & --- & --- & $1.6 \mathrm{E}+17$ & $3.7 \mathrm{E}+09$ & $5.7 \mathrm{E}+08$ & $4.9 \mathrm{E}+08$ & $3.0 \mathrm{E}+17$ & $2.3 \mathrm{E}+17$ & $2.2 \mathrm{E}+17$ & $5.7 \mathrm{E}+16$ & --- & $1.5 \mathrm{E}+09$ & $1.9 \mathrm{E}+08$ & $4.4 \mathrm{E}+11$ & $1.0 \mathrm{E}+05$ & --- & --- \\
\hline $\mathrm{Cm}-245$ & $3.6 \mathrm{E}+12$ & $8.7 \mathrm{E}+08$ & $3.9 \mathrm{E}+02$ & $8.6 \mathrm{E}+00$ & $4.3 \mathrm{E}+00$ & $4.2 \mathrm{E}+00$ & --- & --- & --- & $1.7 \mathrm{E}+12$ & $6.2 \mathrm{E}+03$ & $3.2 \mathrm{E}+00$ & $1.5 \mathrm{E}+00$ & $2.4 \mathrm{E}+03$ & $7.7 \mathrm{E}+02$ & --- & --- \\
\hline Cm-246 & --- & --- & $1.6 \mathrm{E}+14$ & $1.6 \mathrm{E}+01$ & $8.5 \mathrm{E}+00$ & $8.1 \mathrm{E}+00$ & $1.0 \mathrm{E}+16$ & $3.1 \mathrm{E}+15$ & $2.9 \mathrm{E}+15$ & $4.1 \mathrm{E}+12$ & $7.3 \mathrm{E}+17$ & $6.0 \mathrm{E}+00$ & $3.0 \mathrm{E}+00$ & $1.0 \mathrm{E}+11$ & $1.5 \mathrm{E}+03$ & $-\ldots$ & --- \\
\hline $\mathrm{Cm}-247$ & --- & --- & $1.1 \mathrm{E}+03$ & $1.3 \mathrm{E}+01$ & $6.5 \mathrm{E}+00$ & $6.3 \mathrm{E}+00$ & --- & --- & --- & $2.9 \mathrm{E}+12$ & $6.0 \mathrm{E}+12$ & $5.1 \mathrm{E}+00$ & $2.5 \mathrm{E}+00$ & $7.9 \mathrm{E}+01$ & $1.3 \mathrm{E}+03$ & --- & --- \\
\hline Cm-248 & --- & --- & $7.8 \mathrm{E}+08$ & $1.5 \mathrm{E}+01$ & $7.9 \mathrm{E}+00$ & $7.5 \mathrm{E}+00$ & --- & --- & --- & $5.3 \mathrm{E}+16$ & $1.9 \mathrm{E}+17$ & $1.4 \mathrm{E}+00$ & $7.0 \mathrm{E}-01$ & $5.5 \mathrm{E}+06$ & $3.9 \mathrm{E}+02$ & --- & --- \\
\hline Co-60 & --- & --- & --- & --- & --- & --- & --- & --- & --- & --- & --- & --- & --- & $2.0 \mathrm{E}+09$ & $8.3 \mathrm{E}+08$ & --. & --- \\
\hline Cs-134 & --- & --- & --- & -- & --- & --- & -- & --- & --- & -- & -- & -- & -- & $1.5 \mathrm{E}+19$ & $4.8 \mathrm{E}+17$ & --- & --- \\
\hline Cs-135 & --- & -- & --- & -- & -- & -- & -- & --- & -- & -- & --- & -- & -- & --- & $2.4 \mathrm{E}+04$ & --- & --- \\
\hline $\begin{array}{l}\text { Cs- } 137 \\
\end{array}$ & -- & -- & -- & -- & -- & -- & -- & --- & -- & -- & --- & -- & -- & $2.1 \mathrm{E}+06$ & $2.4 \mathrm{E}+04$ & --- & --- \\
\hline Eu-152 & --- & -- & -- & -- & -- & -- & -- & --- & -- & - & --- & -- & -- & $2.3 \mathrm{E}+06$ & $6.5 \mathrm{E}+05$ & --- & --- \\
\hline Eu-154 & --- & --- & --- & --- & --- & --- & --- & --- & --- & --- & --- & --- & -- & $4.1 \mathrm{E}+07$ & $1.1 \mathrm{E}+07$ & --- & --- \\
\hline Eu-155 & --- & -- & --- & -- & -- & -- & -- & -- & -- & - & --- & --- & -- & $4.0 \mathrm{E}+18$ & $2.4 \mathrm{E}+11$ & $-\cdots$ & -- \\
\hline H-3 & $4.2 \mathrm{E}+00$ & $4.5 \mathrm{E}+00$ & $2.6 \mathrm{E}+04$ & $-\ldots$ & --- & --- & --- & --- & $-\ldots$ & --- & $4.0 \mathrm{E}+06$ & $4.0 \mathrm{E}+06$ & $4.0 \mathrm{E}+06$ & --- & $2.1 \mathrm{E}+06$ & $2.8 \mathrm{E}+18$ & --- \\
\hline $\mathrm{I}-129$ & $2.3 \mathrm{E}-04$ & $2.3 \mathrm{E}-04$ & $1.1 \mathrm{E}-02$ & --- & --- & --- & --- & --- & --- & --- & $7.5 \mathrm{E}-01$ & $7.5 \mathrm{E}-01$ & $7.5 \mathrm{E}-01$ & $7.3 \mathrm{E}+09$ & $3.8 \mathrm{E}+02$ & --- & --- \\
\hline K-40 & $2.0 \mathrm{E}-01$ & $1.5 \mathrm{E}-01$ & $1.6 \mathrm{E}+00$ & --- & --- & --- & --- & --- & --- & --- & $4.0 \mathrm{E}+00$ & $5.4 \mathrm{E}+00$ & $2.8 \mathrm{E}+01$ & $6.7 \mathrm{E}+01$ & $5.1 \mathrm{E}+02$ & --- & --- \\
\hline $\mathrm{Kr}-85$ & --- & --- & --- & -- & --- & -- & --- & --- & --- & -- & --- & --- & --- & $9.9 \mathrm{E}+10$ & $1.2 \mathrm{E}+09$ & --- & --- \\
\hline Mo-93 & $1.7 \mathrm{E}-01$ & $1.9 \mathrm{E}-01$ & $3.9 \mathrm{E}+00$ & -- & --- & --- & --- & --- & --- & --- & $2.1 \mathrm{E}+01$ & $2.1 \mathrm{E}+01$ & $2.1 \mathrm{E}+01$ & --- & $4.7 \mathrm{E}+05$ & --- & --- \\
\hline Na-22 & --- & --- & --- & -- & -- & -- & -- & --- & -- & -- & --- & --- & --- & $2.7 \mathrm{E}+15$ & $5.9 \mathrm{E}+14$ & --- & --- \\
\hline $\mathrm{Nb}-93 \mathrm{~m}$ & --- & -- & $-\ldots$ & -- & --- & --- & --- & --- & $-\ldots$ & -- & --- & --- & $-\ldots$ & --- & $1.2 \mathrm{E}+08$ & $\ldots$ & $\ldots$ \\
\hline
\end{tabular}

a Most limiting pathway for each parent nuclide is shown shaded in blue.

b Only 74 out of possible 78 parent nuclides listed (i.e., Bk-249, Ca-41, W-185, and W-188 omitted because no prior historical inventories are available). 
SRNL-STI-2013-00393, REV. 0

Table 7-4 Current inventory limits ${ }^{\mathrm{a}}$ for $\mathrm{ST} \# 12^{\mathrm{b}}$. (continued)

\begin{tabular}{|c|c|c|c|c|c|c|c|c|c|c|c|c|c|c|c|c|c|}
\hline \multirow[b]{2}{*}{ Radionuclide } & \multicolumn{3}{|c|}{ Beta-Gamma (Ci) } & \multicolumn{3}{|c|}{ Gross Alpha (Ci) } & \multicolumn{3}{|c|}{ Radium (Ci) } & \multirow{2}{*}{$\begin{array}{c}\text { Uranium (Ci) } \\
\text { All Years }\end{array}$} & \multicolumn{3}{|c|}{ All-Pathways Limits (Ci) } & \multicolumn{2}{|c|}{ Intruder Limits (Ci) } & \multirow{2}{*}{$\begin{array}{c}\text { Air Pathway } \\
\text { (Ci) }\end{array}$} & \multirow{2}{*}{$\begin{array}{c}\text { Radon Pathway } \\
\text { (Ci) }\end{array}$} \\
\hline & $0-12 \mathrm{yrs}$ & $12-100 \mathrm{yrs}$ & $100-1130 \mathrm{yrs}$ & $0-1000 \mathrm{yrs}$ & $1000-1120 \mathrm{yrs}$ & $1120-1130 \mathrm{yrs}$ & $0-1000 \mathrm{yrs}$ & $1000-1120 \mathrm{yrs}$ & $1120-1130 \mathrm{yrs}$ & & $130-200 \mathrm{yrs}$ & 200-1000 yr: & $1000-1130 \mathrm{yrs}$ & Resident & Post-drilling & & \\
\hline Nb-94 & $8.6 \mathrm{E}-02$ & \begin{tabular}{|l|}
$8.9 \mathrm{E}-02$ \\
\end{tabular} & $3.6 \mathrm{E}+00$ & --- & \begin{tabular}{|c|}
--- \\
\end{tabular} & \begin{tabular}{|c|}
--- \\
\end{tabular} & --- & \begin{tabular}{|c|}
--- \\
\end{tabular} & \begin{tabular}{|c|}
--- \\
\end{tabular} & \begin{tabular}{|c|}
-- \\
\end{tabular} & $2.3 \mathrm{E}+00$ & $2.3 \mathrm{E}+00$ & $2.3 \mathrm{E}+00$ & $9.6 \mathrm{E}+00$ & \begin{tabular}{|l|}
$2.7 \mathrm{E}+03$ \\
\end{tabular} & \begin{tabular}{|c|}
--- \\
\end{tabular} & \begin{tabular}{|c|}
--- \\
\end{tabular} \\
\hline $\mathrm{Ni}-59$ & $5.8 \mathrm{E}+17$ & $2.3 \mathrm{E}+09$ & $3.2 \mathrm{E}+00$ & 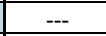 & - & - & - & $-\ldots$ & --- & - & $1.2 \mathrm{E}+05$ & $1.7 \mathrm{E}+03$ & $8.3 \mathrm{E}+02$ & --- & $4.2 \mathrm{E}+05$ & - & -- \\
\hline $\mathrm{Ni}-63$ & --- & --- & --- & -- & - & -- & -- & -- & -- & - & --- & --- & --- & --- & $3.0 \mathrm{E}+05$ & --- & --- \\
\hline Np-237 & $6.3 \mathrm{E}+02$ & $3.2 \mathrm{E}+00$ & $1.6 \mathrm{E}+00$ & $8.4 \mathrm{E}-02$ & $1.6 \mathrm{E}-01$ & 3.7E-01 & -- & --- & -- & $2.6 \mathrm{E}+08$ & $2.6 \mathrm{E}-02$ & $2.6 \mathrm{E}-02$ & $4.9 \mathrm{E}-02$ & $1.7 \mathrm{E}+02$ & $1.1 \mathrm{E}+02$ & -- & -- \\
\hline $\mathrm{Pa}-231$ & --- & --- & --- & --- & --- & --- & --- & --- & --- & --- & --- & --- & --- & $8.1 \mathrm{E}+01$ & $1.2 \mathrm{E}+02$ & --- & -- \\
\hline $\mathrm{Pb}-210$ & -- & -- & --- & -- & -- & -- & -- & -- & -- & -- & --- & -- & -- & $1.4 \mathrm{E}+11$ & $2.2 \mathrm{E}+03$ & --- & --- \\
\hline Pd-107 & -- & $2.8 \mathrm{E}+11$ & $3.9 \mathrm{E}+02$ & --- & --- & --- & --- & --- & --- & --- & $1.9 \mathrm{E}+05$ & $2.6 \mathrm{E}+03$ & $1.3 \mathrm{E}+03$ & --- & $8.7 \mathrm{E}+05$ & - & --- \\
\hline Pu-238 & --- & --- & $8.7 \mathrm{E}+06$ & $3.1 \mathrm{E}+05$ & $1.0 \mathrm{E}+05$ & $9.7 \mathrm{E}+04$ & $3.2 \mathrm{E}+05$ & $1.0 \mathrm{E}+05$ & $9.7 \mathrm{E}+04$ & $6.4 \mathrm{E}+15$ & $4.4 \mathrm{E}+08$ & $9.3 \mathrm{E}+05$ & $2.9 \mathrm{E}+05$ & $1.3 \mathrm{E}+07$ & $3.6 \mathrm{E}+03$ & -- & $7.7 \mathrm{E}+12$ \\
\hline $\begin{array}{l}\mathrm{Pu}-239 \\
\end{array}$ & $2.1 \mathrm{E}+17$ & $6.1 \mathrm{E}+12$ & $1.0 \mathrm{E}+07$ & $5.5 \mathrm{E}+06$ & $1.5 \mathrm{E}+06$ & $1.3 \mathrm{E}+06$ & --- & $-\cdots$ & --- & $1.9 \mathrm{E}+14$ & $4.1 \mathrm{E}+07$ & $9.7 \mathrm{E}+05$ & $3.9 \mathrm{E}+05$ & $3.8 \mathrm{E}+06$ & $1.5 \mathrm{E}+03$ & $-\ldots$ & --- \\
\hline Pu-240 & --- & --- & $4.3 \mathrm{E}+14$ & $1.4 \mathrm{E}+07$ & $2.0 \mathrm{E}+06$ & $1.7 \mathrm{E}+06$ & $7.8 \mathrm{E}+14$ & $6.0 \mathrm{E}+14$ & $5.8 \mathrm{E}+14$ & $2.1 \mathrm{E}+14$ & $1.6 \mathrm{E}+17$ & $5.4 \mathrm{E}+06$ & $6.6 \mathrm{E}+05$ & $1.2 \mathrm{E}+09$ & $1.5 \mathrm{E}+03$ & -- & -- \\
\hline $\begin{array}{l}\text { Pu-241 } \\
\end{array}$ & $3.2 \mathrm{E}+11$ & $2.1 \mathrm{E}+08$ & $3.2 \mathrm{E}+05$ & $1.9 \mathrm{E}+03$ & $1.3 \mathrm{E}+03$ & $1.2 \mathrm{E}+03$ & --- & --- & --- & $4.9 \mathrm{E}+13$ & $2.0 \mathrm{E}+04$ & $7.0 \mathrm{E}+02$ & $4.5 \mathrm{E}+02$ & $1.9 \mathrm{E}+07$ & $4.1 \mathrm{E}+04$ & --- & --- \\
\hline Pu-242 & --- & --- & $8.7 \mathrm{E}+13$ & $1.3 \mathrm{E}+07$ & $1.7 \mathrm{E}+06$ & $1.5 \mathrm{E}+06$ & $3.2 \mathrm{E}+12$ & $1.0 \mathrm{E}+12$ & $9.4 \mathrm{E}+11$ & $1.9 \mathrm{E}+14$ & $6.1 \mathrm{E}+16$ & $5.1 \mathrm{E}+06$ & $6.2 \mathrm{E}+05$ & $6.9 \mathrm{E}+08$ & $1.5 \mathrm{E}+03$ & --. & --- \\
\hline $\begin{array}{l}\mathrm{Pu}-244 \\
\end{array}$ & --- & --- & $1.3 \mathrm{E}+08$ & $1.1 \mathrm{E}+07$ & $1.5 \mathrm{E}+06$ & $1.4 \mathrm{E}+06$ & $3.2 \mathrm{E}+16$ & $2.3 \mathrm{E}+16$ & $2.2 \mathrm{E}+16$ & $1.7 \mathrm{E}+15$ & $3.2 \mathrm{E}+19$ & $4.7 \mathrm{E}+06$ & $5.6 \mathrm{E}+05$ & $4.4 \mathrm{E}+01$ & $1.3 \mathrm{E}+03$ & --. & --- \\
\hline Ra-226 & $4.2 \mathrm{E}+15$ & $1.9 \mathrm{E}+07$ & $2.9 \mathrm{E}+00$ & $5.5 \mathrm{E}-02$ & $3.7 \mathrm{E}-02$ & $3.8 \mathrm{E}-02$ & $5.5 \mathrm{E}-02$ & $3.7 \mathrm{E}-02$ & $3.8 \mathrm{E}-02$ & --- & $1.3 \mathrm{E}+00$ & $1.6 \mathrm{E}-01$ & $1.1 \mathrm{E}-01$ & $9.1 \mathrm{E}+00$ & $7.1 \mathrm{E}+01$ & -- & $2.2 \mathrm{E}+04$ \\
\hline Ra-228 & --- & --- & --- & --- & --- & --- & --- & --- & --- & -- & --- & --- & --- & $1.3 \mathrm{E}+08$ & $2.5 \mathrm{E}+07$ & --. & --- \\
\hline Rb-87 & --- & -- & -- & -- & -- & -- & -- & -- & -- & -- & -- & -- & -- & --- & $1.5 \mathrm{E}+04$ & --. & --- \\
\hline S-35 & --- & -- & -- & -- & -- & -- & -- & -- & -- & -- & -- & -- & -- & --- & --- & --- & -- \\
\hline Sb-125 & -- & -- & -- & -- & -- & -- & -- & -- & -- & -- & -- & -- & -- & $5.0 \mathrm{E}+16$ & $7.4 \mathrm{E}+14$ & --. & --- \\
\hline $\begin{array}{l}\text { Sc-46 } \\
\end{array}$ & --- & -- & -- & -- & -- & -- & -- & -- & -- & -- & -- & -- & --- & --- & --- & --- & --- \\
\hline Se-79 & --- & -- & $4.2 \mathrm{E}+17$ & --- & -- & -- & --- & --- & -- & -- & --- & $5.9 \mathrm{E}+18$ & $4.4 \mathrm{E}+17$ & --- & $2.4 \mathrm{E}+04$ & --- & --- \\
\hline Sm-151 & --- & --- & --- & --- & --- & --- & --- & --- & --- & --- & --- & --- & --- & --- & $5.9 \mathrm{E}+06$ & --- & --- \\
\hline Sn- $121 \mathrm{~m}$ & -- & -- & -- & -- & -- & -- & -- & -- & -- & -- & -- & -- & -- & --- & $1.6 \mathrm{E}+06$ & --- & --- \\
\hline Sn-126 & --- & --- & --- & -- & -- & -- & -- & -- & -- & -- & --- & --- & --- & $8.7 \mathrm{E}+00$ & $2.1 \mathrm{E}+03$ & -- & -- \\
\hline Sr-90 & $1.7 \mathrm{E}+13$ & $1.4 \mathrm{E}+06$ & $3.7 \mathrm{E}+01$ & --- & --- & -- & -- & --- & -- & -- & $1.4 \mathrm{E}+03$ & $7.1 \mathrm{E}+02$ & $2.0 \mathrm{E}+10$ & --- & $1.6 \mathrm{E}+03$ & --- & -- \\
\hline Tc-99 & \begin{tabular}{|l|}
$1.4 \mathrm{E}-01$ \\
\end{tabular} & $1.3 \mathrm{E}-01$ & $4.5 \mathrm{E}+00$ & 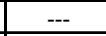 & --- & --- & --- & $-\cdots$ & --. & --- & $8.5 \mathrm{E}+00$ & $8.5 \mathrm{E}+00$ & $8.5 \mathrm{E}+00$ & $1.0 \mathrm{E}+09$ & $2.4 \mathrm{E}+03$ & --- & -- \\
\hline Th-228 & --- & -- & --- & -- & -- & -- & -- & -- & -- & -- & --- & -- & -- & $6.6 \mathrm{E}+18$ & $3.4 \mathrm{E}+18$ & --- & --- \\
\hline Th-229 & --- & --- & --- & --- & --- & --- & --- & --- & --- & --- & --- & --- & -- & $9.0 \mathrm{E}+01$ & $5.0 \mathrm{E}+02$ & --- & --- \\
\hline Th-230 & $6.5 \mathrm{E}+18$ & $1.5 \mathrm{E}+10$ & $7.9 \mathrm{E}+00$ & $2.6 \mathrm{E}-01$ & $9.7 \mathrm{E}-02$ & $9.5 \mathrm{E}-02$ & $2.6 \mathrm{E}-01$ & $9.7 \mathrm{E}-02$ & $9.5 \mathrm{E}-02$ & --. & $2.9 \mathrm{E}+01$ & $7.5 \mathrm{E}-01$ & $2.8 \mathrm{E}-01$ & $1.9 \mathrm{E}+01$ & $1.9 \mathrm{E}+02$ & $-\cdots$ & $4.2 \mathrm{E}+05$ \\
\hline Th-232 & $9.3 \mathrm{E}+14$ & $5.8 \mathrm{E}+08$ & $5.1 \mathrm{E}+02$ & $5.2 \mathrm{E}+02$ & $1.3 \mathrm{E}+03$ & $1.5 \mathrm{E}+03$ & $6.8 \mathrm{E}+02$ & $1.6 \mathrm{E}+03$ & $2.1 \mathrm{E}+03$ & --- & $2.2 \mathrm{E}+03$ & $1.4 \mathrm{E}+03$ & $3.2 \mathrm{E}+03$ & $4.4 \mathrm{E}+00$ & $1.5 \mathrm{E}+02$ & -- & --- \\
\hline U-232 & --- & --- & --- & -- & --- & --- & --- & --- & --- & --- & --- & --- & --- & $3.2 \mathrm{E}+03$ & $9.4 \mathrm{E}+02$ & --- & -- \\
\hline U-233 & - & --- & $1.9 \mathrm{E}+10$ & $3.9 \mathrm{E}+10$ & $4.6 \mathrm{E}+09$ & $3.9 \mathrm{E}+09$ & --- & --- & --- & $6.7 \mathrm{E}+11$ & -.- & $1.4 \mathrm{E}+09$ & $1.6 \mathrm{E}+08$ & $9.3 \mathrm{E}+02$ & $2.2 \mathrm{E}+03$ & --- & --- \\
\hline U-234 & --- & $5.5 \mathrm{E}+14$ & $2.3 \mathrm{E}+03$ & $8.0 \mathrm{E}+01$ & $2.7 \mathrm{E}+01$ & $2.6 \mathrm{E}+01$ & $8.0 \mathrm{E}+01$ & $2.8 \mathrm{E}+01$ & $2.6 \mathrm{E}+01$ & $1.6 \mathrm{E}+12$ & $4.5 \mathrm{E}+04$ & $2.3 \mathrm{E}+02$ & $7.5 \mathrm{E}+01$ & $3.8 \mathrm{E}+03$ & $3.4 \mathrm{E}+03$ & -- & $7.2 \mathrm{E}+08$ \\
\hline U-235 & $3.8 \mathrm{E}+08$ & $2.7 \mathrm{E}+04$ & $6.0 \mathrm{E}+00$ & $4.6 \mathrm{E}+00$ & $4.9 \mathrm{E}+00$ & $5.8 \mathrm{E}+00$ & --- & --- & --- & $5.6 \mathrm{E}+08$ & $3.0 \mathrm{E}+00$ & $5.7 \mathrm{E}-01$ & $6.1 \mathrm{E}-01$ & $5.0 \mathrm{E}+02$ & $2.2 \mathrm{E}+03$ & --- & --- \\
\hline U-236 & --- & $3.5 \mathrm{E}+18$ & $4.4 \mathrm{E}+09$ & $5.8 \mathrm{E}+09$ & $4.6 \mathrm{E}+09$ & $4.4 \mathrm{E}+09$ & $7.8 \mathrm{E}+09$ & $6.1 \mathrm{E}+09$ & $5.9 \mathrm{E}+09$ & $1.6 \mathrm{E}+10$ & $3.2 \mathrm{E}+11$ & $5.2 \mathrm{E}+09$ & $6.1 \mathrm{E}+08$ & $2.8 \mathrm{E}+07$ & $3.9 \mathrm{E}+03$ & --- & --- \\
\hline U-238 & --- & --- & $2.9 \mathrm{E}+06$ & $1.1 \mathrm{E}+05$ & $3.5 \mathrm{E}+04$ & $3.2 \mathrm{E}+04$ & $1.1 \mathrm{E}+05$ & $3.5 \mathrm{E}+04$ & $3.2 \mathrm{E}+04$ & $8.7 \mathrm{E}+07$ & $3.4 \mathrm{E}+08$ & $3.1 \mathrm{E}+05$ & $9.4 \mathrm{E}+04$ & $9.7 \mathrm{E}+02$ & $4.0 \mathrm{E}+03$ & -- & $6.1 \mathrm{E}+12$ \\
\hline W-181 & --- & -- & --- & -- & --- & -- & -- & --- & --- & -- & --- & -- & --- & --- & --- & -- & --- \\
\hline $\begin{array}{ll}\mathrm{Zr}-93 \\
\end{array}$ & $1.3 \mathrm{E}+00$ & $6.5 \mathrm{E}-01$ & $7.7 \mathrm{E}-01$ & -.- & $-\cdots$ & $-\cdots$ & $-\ldots$ & $\ldots$ & $-\ldots$ & $-\cdots$ & $8.2 \mathrm{E}+00$ & $5.0 \mathrm{E}+00$ & $4.5 \mathrm{E}+00$ & --- & $9.5 \mathrm{E}+05$ & $-\ldots$ & - \\
\hline
\end{tabular}

a Most limiting pathway for each parent nuclide is shown shaded in blue.

b Only 74 out of possible 78 parent nuclides listed (i.e., Bk-249, Ca-41, W-185, and W-188 omitted because no prior historical inventories are available). 
SRNL-STI-2013-00393, REV . 0

\subsection{STOCHASTIC ANALYSIS}

In this chapter a stochastic analysis approach is presented to demonstrate that overall performance measures will not be exceeded, with a high degree of confidence, by employing the current ST\#12 inventory limits in lieu of ET\#3-specific limits. To arrive at this statistically based conclusion, historical inventory distributions were employed. The probability of exceeding a SOF of unity was estimated to be $0.02 \%(0.05 \%$ for $\mathrm{SOF}>0.95)$ based on looking at all nine pathways. The specific details in computing this probability are presented in this section.

As described in earlier chapters of this UDQE, new ET\#3 inventory limits were created using a new transport analysis performed for ET\#3 for seven out of the $38 \mathrm{GW}$ parent nuclides considered in the 2008 PA and likely to be buried in ET\#3 in the future. The seven selected parent nuclides were based on prior knowledge of those parents whose SOF contributions exceeded 1\% (Sink, 2013). The remaining 31 parent nuclide inventory limits were created by using the available transport analyses performed for SLITw in the 2008 PA and then adjusted specifically to apply to ST\#12 in the 2012 IM assessment as described in Chapter 5. The same plume interaction factor for ET\#3 is employed for all 38 parent nuclides.

The Intruder pathway yielded 74 parent nuclides which included the 38 groundwater parent nuclides. New ET\#3 Intruder limits were calculated using the Inadvertent Intruder application employed in the $2008 \mathrm{PA}$ as described in Chapter 7. All these parent nuclides were evaluated in the stochastic analysis.

\subsection{Stochastic Approach}

In the Introduction chapter we saw that our current methodology of setting inventory limits deterministically for each individual parent nuclide would require establishing new ET\#3 limits for some parent nuclides. However, when we factor in the likelihood of final inventory distributions for the ET\#3 disposal unit we will see that the expected range of final SOFs are significantly below the threshold value of one. The following outlines a stochastic approach where historical inventory distributions are taken into account directly. Also all nine pathways are employed.

The basic stochastic approach taken here is the following:

1. Randomly pick a final inventory composition from historical trench inventories for the 74 parent nuclides.

2. From this inventory composition (represented as $\mathrm{Ci}$ fractions), compute the total inventory that yields a SOF of unity based on the current ST\#12 inventory limits in Table 7-4.

3. Given the individual inventories from the first two steps, compute the SOF based on the new estimated ET\#3 inventory limits in Table 7-3.

The above three-step process is applied a large number of times (i.e., 10,000 trials performed) and statistically relates to a "Monte Carlo" like process. The key stochastic aspect here is in the choice of each new inventory composition. Based on historical inventory distributions log-normal probability density functions are used where the random 
number generator within Excel is employed (i.e., actually their cumulative density functions [cdf's] are directly employed). The selected inventory composition is assumed to be made up of random distribution fractions that are independent of each other.

A summary of historical parent nuclide inventories is listed in Table 8-1 extracted from Sink (2012). Even though Sink (2012) contains inventories for most of the entire ELLWF disposal units, only the ET and ST units were considered appropriate here. The table entries represent the total for the category shown (e.g., the Engineered Trench column is the sum total inventory of both ET\#1 and ET\#2). The inventories were provided as activities in units of curies. Only the inventories of the 74 out of the 78 parent nuclides are listed in Table 8-1 (i.e., four have no prior historical inventories).

Table 8-1 Historical inventories for the $\mathbf{7 4}$ parent nuclides considered for $\mathbf{E T \# 3 .}$

\begin{tabular}{|c|c|c|c|c|}
\hline $\begin{array}{c}\text { ET\#3 } \\
\text { Radionuclide }\end{array}$ & $\begin{array}{l}\text { Engineered Trench } \\
\text { (ET\#1 and ET\#2) (Ci) }\end{array}$ & $\begin{array}{l}\text { Center Slit Trenches } \\
\text { (SLIT1-SLIT7) (Ci) }\end{array}$ & $\begin{array}{l}\text { West Slit Trenches } \\
\text { (SLIT8 - SLIT13) (Ci) }\end{array}$ & $\begin{array}{l}\text { East Slit Trenches } \\
\text { (SLIT14 - SLIT23) (Ci) }\end{array}$ \\
\hline AC227 & $0.00 \mathrm{E}+00$ & $2.51 \mathrm{E}-04$ & $0.00 \mathrm{E}+00$ & $1.40 \mathrm{E}-10$ \\
\hline AG108M & $1.84 \mathrm{E}-07$ & $5.63 \mathrm{E}-05$ & $0.00 \mathrm{E}+00$ & $3.29 \mathrm{E}+00$ \\
\hline AL26 & $4.97 \mathrm{E}-11$ & $0.00 \mathrm{E}+00$ & $0.00 \mathrm{E}+00$ & $0.00 \mathrm{E}+00$ \\
\hline AM241 & $1.73 \mathrm{E}+00$ & $2.81 \mathrm{E}+00$ & $1.11 \mathrm{E}+00$ & $1.47 \mathrm{E}-01$ \\
\hline AM242M & $1.91 \mathrm{E}-01$ & $4.46 \mathrm{E}-01$ & $3.57 \mathrm{E}-01$ & $2.71 \mathrm{E}-08$ \\
\hline AM243 & $3.02 \mathrm{E}-02$ & $1.70 \mathrm{E}-01$ & $4.25 \mathrm{E}-02$ & $1.07 \mathrm{E}-06$ \\
\hline AR39 & $0.00 \mathrm{E}+00$ & $1.07 \mathrm{E}-18$ & $0.00 \mathrm{E}+00$ & $5.78 \mathrm{E}-14$ \\
\hline BA133 & $2.83 \mathrm{E}-05$ & $5.37 \mathrm{E}-05$ & $0.00 \mathrm{E}+00$ & $1.89 \mathrm{E}-13$ \\
\hline BI207 & $7.82 \mathrm{E}-06$ & $0.00 \mathrm{E}+00$ & $0.00 \mathrm{E}+00$ & $0.00 \mathrm{E}+00$ \\
\hline BK249 & $0.00 \mathrm{E}+00$ & $0.00 \mathrm{E}+00$ & $0.00 \mathrm{E}+00$ & $0.00 \mathrm{E}+00$ \\
\hline $\mathrm{C} 14$ & $1.66 \mathrm{E}-01$ & $1.78 \mathrm{E}-01$ & $2.07 \mathrm{E}-02$ & $1.45 \mathrm{E}-02$ \\
\hline CA41 & $0.00 \mathrm{E}+00$ & $0.00 \mathrm{E}+00$ & $0.00 \mathrm{E}+00$ & $0.00 \mathrm{E}+00$ \\
\hline CD113M & $9.44 \mathrm{E}-12$ & $3.60 \mathrm{E}-06$ & $8.56 \mathrm{E}-08$ & $1.60 \mathrm{E}-01$ \\
\hline CF249 & $4.32 \mathrm{E}-02$ & $9.68 \mathrm{E}-02$ & $8.42 \mathrm{E}-02$ & $6.58 \mathrm{E}-15$ \\
\hline CF250 & $1.40 \mathrm{E}-04$ & $1.65 \mathrm{E}-01$ & $8.11 \mathrm{E}-03$ & $0.00 \mathrm{E}+00$ \\
\hline CF251 & $3.93 \mathrm{E}-02$ & $8.87 \mathrm{E}-02$ & $7.66 \mathrm{E}-02$ & $2.64 \mathrm{E}-16$ \\
\hline CF252 & $5.64 \mathrm{E}-03$ & $2.32 \mathrm{E}-02$ & $1.13 \mathrm{E}-03$ & $0.00 \mathrm{E}+00$ \\
\hline CL36 & $7.00 \mathrm{E}-05$ & $1.49 \mathrm{E}-05$ & $2.02 \mathrm{E}-06$ & $9.07 \mathrm{E}-08$ \\
\hline CM242 & $5.78 \mathrm{E}-05$ & $3.91 \mathrm{E}-04$ & $1.07 \mathrm{E}-05$ & $3.94 \mathrm{E}-05$ \\
\hline CM243 & $8.42 \mathrm{E}-04$ & 7.22E-03 & $1.67 \mathrm{E}-03$ & $2.00 \mathrm{E}-06$ \\
\hline CM244 & $2.83 \mathrm{E}+00$ & $5.76 \mathrm{E}+00$ & $3.01 \mathrm{E}+00$ & $5.74 \mathrm{E}-06$ \\
\hline CM245 & $1.04 \mathrm{E}-03$ & $2.22 \mathrm{E}-03$ & $1.47 \mathrm{E}-03$ & $2.15 \mathrm{E}-06$ \\
\hline CM246 & $6.56 \mathrm{E}-04$ & $1.68 \mathrm{E}-03$ & $2.76 \mathrm{E}-05$ & $2.15 \mathrm{E}-06$ \\
\hline CM247 & $4.23 \mathrm{E}-04$ & $2.27 \mathrm{E}-03$ & $3.18 \mathrm{E}-03$ & $3.96 \mathrm{E}-16$ \\
\hline CM248 & $1.19 \mathrm{E}-14$ & 8.84E-04 & $2.35 \mathrm{E}-05$ & $1.25 \mathrm{E}-15$ \\
\hline CO60 & $1.25 \mathrm{E}+01$ & $1.27 \mathrm{E}+05$ & $7.48 \mathrm{E}-01$ & $2.01 \mathrm{E}+02$ \\
\hline CS134 & $1.88 \mathrm{E}-01$ & $2.98 \mathrm{E}-01$ & 4.04E-03 & $2.23 \mathrm{E}-04$ \\
\hline CS135 & $1.43 \mathrm{E}-11$ & $1.30 \mathrm{E}-07$ & $0.00 \mathrm{E}+00$ & $6.09 \mathrm{E}-08$ \\
\hline CS137 & $8.49 \mathrm{E}+01$ & $1.67 \mathrm{E}+02$ & $6.04 \mathrm{E}+01$ & $2.33 \mathrm{E}+01$ \\
\hline EU152 & $6.82 \mathrm{E}+00$ & $2.39 \mathrm{E}-01$ & $1.50 \mathrm{E}-02$ & $1.75 \mathrm{E}-03$ \\
\hline EU154 & $2.82 \mathrm{E}+00$ & $2.95 \mathrm{E}+01$ & $2.42 \mathrm{E}+00$ & 5.79E-06 \\
\hline EU155 & $9.00 \mathrm{E}-02$ & $4.19 \mathrm{E}+00$ & $2.06 \mathrm{E}-01$ & $3.38 \mathrm{E}-06$ \\
\hline H3 & $2.59 \mathrm{E}+00$ & $1.23 \mathrm{E}+01$ & $3.92 \mathrm{E}-01$ & $2.49 \mathrm{E}-02$ \\
\hline
\end{tabular}


SRNL-STI-2013-00393, REV. 0

\begin{tabular}{|c|c|c|c|c|}
\hline $\begin{array}{c}\text { ET\#3 } \\
\text { Radionuclide }\end{array}$ & $\begin{array}{l}\text { Engineered Trench } \\
\text { (ET\#1 and ET\#2) (Ci) }\end{array}$ & $\begin{array}{l}\text { Center Slit Trenches } \\
\text { (SLIT1-SLIT7) (Ci) }\end{array}$ & $\begin{array}{l}\text { West Slit Trenches } \\
\text { (SLIT8 - SLIT13) (Ci) }\end{array}$ & $\begin{array}{l}\text { East Slit Trenches } \\
\text { (SLIT14 - SLIT23) (Ci) }\end{array}$ \\
\hline I129 & $9.19 \mathrm{E}-05$ & $2.80 \mathrm{E}-04$ & $9.75 \mathrm{E}-05$ & $5.80 \mathrm{E}-06$ \\
\hline $\mathrm{K} 40$ & $1.61 \mathrm{E}-04$ & $4.43 \mathrm{E}-03$ & $6.73 \mathrm{E}-08$ & $8.07 \mathrm{E}-07$ \\
\hline KR85 & $1.99 \mathrm{E}-01$ & $9.73 \mathrm{E}-02$ & 7.00E-03 & $3.25 \mathrm{E}-04$ \\
\hline MO93 & $3.16 \mathrm{E}-03$ & $1.03 \mathrm{E}-03$ & $3.24 \mathrm{E}-03$ & $0.00 \mathrm{E}+00$ \\
\hline NA22 & $5.55 \mathrm{E}-05$ & $3.05 \mathrm{E}-06$ & 4.49E-06 & $2.10 \mathrm{E}-07$ \\
\hline NB93M & $9.79 \mathrm{E}-02$ & $3.66 \mathrm{E}-01$ & $1.34 \mathrm{E}-02$ & $1.94 \mathrm{E}-02$ \\
\hline NB94 & $4.20 \mathrm{E}-03$ & $6.12 \mathrm{E}-03$ & $1.31 \mathrm{E}-04$ & $2.64 \mathrm{E}-04$ \\
\hline NI59 & $1.70 \mathrm{E}-01$ & $2.27 \mathrm{E}-01$ & 4.34E-02 & $4.14 \mathrm{E}-03$ \\
\hline NI63 & $8.30 \mathrm{E}+00$ & $1.32 \mathrm{E}+01$ & $6.72 \mathrm{E}-02$ & $3.94 \mathrm{E}-01$ \\
\hline NP237 & $3.44 \mathrm{E}-02$ & $4.38 \mathrm{E}-02$ & $3.63 \mathrm{E}-03$ & $4.06 \mathrm{E}-03$ \\
\hline PA231 & $0.00 \mathrm{E}+00$ & $2.82 \mathrm{E}-10$ & $0.00 \mathrm{E}+00$ & $2.89 \mathrm{E}-10$ \\
\hline PB210 & $3.61 \mathrm{E}-03$ & $4.02 \mathrm{E}-02$ & $7.45 \mathrm{E}-13$ & $3.21 \mathrm{E}-07$ \\
\hline PD107 & $0.00 \mathrm{E}+00$ & $1.27 \mathrm{E}-07$ & $0.00 \mathrm{E}+00$ & $1.69 \mathrm{E}-08$ \\
\hline PU238 & $8.85 \mathrm{E}+00$ & $6.06 \mathrm{E}+01$ & $7.77 \mathrm{E}+00$ & $2.05 \mathrm{E}+00$ \\
\hline PU239 & $6.04 \mathrm{E}+00$ & $7.12 \mathrm{E}+00$ & $3.06 \mathrm{E}+00$ & $3.06 \mathrm{E}-01$ \\
\hline PU240 & $1.42 \mathrm{E}+00$ & $1.88 \mathrm{E}+00$ & $7.36 \mathrm{E}-01$ & $7.31 \mathrm{E}-02$ \\
\hline PU241 & $2.82 \mathrm{E}+01$ & $4.51 \mathrm{E}+01$ & $1.08 \mathrm{E}+01$ & $1.60 \mathrm{E}+00$ \\
\hline PU242 & $3.90 \mathrm{E}-02$ & $6.69 \mathrm{E}-02$ & $1.26 \mathrm{E}-01$ & $1.04 \mathrm{E}-04$ \\
\hline PU244 & $6.84 \mathrm{E}-10$ & $1.13 \mathrm{E}-09$ & $8.21 \mathrm{E}-17$ & $5.92 \mathrm{E}-16$ \\
\hline RA226 & $4.06 \mathrm{E}-03$ & $3.65 \mathrm{E}-03$ & $4.06 \mathrm{E}-06$ & $3.21 \mathrm{E}-07$ \\
\hline RA228 & $7.49 \mathrm{E}-03$ & $1.35 \mathrm{E}-02$ & $6.41 \mathrm{E}-05$ & $3.79 \mathrm{E}-07$ \\
\hline RB87 & $0.00 \mathrm{E}+00$ & $1.27 \mathrm{E}-11$ & $0.00 \mathrm{E}+00$ & $1.30 \mathrm{E}-11$ \\
\hline S35 & $3.59 \mathrm{E}-21$ & $2.96 \mathrm{E}-03$ & $0.00 \mathrm{E}+00$ & $0.00 \mathrm{E}+00$ \\
\hline SB125 & $1.15 \mathrm{E}-01$ & $1.21 \mathrm{E}+00$ & $2.47 \mathrm{E}-03$ & $1.30 \mathrm{E}-02$ \\
\hline SC46 & $2.29 \mathrm{E}-21$ & $0.00 \mathrm{E}+00$ & $0.00 \mathrm{E}+00$ & $0.00 \mathrm{E}+00$ \\
\hline SE79 & $9.34 \mathrm{E}-03$ & $1.79 \mathrm{E}-02$ & $1.97 \mathrm{E}-05$ & $1.61 \mathrm{E}-06$ \\
\hline SM151 & $2.00 \mathrm{E}-04$ & $2.37 \mathrm{E}+00$ & $1.33 \mathrm{E}-04$ & $4.80 \mathrm{E}-04$ \\
\hline SN121M & $1.72 \mathrm{E}-06$ & 4.27E-07 & $6.94 \mathrm{E}-05$ & $6.58 \mathrm{E}-03$ \\
\hline SN126 & $7.73 \mathrm{E}-05$ & $1.53 \mathrm{E}-03$ & $6.86 \mathrm{E}-07$ & $4.74 \mathrm{E}-05$ \\
\hline SR90 & $7.83 \mathrm{E}+01$ & $1.31 \mathrm{E}+02$ & $8.31 \mathrm{E}+00$ & $1.27 \mathrm{E}+01$ \\
\hline TC99 & $7.73 \mathrm{E}-02$ & $1.90 \mathrm{E}-01$ & $1.75 \mathrm{E}-02$ & $5.47 \mathrm{E}-03$ \\
\hline TH228 & $1.14 \mathrm{E}-01$ & $2.94 \mathrm{E}-02$ & $8.22 \mathrm{E}-04$ & $3.79 \mathrm{E}-07$ \\
\hline TH229 & $2.27 \mathrm{E}-02$ & $3.01 \mathrm{E}-03$ & $1.63 \mathrm{E}-04$ & $4.01 \mathrm{E}-11$ \\
\hline TH230 & $1.04 \mathrm{E}-02$ & $1.26 \mathrm{E}-03$ & $6.41 \mathrm{E}-05$ & $3.33 \mathrm{E}-07$ \\
\hline TH232 & $7.70 \mathrm{E}-03$ & $1.37 \mathrm{E}-02$ & $7.65 \mathrm{E}-05$ & $3.80 \mathrm{E}-07$ \\
\hline U232 & $1.06 \mathrm{E}-01$ & $5.54 \mathrm{E}-02$ & $7.76 \mathrm{E}-04$ & $1.12 \mathrm{E}-07$ \\
\hline U233 & $8.11 \mathrm{E}+00$ & $3.17 \mathrm{E}+00$ & $2.31 \mathrm{E}-01$ & $1.24 \mathrm{E}-04$ \\
\hline U234 & $7.25 \mathrm{E}-01$ & $8.61 \mathrm{E}+00$ & $2.44 \mathrm{E}-01$ & $1.44 \mathrm{E}-03$ \\
\hline U235 & $2.04 \mathrm{E}-02$ & $2.82 \mathrm{E}-01$ & $1.18 \mathrm{E}-02$ & $1.15 \mathrm{E}-04$ \\
\hline U236 & $4.11 \mathrm{E}-02$ & $1.17 \mathrm{E}-01$ & $2.11 \mathrm{E}-03$ & $2.54 \mathrm{E}-07$ \\
\hline U238 & $4.80 \mathrm{E}+00$ & $7.39 \mathrm{E}+00$ & $4.68 \mathrm{E}-01$ & $5.30 \mathrm{E}-04$ \\
\hline W181 & $0.00 \mathrm{E}+00$ & $5.81 \mathrm{E}-08$ & $0.00 \mathrm{E}+00$ & $0.00 \mathrm{E}+00$ \\
\hline W185 & $0.00 \mathrm{E}+00$ & $0.00 \mathrm{E}+00$ & $0.00 \mathrm{E}+00$ & $0.00 \mathrm{E}+00$ \\
\hline W188 & $0.00 \mathrm{E}+00$ & $0.00 \mathrm{E}+00$ & $0.00 \mathrm{E}+00$ & $0.00 \mathrm{E}+00$ \\
\hline ZR93 & $2.46 \mathrm{E}-05$ & $8.63 \mathrm{E}-05$ & $1.74 \mathrm{E}-05$ & 7.44E-05 \\
\hline Total $(\mathrm{Ci})$ & $2.61 \mathrm{E}+02$ & $1.28 \mathrm{E}+05$ & $1.01 \mathrm{E}+02$ & $2.45 \mathrm{E}+02$ \\
\hline
\end{tabular}


To illustrate one example, Np-237 was selected and its distribution is shown in Figure 8-1. From the data in Table 8-1 we have:

- $3.63 \times 10^{-3} \mathrm{Ci}$ (min value)

- $4.38 \times 10^{-2} \mathrm{Ci}$ (max value)

- $2.15 \times 10^{-2} \mathrm{Ci}$ (avg value)

- $1.07 \times 10^{-2} \mathrm{Ci}$ (std deviation value)

These values are also plotted in Figure 8-1 to see how the distribution related to these basic parameter values.

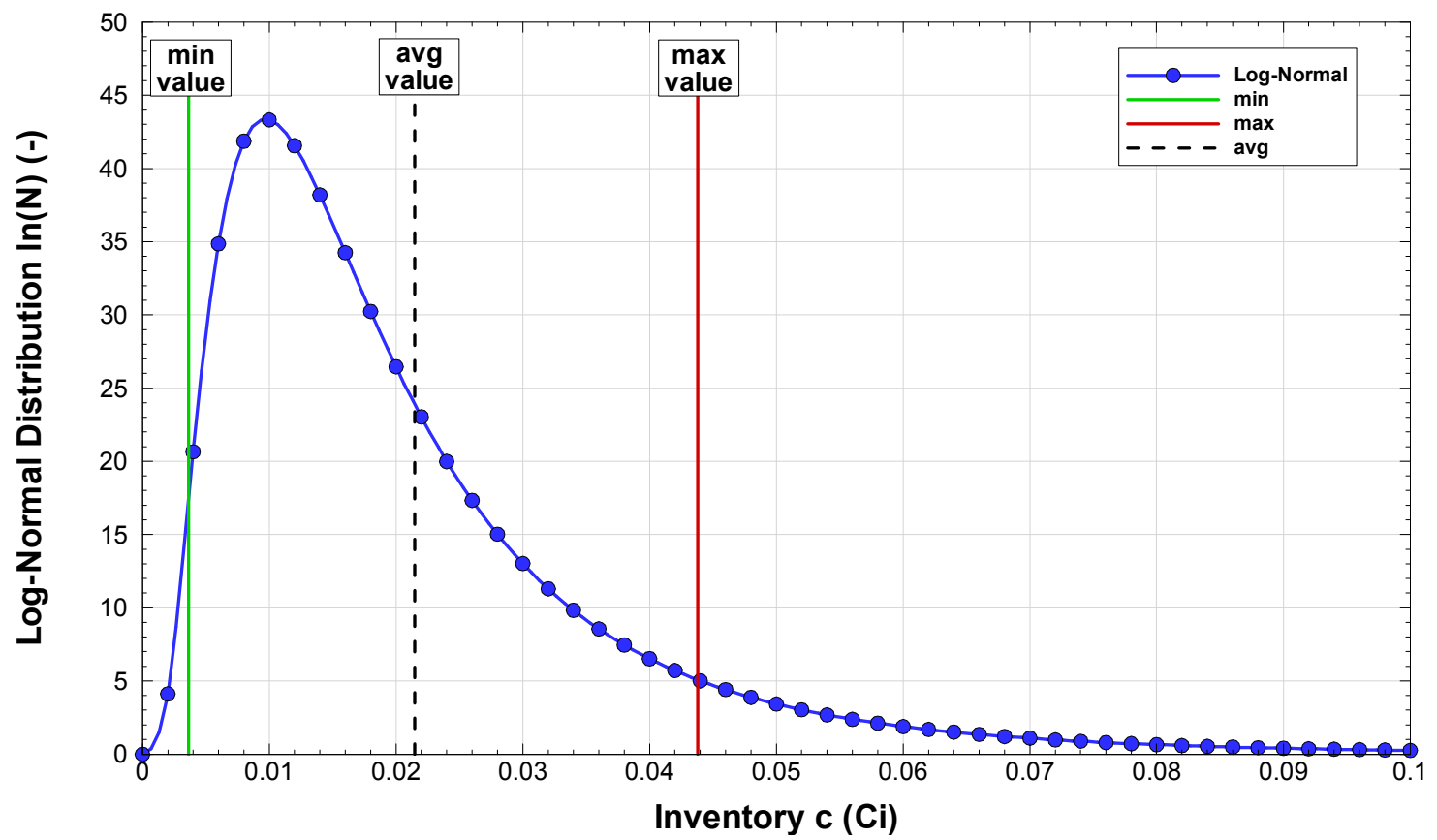

Figure 8-1 Log-normal distribution for $\mathrm{Np-237}$ based on available historical inventory data for ST and ET facilities.

Figure 8-2 shows the cumulative density function associated with this log-normal distribution that was sampled in the 10,000 trials. A random number ranging from zero to one (based on the random number generating function in Excel, $[\mathrm{RAND}()])$ is computed such as the value 0.54 as shown in Figure 8-2. From the cdf for $\mathrm{Np}-237$ a computed inventory value of 0.018 $\mathrm{Ci}$ is determined as shown in Figure 8-2. 
SRNL-STI-2013-00393, REV. 0

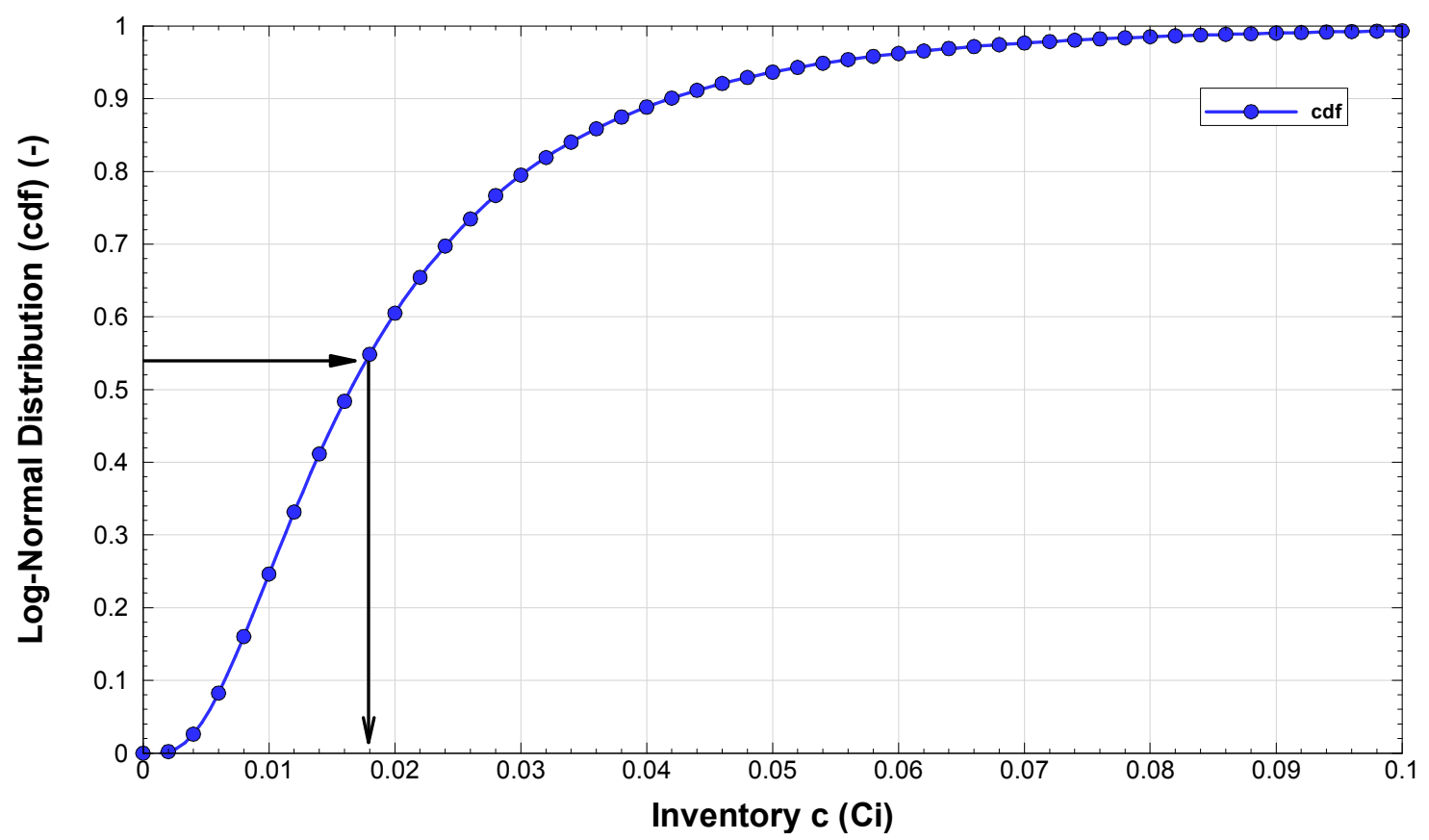

Figure 8-2 cdf for Np-237 based on available historical inventory data for ST and ET facilities (example calculation shown by arrows).

For every randomly generated composition, the SOF based on the new ET\#3 limits is stored for final processing into a histogram. Two options were considered in the calculation of the SOF based on the new ET\#3 limits:

- SOF for each pathway including its individual time windows, and

- SOF for each pathway where the minimum inventory limit from its time windows was employed (i.e., disregarding the time windowing aspect).

Because significant shifts (i.e., time delays) in peak well concentrations were observed for most of the seven selected nuclides analyzed for new ET\#3 limits, time windowing was not considered and method 2 above was chosen for computing max SOFs during the 10,000 trial simulation. The resulting histogram plot is provided in Figure 8-3. Figure 8-3 contains two separate sets of 10,000 trial runs to illustrate the inherent variability of a stochastic process. Both histograms are very similar indicating that 10,000 trials provide adequate statistical resolution. 


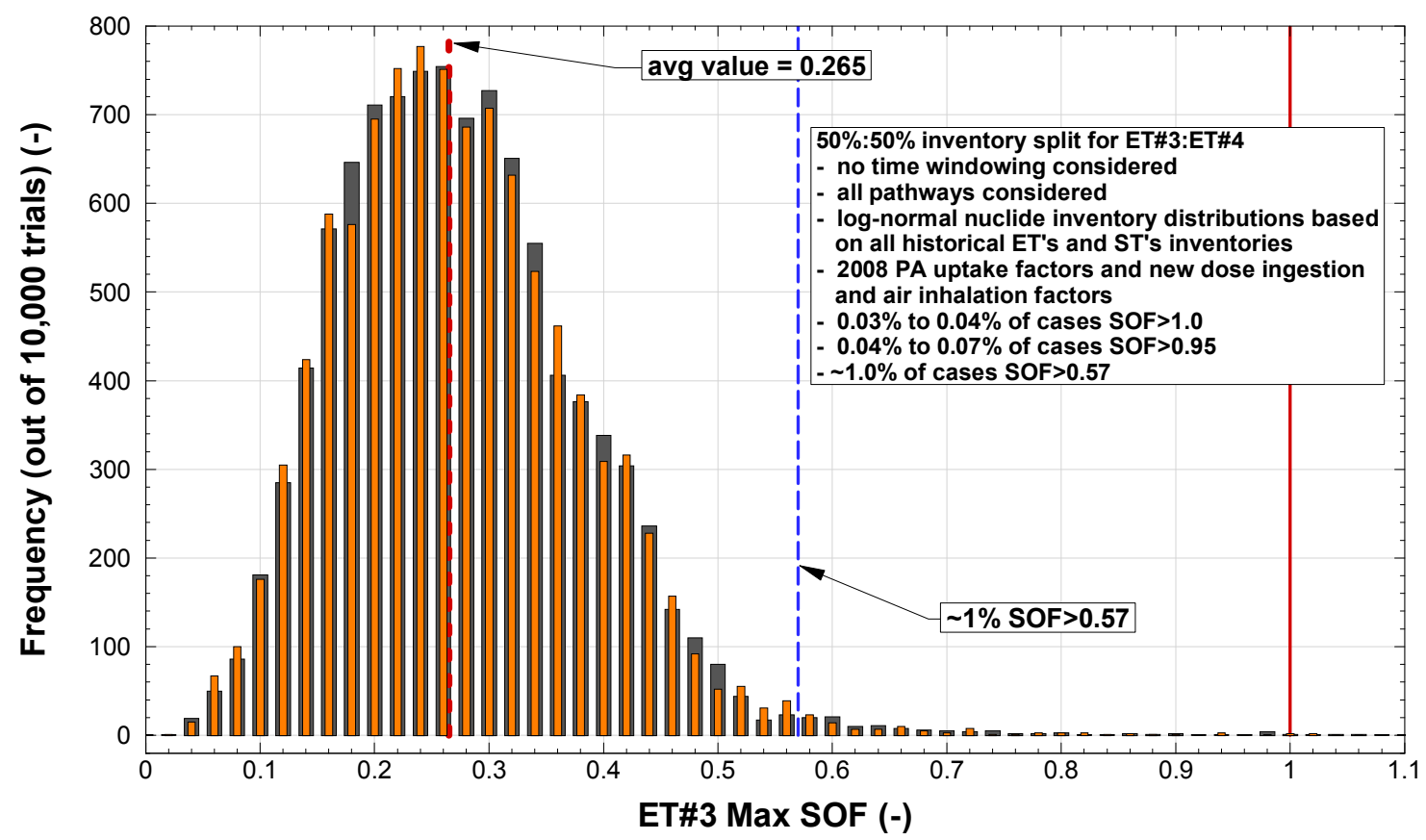

Figure 8-3 Max SOF histogram plot (no time windowing option) based on two 10,000 trial simulations.

Three key confidence levels were extracted from the simulation for estimating the probability of exceeding a given SOF value:

- $0.05 \%$ for $\max \mathrm{SOF}>1.0$

- $0.07 \%$ for $\max \mathrm{SOF}>0.95$

- $\sim 1.0 \%$ for $\max \mathrm{SOF}>0.57$

The various small peaks seen in the histogram plot are not a result of the number of trial runs; instead, they represent dominant shapes associated with certain parent nuclides. For example, the peak near a SOF of $\sim 0.42$ results from $\mathrm{Np}-237$.

The average max SOF during this simulation was $26.5 \%$ which is close to the peak in the distribution as seen in Figure 8-3. This can be interpreted to mean that operating ET\#3 to a SOF of 1.0 using ST\#12 limits will result in a "true" SOF of 0.265 for the average radionuclide compositions from Sink's historical trench inventories (Sink, 2012).

The average SOF value for each parent nuclide is listed in Table 8-2 where they are sorted from largest to smallest SOF value. As Table 8-2 indicates four out of the top six parent nuclides listed are also members of the seven selected nuclides (i.e., shaded in orange) where detailed ET\#3 transport analyses were performed. 
Table 8-2 Average SOF Contribution for each of the 74 parent nuclides during the 10,000 trial simulation sorted from largest to smallest.

\begin{tabular}{|c|c|c|c|}
\hline Nuclide & avg SOF & Nuclide & avg SOF \\
\hline Np-237 & $1.36 \mathrm{E}-01$ & $\mathrm{Cm}-244$ & $2.71 \mathrm{E}-06$ \\
\hline H-3 & $1.21 \mathrm{E}-01$ & U-236 & $2.50 \mathrm{E}-06$ \\
\hline U-234 & $3.45 \mathrm{E}-02$ & Pb-210 & 1.19E-06 \\
\hline Ra-226 & $2.00 \mathrm{E}-02$ & Eu-152 & $8.68 \mathrm{E}-07$ \\
\hline I-129 & 1.99E-02 & $\mathrm{Cm}-245$ & 7.27E-07 \\
\hline Tc-99 & $1.90 \mathrm{E}-02$ & Cd-113m & $2.64 \mathrm{E}-07$ \\
\hline Ag-108m & $1.51 \mathrm{E}-02$ & Eu-154 & $2.59 \mathrm{E}-07$ \\
\hline Ni-59 & 1.31E-02 & Se-79 & $1.85 \mathrm{E}-07$ \\
\hline Th-230 & 1.19E-02 & $\mathrm{Cm}-248$ & 4.55E-08 \\
\hline Nb-94 & $1.18 \mathrm{E}-02$ & Sm-151 & 4.27E-08 \\
\hline U-235 & 9.99E-03 & $\mathrm{Cm}-246$ & $3.25 \mathrm{E}-08$ \\
\hline Sr-90 & 9.06E-03 & Cf-250 & $2.34 \mathrm{E}-08$ \\
\hline C-14 & 6.23E-03 & $\mathrm{Cm}-243$ & $1.11 \mathrm{E}-08$ \\
\hline K-40 & $2.96 \mathrm{E}-03$ & Ac-227 & $4.89 \mathrm{E}-09$ \\
\hline$U-238$ & $1.67 \mathrm{E}-03$ & Sn-121m & $4.14 \mathrm{E}-10$ \\
\hline$U-233$ & 1.57E-03 & $\mathrm{Nb}-93 \mathrm{~m}$ & $4.04 \mathrm{E}-10$ \\
\hline Cs-137 & 1.13E-03 & Ra-228 & $2.07 \mathrm{E}-10$ \\
\hline Am-241 & $1.06 \mathrm{E}-03$ & Bi-207 & $1.08 \mathrm{E}-10$ \\
\hline Mo-93 & 7.79E-04 & Pd-107 & $6.91 \mathrm{E}-11$ \\
\hline Th-232 & 6.19E-04 & $\mathrm{Kr}-85$ & $2.09 \mathrm{E}-11$ \\
\hline Pu-238 & 5.60E-04 & $\mathrm{Cm}-242$ & $1.78 \mathrm{E}-11$ \\
\hline Pu-241 & $5.08 \mathrm{E}-04$ & Cf-252 & $1.49 \mathrm{E}-11$ \\
\hline Pu-239 & $2.81 \mathrm{E}-04$ & Al-26 & $6.53 \mathrm{E}-12$ \\
\hline $\mathrm{Cl}-36$ & $1.08 \mathrm{E}-04$ & Pu-244 & $5.34 \mathrm{E}-12$ \\
\hline Am-243 & $7.78 \mathrm{E}-05$ & Pa-231 & $1.80 \mathrm{E}-12$ \\
\hline Cf-249 & 7.76E-05 & Eu-155 & $1.57 \mathrm{E}-12$ \\
\hline Pu-240 & $6.93 \mathrm{E}-05$ & Ba-133 & $1.29 \mathrm{E}-12$ \\
\hline Th-229 & $3.78 \mathrm{E}-05$ & Cs-135 & $1.19 \mathrm{E}-12$ \\
\hline Zr-93 & 2.97E-05 & Rb-87 & $4.23 \mathrm{E}-16$ \\
\hline Sn-126 & $2.42 \mathrm{E}-05$ & Sb-125 & $1.69 \mathrm{E}-16$ \\
\hline Cf-251 & $1.92 \mathrm{E}-05$ & Cs-134 & $7.86 \mathrm{E}-20$ \\
\hline U-232 & $1.62 \mathrm{E}-05$ & $\mathrm{Na}-22$ & 8.90E-21 \\
\hline Am-242m & $1.52 \mathrm{E}-05$ & Th-228 & $4.03 E-21$ \\
\hline Co-60 & $1.22 \mathrm{E}-05$ & Ar-39 & $2.65 \mathrm{E}-22$ \\
\hline $\mathrm{Cm}-247$ & 9.63E-06 & $S-35$ & $0.00 \mathrm{E}+00$ \\
\hline $\mathrm{Ni}-63$ & 7.59E-06 & Sc-46 & $0.00 \mathrm{E}+00$ \\
\hline Pu-242 & $3.67 \mathrm{E}-06$ & W-181 & $0.00 E+00$ \\
\hline
\end{tabular}




\subsection{EVALUATION}

1.a. Is the proposed activity or new information outside the bounds of the approved PA/CA (e.g., does the proposed activity or new information involve a change to the basic disposal concept as described in the PA/CA such as critical inputs/assumptions or an increase in inventory analyzed in the $\mathrm{CA})$ ?

No. The proposed activity is to use the existing ST\#12 limits currently in the ELLWF limits database as inventory limits for the new ET\#3. This will only be allowed if the facility can operate under these limits and still meet DOE 435.1 LLW disposal performance measures

and objectives. The analysis supporting this UDQE demonstrates with a high degree of confidence that this is the case. Thus the proposed activity is within the bounds of the approved $P A / C A$.

1.b. Would the proposed activity if implemented, or does the new information, result in the $\mathrm{PA} / \mathrm{CA}$ performance measures being exceeded?

No. The results from the stochastic analysis indicate that the likelihood of exceeding a maximum SOF greater than one is less than 0.02\%. Thus, the analysis demonstrates that use of ST\#12 limits for the new ET\#3 disposal unit will provide reasonable assurance that Department of Energy (DOE) 435.1 performance objectives and measures will be protected.

1.c. Would the radionuclide disposal limits in the approved PA need to be changed to implement the proposed activity?

No. The analysis demonstrates that existing approved ST\#12 limits currently in the ELLWF disposal limits database can be employed as inventory limits for ET\#3. Thus, the existing limits can be preserved.

1.d. Does the new information result in a change in the radionuclide disposal limits in the approved PA?

No. The new ET\#3 model employed only the new information addressed in the recent UDQE (Flach, 2013) and the specific considerations necessary to account for new ET\#3 geometry. Considering these changes in the new ET\#3 model showed that utilizing the existing ST\#12 limits would be conservative relative to establishing new ET\#3 inventory limits based on the aggregate performance of the disposal unit. For example, the average maximum SOF from the stochastic simulation was 26.5\%. This can be interpreted to mean that operating ET\#3 to a SOF of 1.0 using ST\#12 limits will result in a "true" SOF of 0.265 for the average radionuclide compositions from Sink's historical trench inventories (Sink, 2012).

1.e. Would the proposed activity if implemented, or does the new information result in a change to the Disposal Authorization Statement (DAS)?

No. No changes to the DAS result from this proposed activity. Because operation is maintained within the approved PA baseline and no limits are being changed from that evaluated in the PA/CA, the DAS would not need to be changed as a result of the proposed activity. 


\subsection{CONCLUSIONS}

This analysis demonstrates that use of ST\#12 limits for the new ET\#3 disposal unit will provide reasonable assurance that DOE 435.1 performance objectives and measures (USDOE, 1999) will be protected. Therefore new ET\#3 inventory limits as determined by a special analysis are not needed.

The results from the stochastic analysis indicate that the likelihood of exceeding a maximum SOF greater than one is less than $0.02 \%$. This result assumes a 50\%:50\% inventory split between ET\#3 and ET\#4.

The average maximum SOF during this simulation was $26.5 \%$. This can be interpreted to mean that operating ET\#3 to a SOF of 1.0 using ST\#12 limits will result in a "true" SOF of 0.265 for the average radionuclide compositions from Sink's historical trench inventories (Sink, 2012).

For the seven key GW parent nuclides a new model was generated that reflects the proposed geometry of ET\#3 and incorporates the new PA information considered by Flach (2013). As shown in the aquifer results, these nuclides have 100-m boundary well concentration peaks at drastically different times than those predicted during the 2008 PA. However, peak groundwater concentrations did not increase above the previous analyzed values.

In many cases the limiting dose pathway shifted between the current ST\#12 limits and the ET\#3 analyses. This was caused by three factors: 1) changes in $K_{d}, 2$ ) changes in ingestion dose coefficients, and 3 ) the change in interim cover timing.

In some cases, specific new estimated ET\#3 GW disposal limits are lower than the corresponding ST\#12 limits, however, in all cases the 2008 PA gives the minimum GW disposal limit and is therefore bounding.

In all cases, Air Pathway and Radon limits determined by the ET\#3 analysis are equal to or greater than current ST\#12 limits. Intruder limits determined by the ET\#3 analysis for Pa231, Pu-244, Se-79, Sn-126, U-233 and U-238 are lower than the current ST\#12 limits and are the minimum disposal limits for these radionuclides. However, the stochastic analysis does not rigorously ensure performance objectives at the individual parent nuclide level for ET\#3. Rather it relies on the aggregate performance of the disposal unit (i.e., the SOF) to help ensure that performance measures and objectives are being protected.

The ST\#12 and ST\#13 footprints are at the northwest end of E-Area and very little plume overlap is occurring with other adjacent disposal units due to the general direction of groundwater flow. Neither the adjacent west set of ST (ST\#8-11) disposal units nor the Intermediate Level Vault (ILV) contributes significantly to groundwater concentrations in line with these units thereby providing significant margin for higher inventories in both these units. This kind of margin is not available in the remainder of disposal units in the ELLWF. 


\subsection{REFERENCES}

ACRi, 2010. ACRi, "PORFLOW Version 6.3 User's Manual," Revision 3, Analytical \& Computational Research, Inc., Los Angeles, California, June 27, 2010.

Aleman, 2007. S. E. Aleman, PORFLOW Testing and Verification Document, WSRC-STI2007-00150, Revision 0, Savannah River National Laboratory, Savannah River Site, Aiken, SC 29808, June 2007.

Butcher and Hiergesell, 2012. B. T. Butcher and R. A. Hiergesell, Performance Assessment Interim Measures for Returning E-Area Low-Level Waste Facility Trenches to Operation, SRNL-STI-2012-00320, Revision 0, Savannah River National Laboratory, Savannah River Site, Aiken, SC 29808, May 2012.

Collard, 2011. L. B. Collard, LimitsAndDoses Batch Version Software Quality Assurance Plan, L. B. Collard, G-SQP-A-00021, Revision 0, Savannah River National Laboratory, Savannah River Site, Aiken, SC 29808, September 2011.

Collard and Hamm, 2012. L. B. Collard and L.L. Hamm, Alternatives Analysis for Selecting ET\#3 Site, SRNL-STI-2012-00047, Revision 0, Savannah River National Laboratory, Savannah River Site, Aiken, SC 29808, February 2012.

Flach, 2007. G. P. Flach, Software Quality Assurance Plan or Aquifer Model Refinement Tool (MESH3D), Q-SQP-G-00003, Revision 0, Savannah River National Laboratory, Savannah River Site, Aiken, SC 29808, February 2007.

Flach 2013. G. P. Flach, Unreviewed Disposal Question Evaluation: Impact of New Information since 2008 PA on Current Low-Level Solid Waste Operations, SRNL-STI2013-00011, Revision 0, Savannah River National Laboratory, Savannah River Site, Aiken, SC 29808, February 2013.

Fox, 2012. F. L. Fox to D. A. Crowley, Memorandum, "SWM Selection for Engineered Trench \#3 Site", SRNS-N6000-2012-00029, Savannah River Nuclear Solutions, Savannah River Site, Aiken, SC 29808, April 4, 2012.

Hang, 2007. T. Hang, PORFLOW Software Quality Assurance Plan, G-SQP-A-00012, Revision 0, Savannah River National Laboratory, Savannah River Site, Aiken, SC 29808, June 2007.

Hiergesell, 2011. R. A. Hiergesell, Special Analysis Air Pathway Modeling of E-Area LowLevel Waste Facility, SRNL-STI-2011-00327, Revision 0, Savannah River National Laboratory, Savannah River Site, Aiken, SC 29808, August 2011.

ICRP, 2008. Nuclear Decay Data for Dosimetric Calculations, ICRP Publication 107, Annals of the ICRP 38 (3), International Commission on Radiation Protection, 2008.

Jannik and Stone, 2013. D. K. Stone and G. T. Jannik, Site Specific Reference Person Parameters and Derived Concentration Standards for the Savannah River Site, Revision 0, Savannah River National Laboratory, Savannah River Site, Aiken, SC 29808, March 2013. 
Jannik et al. 2010. G. T. Jannik, D. J. Karapatakis, P. L. Lee, and E. B. Farfan, Land and Water Use Characteristics and Human Health Input Parameters for Use in Environmental Dosimetry and Risk Assessments at the Savannah River Site, SRNL-STI2010-00447, Revision 0, Savannah River National Laboratory, Savannah River Site, Aiken, SC, August 6, 2010.

Kaplan, 2010, Geochemical Data Package for Performance Assessment Calculations Related to the Savannah River Site, SRNL-STI-2009-00473, Revision 0, Savannah River National Laboratory, Savannah River Site, Aiken, SC 29808, March 15, 2010.

Koffman, 2006, L. D. Koffman, Automated Inadvertent Intruder Application Version 2, WSRC-TR-2006-00037, Revision 0, Savannah River National Laboratory, Washington Savannah River Company, Aiken, SC 29808, September 28, 2006.

Lee, 2006. P. L. Lee, Air Pathway Dose Modeling for the E-Area Low-Level Waste Facility, WSRC-STI-2006-00262, Revision 0, Savannah River National Laboratory, Washington Savannah River Company, Aiken, SC 29808, October 31, 2006.

Phifer, et al., 2009. M.A. Phifer, K.P. Crapse, M. Millings and M.G. Serrato, Closure Plan For The E-Area Low-Level Waste Facility, SRNL-RP-2009-00075, Revision 0, Savannah River National Laboratory, Savannah River Site, Aiken, SC 29808, March 16, 2009.

Roberts and Kaplan, 2013. K. A. Roberts and D. I. Kaplan, Carbon-14 Geochemistry at the Savannah River Site, SRNS-STI-2008-00445, Revision 1, Savannah River National Laboratory, Savannah River Site, Aiken, SC 29808, May 10, 2013.

Sink, 2012. D. F. Sink, SWMF Performance Assessment Limits Compared to Actual Disposed Inventory, SRNS-RP-2012-00195, Revision 1, Savannah River Nuclear Solutions, Savannah River Site, Aiken, SC 29808, July 2012.

Sink, 2013, D. F. Sink to D. A. Crowley, Memorandum, "Screening WAC Isotopes for Use in Engineered Trench \#3 UDQE Review", SRNS-N3000-2013-00060, Savannah River Nuclear Solutions, Savannah River Site, Aiken, SC 29808, May 15, 2013.

Swingle, 2012a. R. F. Swingle, Special Analysis: Revised Groundwater Protection and AllPathways Limits for E-Area Low-Level Waste Facility Trenches, SRNL-STI-2012-00466, Revision 0, Savannah River National Laboratory, Aiken, SC 29808, August 2012.

Swingle, 2012b. R. F. Swingle to Distribution, Memorandum, "Revision of the ELLWF Disposal Limits Database Adding Revised Trench Limits (Revision 2012-2)", SRNLL3200-2012-00038, Savannah River National Laboratory, Aiken, SC 29808, December 4, 2012.

Tempel, 2012. K. L. Tempel, Email, "Re: Handout from Today's Meeting on ET\#3 SA Planning”, Savannah River Nuclear Solutions, Savannah River Site, Aiken, SC 29808, August 14, 2012.

USDOE, 1999. Radioactive Waste Management Manual, DOE M 435.1-1, U.S. Department of Energy, Washington, D.C., July 9, 1999. 
USDOE, 2011. Derived Concentration Technical Standard, DOE-STD-1196-2011, U.S. Department of Energy, Washington, D.C., April 2011.

Whiteside, 2010. T. Whiteside, Software Testing and Verification of PORFLOW Versions 6.30.1 and 6.30.2, SRNL-STI-2010-00213, Revision 0, Savannah River National Laboratory, Aiken, SC 29808, July 2010.

WSRC, 2008. E-Area Low-Level Waste Facility DOE 435.1 Performance Assessment, WSRC-STI-2007-00306, Revision 0, Washington Savannah River Company LLC, Savannah River Site, Aiken, SC 29808, July 2008. 
SRNL-STI-2013-00393, REV . 0

This page is intentionally left blank 
SRNL-STI-2013-00393, REV. 0

\section{APPENDIX: UDQ SCREENING}


SRNL-STI-2013-00393, REV. 0

Unreviewed Disposal Question (U)

Procedure:

Page:
SW-ENG-0601

ATTACHMENT 1

Page 1 of 2

UNREVIEWED DISPOSAL QUESTION (UDQ) SCREENING CRITERIA

Proposed Activity: NEED FOR DEVEOPMENT OF PA DISPOSAC CIMITS FOR ENGINODREO TRENCH \#3. SEE ATACLIMENT FOR DETAECS.

REVIEW the following questions against the Proposed Activity:

\section{Yes $\square$ No $\square$ N/A}

Does the proposed disposal activity or new information involve a change to the disposal facility from what has been previously described or analyzed in the most recent Performance Assessment, Composite Analysis, approved Special Analyses, or approved UDQ Evaluations?

2.

No $X$ N/A

Does the proposed disposal activity or new information involve a change to the disposal process or procedures from what has been previously described or analyzed in the most recent Performance Assessment, Composite Analysis, approved Special Analyses, or approved UDQ Evaluations?

3. Yes $\square$ No $\square$ N/A

Does the proposed disposal activity or new information involve a change to the radionuclide disposal limits from what has been previously described or analyzed in the most recent Performance Assessment, Composite Analysis, approved Special Analyses, or approved UDQ Evaluations?

\section{Yes $\square$ No $\square$ N/A}

Does the proposed disposal activity or new information involve a change to the Waste Acceptance Criteria from what has been previously described or analyzed in the most recent Performance Assessment, Composite Analysis, approved Special Analyses, or approved UDQ Evaluations?

5. Yes $\square$ No $\square$ N/A

Does the proposed disposal activity or new information involve a change to what has been previously described or analyzed in the PA / Composite Analysis Inputs and Assumptions (I\&A) Database? 
SRNL-STI-2013-00393, REV. 0

\section{Procedure: \\ Revision:}

Page:

\section{ATTACHMENT 1}

\section{UNREVIEWED DISPOSAL QUESTION (UDQ) SCREENING CRITERIA}

6. Yes $\square$ No $X$ N/A

Does the proposed disposal activity or new information involve a change to the facility closure design or criteria from what has been previously described or analyzed in the most recent Performance Assessment, Composite Analysis, approved Special Analyses, approved UDQ Evaluations or associated Closure Plan?

\section{Yes $\square$ No $\square$ N/A}

Does the proposed disposal activity or new information involve a test or experiment not described or analyzed in the most recent Performance Assessment, Composite Analysis, approved Special Analyses, approved UDQ Evaluations or associated Closure Plan?

8. Yes $\square$ No $\square$ N/A

Does the proposed disposal activity or new information involve any analytical errors, omissions or deficiencies in the most recent Performance Assessment, Composite Analysis, approved Special Analyses, approved UDQ Evaluations or associated Closure Plan?

If all questions above are answered "No" or "N/A" (defined by a $\boldsymbol{\nu}$ in the box provided), then implement Proposed Activity in Performance Assessment space. If any of the questions above answered "Yes" (defined by a $\nu$ in the box provided), then forward to SRNL for development of an UDQ Evaluation or Special Analysis.

Provide Explanation / Justification for all "Yes" answers:

SCE ATIACHOMONT

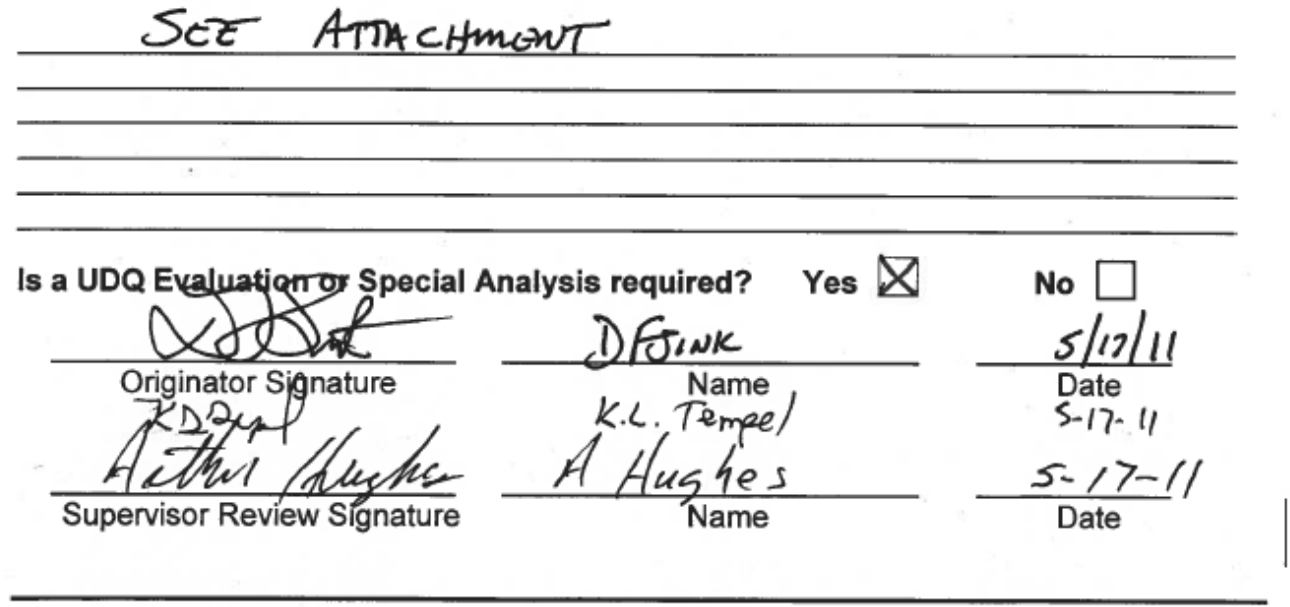


Engineered Trench \#2 will close in Fy14 based on Low Level Waste disposed to date and waste forecasts from the generators. This facility design provides a unique and cost effective disposal option for containerized Low Level Waste, using defined Performance Assessment (PA) disposal limits. Thus, a new facility should be developed for future Low Level Waste trench disposal.

Solid Waste will need to locate the next Engineered Trench (ET\# 3) in E Area. There are four disposal options under consideration (see attachment):

Option 1 - Placement of waste at grade / above grade on existing on TRU Pads 7 through 13 Area and mounding clean soil over disposed waste packages. A sump will be added to collect water runoff for sampling prior to release.

Option 2 - Construct a new Engineered Trench near the Used Equipment Storage Area, using the similar design features of Engineered Trench \#2.

Option 3 - Construct a new Engineered Trench near the 643-26E Naval Reactor Component Disposal Area, using the similar design features of Engineered Trench \#2.

Option 4 - Construct a new Engineered Trench near the TRU Pad \# 26, using similar design features of Engineered Trench \#2.

Solid Waste requests SRNL to develop an assessment report that reviews each disposal option and determines which option provides the best PA disposal limits for LLW. Other location options can be considered by Solid Waste if proposed by SRNL. Once this report is complete and approved by Solid Waste, a Special Analysis (SA) will need to be developed and approved for the preferred option. This SA will define the new PA disposal limits before any design and construction work can begin.

Solid Waste requests such a report and Special Analysis be issued and approved (including DOE approval) in Fy12. 


\section{Option 1}

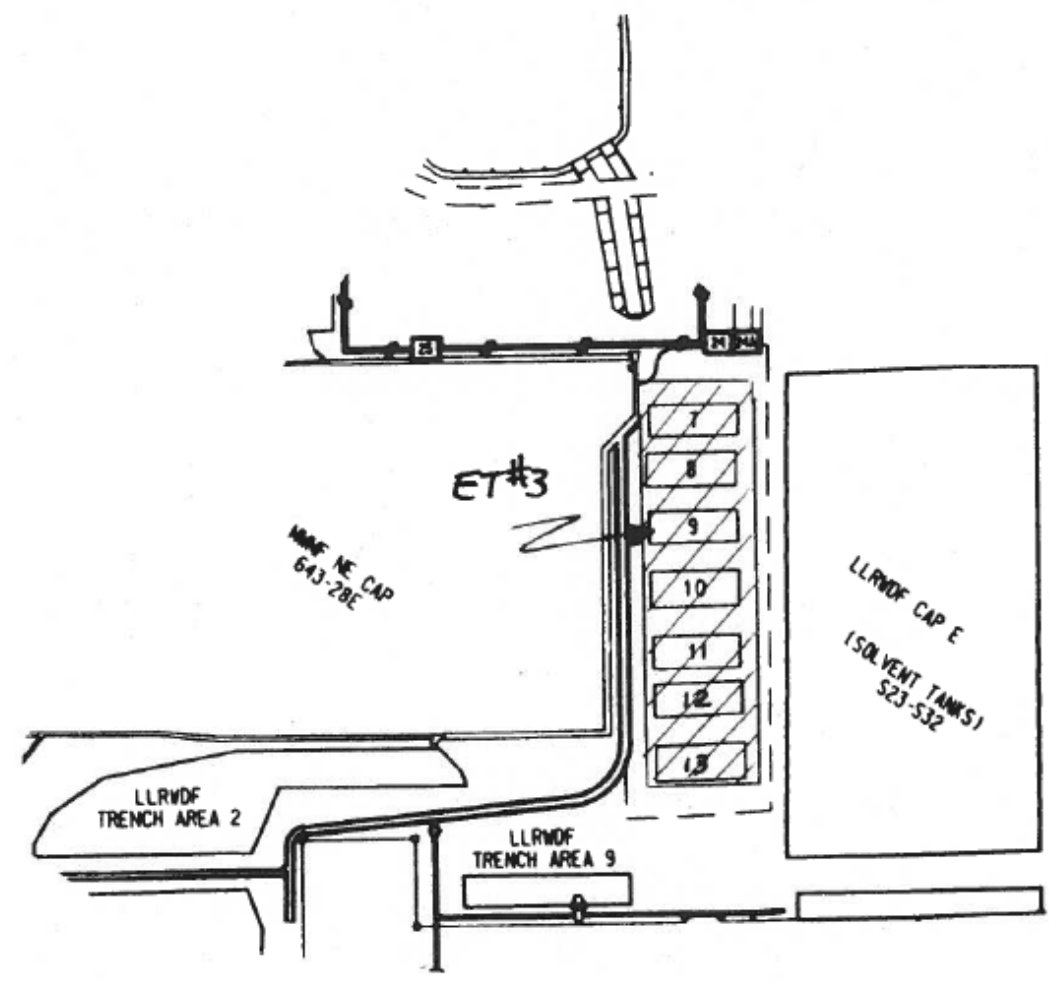


SRNL-STI-2013-00393, REV. 0

\section{Option 2}

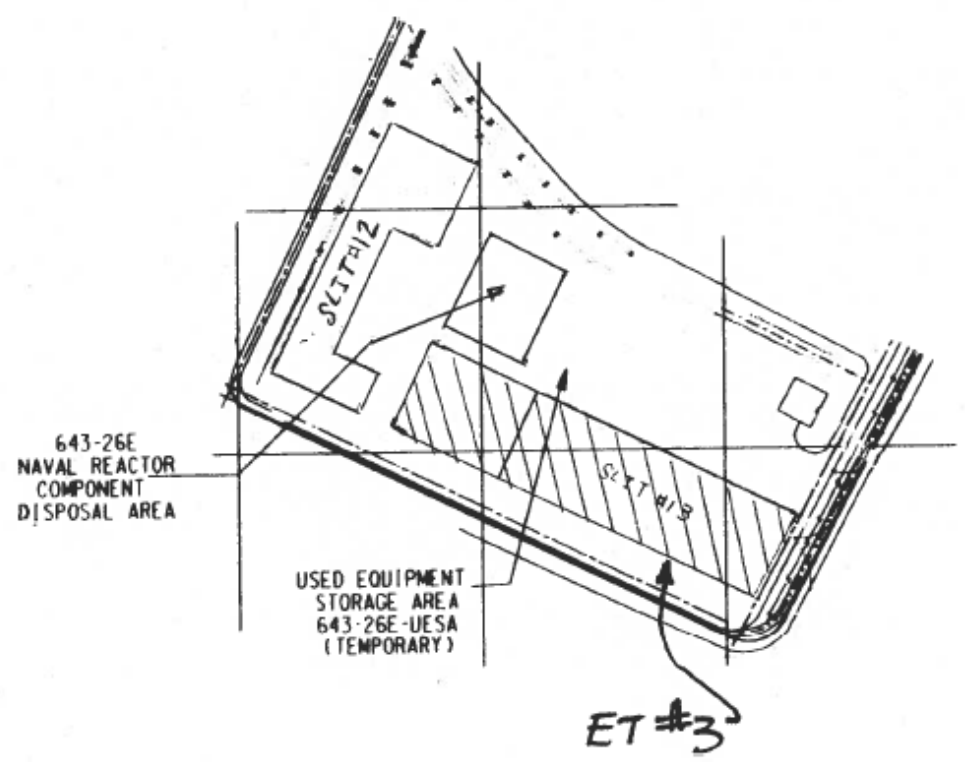


SRNL-STI-2013-00393, REV . 0

\section{Option 3}

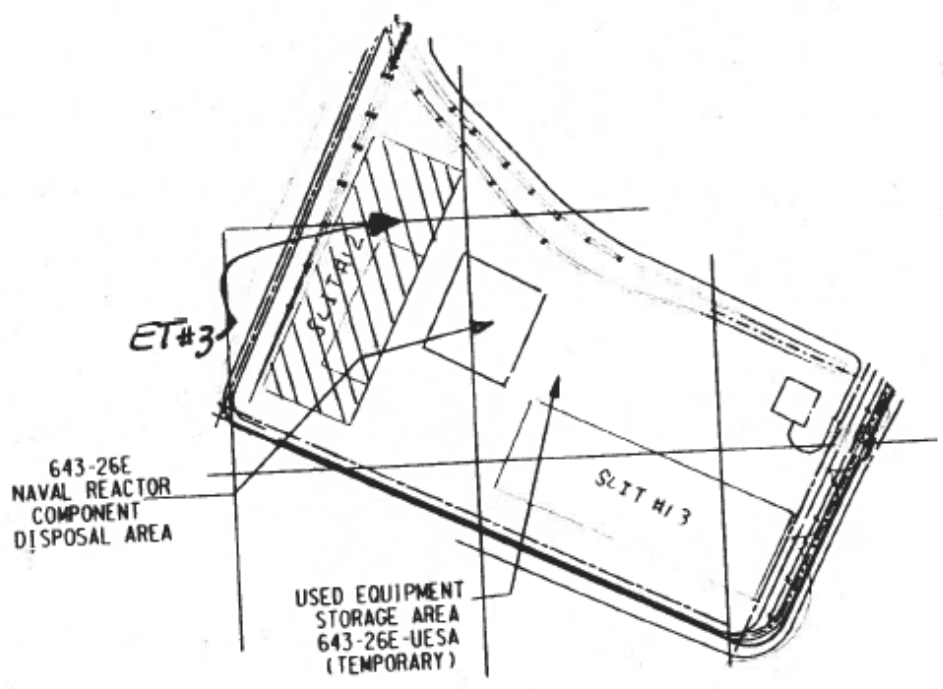


SRNL-STI-2013-00393, REV. 0

\section{Option 4}

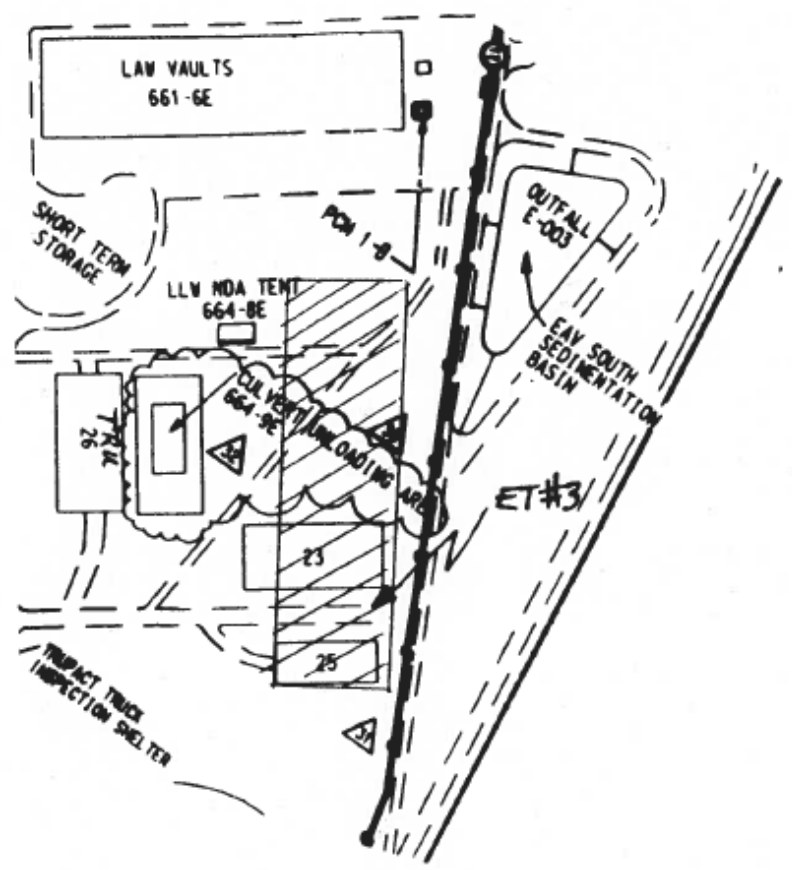


SRNL-STI-2013-00393, REV. 0

This page intentionally left blank 


\section{Distribution:}

R. S. Aylward, 773-42A

B. T. Butcher, 773-43A

D. A. Crowley, 773-43A

P. N. Fairchild, 704-55E

G. P. Flach, 773-42A

F. L. Fox, 704-59E

J. C. Griffin, 773-A

L. L. Hamm, 773-42A

R. A. Hiergesell, 773-43A

G. K. Humphries, 730-4B

J. M. Jordan, 703-41A

D. I. Kaplan, 773-43A

T. F. Kmetz, 730-4B

D. Li, 999-W

M. G. Looper, 704-36E

J. L. Mooneyhan, 704-60E

T. O. Oliver, 773-42A

M. A. Phifer, 773-42A

K. A. Roberts, 773-43A

R. R. Seitz, 773-43A

D. F. Sink, 704-56E

F. G. Smith, III 773-42A

G. A. Taylor, 773-43A

K. L. Tempel, 704-56E

T. S. Whiteside, 773-42A

C. Wilson (1 file copy \& 1 electronic copy), 773-43A - Rm.213 